\title{
Regulatory Costs of Being Public: Evidence from Bunching
}

\section{Estimation*}

\author{
Michael Ewens ${ }^{\dagger}$ Kairong Xiao ${ }^{\ddagger}$ Ting $\mathrm{Xu}^{\S}$
}

September 11, 2022

\begin{abstract}
We quantify the costs of major disclosure and governance regulations by exploiting a regulatory quirk: many rules trigger when a firm's public float exceeds a threshold. Consistent with firms avoiding costly regulation, we document significant bunching around multiple regulatory thresholds. A bunching estimation shows that various disclosure and internal governance rules lead to a total compliance cost of $4.1 \%$ of the median firm's market capitalization. Regulatory costs have a greater impact on private firms' IPO decisions than on public firms' going private decisions, but such costs only explain a small part of the decline in the number of public firms.
\end{abstract}

JEL Classification Codes: G28, G32, K22

Keywords: costs of being public, bunching estimator, capital market regulation, disappearing public firms

\footnotetext{
${ }^{*}$ We thank Reena Aggarwal, Scott Bauguess, Shai Bernstein, Tara Bhandari, Audra Boone, Matthias Breuer, Susan Chaplinsky, Jacelly Cespedes, Joan Ferra-Mensa, Laura Field, Kathleen Hanley, Justin Hopkins, Peter Iliev, Joseph Kalmenovitz, Simi Kedia, Elizabeth Kempf, Marc Lipson, Xiaoding Liu, Elena Loutskina, Katie Moon, Marius A. K. Ring, Jay Ritter, Laura Starks, Paul Tetlock, Emily Wang, Joshua White, Frank Zhou, and seminar and conference participants at SFS Cavalcade, Drexel Corporate Governance Conference, Utah Winter Finance Conference, AFA, MFA, Texas Finance Festival, UT Dallas Finance Conference, CICF, the Securities and Exchange Commission, Berkeley, Toronto Rotman, Georgetown, Minnesota Carlson, UVA Darden, Columbia, Caltech, Stripe, Florida International University, the Junior Corporate Finance Workshop, and the Junior Entrepreneurial Finance/Innovation Lunch Group for helpful comments. We thank John Graham and Jie Yang for sharing data and Tianchen Zhao for excellent research assistance. Data on public floats is available here: https://github.com/michaelewens/public_float_regulation

${ }^{\dagger}$ Columbia Business School and NBER. michael.ewens@columbia.edu

${ }^{\ddagger}$ Columbia Business School. kx2139@gsb.columbia.edu

${ }^{\S}$ Darden School of Business, University of Virginia. xut@darden.virginia.edu
} 
A central explanation for the decline in the number of U.S. publicly listed companies is the increased burden of disclosure and governance regulations. Indeed, practitioners often point to heightened regulatory costs as the culprit of the disappearing public firms, while recent major deregulations such as the 2012 JOBS Act were directly motivated by the perceived costs of being public. ${ }^{1}$ For instance, in the comment letter to the SEC, Morgenstern and Nealis (2004) write that (p.1) "the Sarbanes-Oxley Act of 2002 and its implementing regulations have significantly increased the costs and regulatory burdens associated with being a public company." These issues continue today. Presumably anticipating push-back to proposed climate disclosure rules in 2022, the associated SEC proposal incorporates regulatory cost estimates. ${ }^{2}$ Thus, estimating regulatory costs is a central part of the debate on the regulation's merits. Understanding the role of regulations in the cost of being public and the decline in the number of public firms can address concerns on possible capital market dysfunction (Weild, 2011, p.1).

Researchers have explored this "regulatory overreach hypothesis", but the evidence is mixed. ${ }^{3}$ A key challenge faced by the prior literature is that firms often engage in regulatory avoidance in response to regulations, as many public firm regulations trigger only when a firm's size exceeds a certain threshold. Firms seeking to avoid costly regulation can bunch their public float below the threshold. Such manipulation may create challenges for traditional identification strategies. Furthermore, the existing evidence has been mainly qualitative rather than quantitative and considers only partial direct costs (e.g., in-house labor costs). Most existing literature provides regulatory exposure indices rather than the quantitative estimates of dollar value of regulatory costs central to policy making decisions. As Leuz and Wysocki (2016) write in their survey of the literature (p. 529): "evidence on the causal effects of disclosure and financial reporting regulation is often

\footnotetext{
1 "For business owners who want to take their companies to the next level, this bill will make it easier for you to go public." President Obama's remarks at bill signing (https://obamawhitehouse.archives.gov/the-press-office/ 2012/04/05/remarks-president-jobs-act-bill-signing).

${ }^{2}$ See section IV.C and referenced public comments in "The Enhancement and Standardization of Climate-Related Disclosures for Investors" (Release Nos. 33-11042).

${ }^{3}$ Earlier works such as Gao, Ritter, and Zhu (2013) and Doidge, Karolyi, and Stulz (2013) cast doubt on this narrative by noting that the decline in IPOs precedes major regulatory changes such as Sabranes-Oxley (SOX). In contrast, recent work such as Dambra, Field, and Gustafson (2015) find that IPO activity partially increased after the regulatory relief of the 2012 JOBS Act. Other explanations of the decline in the number of public firms include declining business dynamism (Decker, Haltiwanger, Jarmin, and Miranda, 2016; Doidge, Karolyi, and Stulz, 2017), shifting investment to intangibles (Kahle and Stulz, 2017; Doidge, Kahle, Karolyi, and Stulz, 2018), increased availability of private equity (Ewens and Farre-Mensa, 2020), changing economies of scale and scope (Gao, Ritter, and Zhu, 2013), and changing acquisition behavior (Gao, Ritter, and Zhu, 2013; Eckbo and Lithell, 2021).
} 
difficult to obtain and still relatively rare; [... while we have a lot of evidence that is qualitatively useful, we are still far from being able to perform quantitative cost-benefit analyses."

In this paper, we advance the literature in two ways. First, rather than facing manipulation as an identification impediment, we follow the bunching estimation literature (Saez, 2010; Chetty et al., 2011; Kleven and Waseem, 2013) and use firms' endogenous bunching around the regulatory threshold to infer regulatory costs. The central insight of the approach is a revealed preference argument: greater bunching by public firms to avoid financial regulation implies higher regulatory costs. This approach allows us to analyze multiple regulatory changes over 20 years, which provide a more comprehensive understanding of the regulatory costs borne by public firms. The method also outputs cost estimates that aggregate both direct and indirect costs. Second, this approach quantifies the monetary value of regulatory costs, which allows us to conduct a novel set of counterfactual analyses on the effects of regulation on the choice of public and private status. Quantification crucially improves upon existing estimates, which typically only reveal cross-sectional variations in regulatory costs. The regulatory cost estimates are also critical inputs into regulators' and policymakers' quantitative cost-benefit analyses.

We begin by documenting three regulatory thresholds on a firm's public float (i.e., value of trading equity) introduced since 1992. ${ }^{4}$ Each regulatory threshold is associated with a set of exemptions from disclosure and internal governance rules. The first threshold is $\$ 25 \mathrm{~m}$, which stemmed from the introduction of the "Small Business Issuers" and scaled disclosures in 1992. Firms below $\$ 25 \mathrm{~m}$ float had less stringent disclosure requirements on financial data, business operation, risk, and governance. ${ }^{5}$ The second threshold is $\$ 75 \mathrm{~m}$ introduced in 2002 . Firms below $\$ 75 \mathrm{~m}$ are exempted from the SOX 404 requirement to hire an outside auditor to attest to their internal controls. ${ }^{6}$ The third threshold is $\$ 700 \mathrm{~m}$ implemented in the JOBS Act in 2012. Newly public firms below this threshold ("Emerging Growth Companies") receive several financial reporting accommodations, deferred compliance with new accounting rules, and an exemption from SOX 404(b). These regulatory thresholds create variation in the major components of disclosure and

\footnotetext{
${ }^{4}$ Gao et al. (2009), Iliev (2010), Dharmapala (2019), Weber and Yang (2020), and Liu (2020) have also documented bunching below $\$ 75 \mathrm{~m}$, while Alsabah and Moon (2020) have documented bunching below $\$ 700 \mathrm{~m}$.

${ }^{5}$ These scaled disclosures were later expanded to firms with less than $\$ 75 \mathrm{~m}$ float in 2008 with the introduction of "Small Reporting Companies".

${ }^{6}$ The $\$ 75 \mathrm{~m}$ threshold also features the "Non-accelerated filer" introduced in 2002, which allows firms with a float below $\$ 75 \mathrm{~m}$ to have 10 (15) more days to file their quarterly (annual) reports to the SEC.
} 
internal governance regulations faced by public firms.

Next, we document significant bunching in the distribution of firms' public float around each regulatory threshold in the years the regulations are in place. As shown by Figure 1, the density falls discretely at each regulatory threshold. On its own, such bunching provides compelling evidence that regulations triggered by these thresholds impose significant compliance costs on firms, and that these costs seem to outweigh the regulations' potential benefits to firms such as lower costs of capital. We find that firms close to the thresholds manipulate their public float mainly by substituting debt for equity, without changing their operations or insider ownership.

The validity of bunching estimation relies on the "smoothness" assumption: the distribution of the public float is smooth in the absence of regulation. Consistent with this identifying assumption, we find no excess mass in years before the regulatory threshold is introduced or after it is eliminated, making it unlikely that other factors are changing at the threshold. We also find no excess mass around placebo thresholds without regulations.

Motivated by the above bunching patterns, we develop a model to guide our estimation. In the model, firms can avoid regulatory costs by reducing their public float to a level below the regulatory threshold. However, bunching distorts firms' leverage away from the optimum. Firms thus face a trade-off between regulatory costs and capital structure distortion costs. The optimal bunching choice depends on how far away a firm's undistorted public float is from the regulatory threshold. Firms that are just above the threshold shrink their public float to avoid regulation because the associated leverage distortion is small. Firms that are far above the threshold do not bunch because the cost of leverage distortion outweighs the cost of regulation. There exists a marginal firm that is indifferent between the two costs and hence bunching or not. We can infer the regulatory cost facing this marginal firm from its leverage distortion cost.

We use the Alvero and Xiao (2020) fuzzy bunching estimator to estimate the undistorted float of the marginal firm for each regulatory threshold. ${ }^{7}$ This estimator infers the marginal firm from the area between the actual cumulative distribution function (CDF) with regulation and the counterfactual CDF in the absence of the regulation. We then translate the estimated float

\footnotetext{
${ }^{7}$ The fuzzy bunching estimator is more appropriate than the sharp bunching estimator in settings with smaller samples and greater noise in the data. Our setting fits this well as we focus on a few thousand listed firms and stock price fluctuations can add substantial noise to bunching patterns.
} 
distortion to a dollar value of regulatory costs facing the marginal firm using the leverage distortion cost function from Binsbergen, Graham, and Yang (2010). Finally, we extrapolate the regulatory costs to other firms using the relative share of variable versus fixed costs estimated from SEC surveys (SEC, 2011) and Audit Analytics data.

Our estimates show that the median U.S. public firm spends $0.3 \%$ of its EBITDA on enhanced disclosure compliance, $0.9 \%$ on tightened internal control, and $2.1 \%$ on a combination of disclosure and internal control rules every year. The present value of these regulatory costs represents $4.1 \%$ of the median firm's equity value. Aggregate regulatory costs have increased significantly in the first few years after SOX, but have been declining since, especially after the JOBS Act. Smaller firms bear disproportionate amounts of regulatory costs relative to their size because a large portion of these costs are fixed. Nevertheless, various regulatory exemptions introduced by the SEC substantially alleviated the regulatory burden for firms below the regulatory thresholds.

Using the estimated regulatory costs, we investigate how regulation affects the number of public firms. Doidge et al. (2017) show that the decline in the number of public firms is driven by both low IPO rates and high delisting rates, each explaining about half of the decline. We first examine the effect of regulatory costs on private firms' IPO decisions, using a sample of 21,066 VC-backed firms. ${ }^{8}$ We find that regulatory costs significantly impact these firms' decisions to go public: a one-standard-deviation increase in regulatory costs is associated with a $7 \%$ decrease in IPO likelihood. However, our counterfactual analysis shows that major regulatory changes in the 2000s have had limited impact on IPO volumes. Removing SOX only increases the average annual IPO likelihood after 2000 from $0.95 \%$ to $0.96 \%$, because many potential IPO candidates are small enough to be exempted from this regulation. Removing all estimated regulatory costs increases the average annual IPO likelihood after 2000 from $0.95 \%$ to $1.4 \%$, which explains only $7.4 \%$ of the decline in IPO likelihood from pre-2000 to post-2000.

Next, we examine the impact of the estimated regulatory costs on public firms' decisions to go private. We find that they cannot explain going private decisions. This finding is likely to be explained by the fact that some of the regulatory costs are irreversible, upfront costs, which would enter into firms' going public decisions but are sunk costs for their going private decisions. Our

\footnotetext{
${ }^{8}$ Such firms are an important pipeline of IPOs, representing half of the IPO firms in our sample period (e.g., Ritter, 2020; Ewens and Farre-Mensa, 2020).
} 
result is consistent with Kaplan (1989), Guo et al. (2011), and Bernstein and Sheen (2016), who show that many going-private deals are motivated by financial or operational engineering reasons, rather than to avoid regulatory costs. Our result also echos Leuz (2007), Leuz et al. (2008), and Bartlett III (2009), who find little evidence on the effect of regulations on going private transactions.

Overall, our findings suggest that regulatory costs affect firms' public-vs-private choice mainly through their going public decision. Nevertheless, regulatory costs only explain a small fraction of the disappeared IPOs, in contrast to the popular claim by practitioners. Instead, our results are consistent with Gao et al. (2013) and Doidge et al. (2013), who suggest that regulatory changes in the early 2000s did not cause the decline of public firms.

Although we believe our estimation approach addresses some limitations in the current literature, its implementation requires several assumptions. First, although we study several major regulatory changes over 20 years, the bunching estimator only uses threshold-based regulations and thus excludes uniformly implemented regulations (e.g., Reg FD or the introduction of EDGAR). Nevertheless, our analysis covers important regulatory changes that are often attributed to changes in the number of public firms, such as SOX in 2002 and JOBS Act in 2012. Second, our baseline bunching estimation forms the counterfactual distribution using the years before the regulatory threshold is introduced or after it is eliminated. We show that our estimates are robust to dropping the two years before regulation changes to exclude potential anticipation-based bunching, or using a smooth polynominal to estimate counterfactual distributions in the bunching samples. Finally, we use the leverage distortion costs estimated by Binsbergen et al. (2010) to translate observed bunching to a dollar value of regulatory costs. The main results are robust to alternative parameters for leverage distortion costs and the Korteweg (2010) leverage distortion cost function.

This paper contributes to a growing literature on the disappearing public firms puzzle. Aside from the "regulatory overreach hypothesis" and the aforementioned papers, the literature has also proposed five other major hypotheses: (1) declining business dynamism (Decker et al., 2016; Doidge et al., 2017), (2) shifting investment to intangibles (Kahle and Stulz, 2017; Doidge et al., 2018), (3) increased availability of private equity (Ewens and Farre-Mensa, 2020), (4) changing economies of scale and scope (Gao et al., 2013), and (5) changing acquisition behavior (Gao et al., 2013; Eckbo and Lithell, 2021). Using the new bunching estimation strategy developed from the public 
economics literature, our paper provides an in-depth study of the "regulatory overreach hypothesis" by estimating the regulatory costs of being a public firm, examining the margins through which regulatory costs affect public-vs-private decisions, and quantifying how much of the decline in IPOs can be attributed to heightened regulatory costs. Our study suggests that regulatory costs only explain a small fraction of the decline in public firms; non-regulatory factors facing public firms seem to be playing a more important role.

Our paper also adds to the extensive literature studying the impact of disclosure and internal governance regulations on firms. As surveyed by Leuz and Wysocki (2016), most of this literature has been qualitative. We quantify the net compliance costs of these regulations, providing useful inputs to regulators' cost-benefit analysis. Our estimates also shed light on the ongoing debate on whether public firms face excessive regulatory burdens (Coates, 2007). Related to our work, Gao et al. (2009), Iliev (2010), Dharmapala (2019), Alsabah and Moon (2020), Weber and Yang (2020), and Liu (2020) study the effects of regulatory thresholds on public firms' outcomes such as earnings quality, audit fees, leverage, and firm value. ${ }^{9}$ While these works have also documented bunching, we are the first to use a bunching estimator to translate bunching to dollar costs of regulations. ${ }^{10}$ Rather than facing regulatory avoidance as an identification challenge, our approach exploit it for identification. Our approach thus complements traditional identification strategies such as DiD and RD by expanding the scope of regulations that can be studied.

Our paper also advances the literature on regulatory economics. An important question in this literature is how to measure regulatory burdens. Existing literature has proposed various measures, such as the number of rules facing firms (Porta, Lopez-de Silanes, Shleifer, and Vishny, 1998; AlUbaydli and McLaughlin, 2017), number of employees hired by regulators (Jackson, 2007), labor spending on compliance-related occupations (Simkovic and Zhang, 2020), hours firms spend on regulatory paperwork (Kalmenovitz, 2019), complexity of regulatory languages (Amadxarif, Brookes, Garbarino, Patel, and Walczak, 2019), and how frequently firms mention regulations in their 10-K

\footnotetext{
${ }^{9}$ Dambra et al. (2015), Chaplinsky et al. (2017), Barth et al. (2017), and Dambra and Gustafson (2020) study the impact of JOBS Act on IPO firms; Coates and Srinivasan (2014) survey the literature on the effect of SOX on firm outcomes; Iliev and Vitanova (2019) study the effect of Say-on-Pay on compensation and firm value. Relatedly, several papers also noted regulatory avoidance behavior in other contexts. See, for example, Ballew et al. (2021), Bouwman et al. (2018), and Bindal et al. (2020) on banking regulation, Bernard et al. (2018) on disclosure of private firms, and Schivardi and Torrini (2008) and Amirapu and Gechter (2020) on labor regulation.

${ }^{10}$ Dharmapala (2019) estimates the extent of bunching but does not translate it into regulatory costs.
} 
(Gong and Yannelis, 2018; Calomiris, Mamaysky, and Yang, 2020). We introduce a revealed preference approach using regulatory-based bunching that complements existing approaches in several ways. First, existing approaches often generate an index of regulatory exposure, while we directly quantify the dollar costs of regulations, which can be used as inputs into regulators' cost-benefit analysis. Second, most existing measures only capture direct regulatory costs (e.g., paperwork costs, labor costs, or external fees), while our revealed preference approach additionally captures indirect costs, such as proprietary costs, diversion of managerial attention, and operational distortions. That said, our approach can only be applied to threshold-based regulations, which is a limitation. Nevertheless, many regulations are threshold-based and are increasingly so. Thus, our approach has ample applications.

Finally, our application of bunching estimation to public firms adds to a growing literature that uses the bunching technique to study finance topics. Prior applications includes mortgage (DeFusco and Paciorek, 2017; DeFusco, Johnson, and Mondragon, 2020), small business lending (Bachas, Liu, and Morrison, 2020; Bachas, Kim, and Yannelis, 2020), municipal bonds (Dagostino, 2018), student loans (Fagereng and Ring, 2021), bankruptcy fees (Antill, 2020), and banks (Alvero, Ando, and Xiao, 2020). The prior literature typically uses large administrative data with little noise. Hence, their bunching pattern exhibits a sharp density spike at the threshold and is suitable for the traditional "sharp bunching" approach. Our setting has a smaller sample size and the running variable contains more randomness (i.e., public float fluctuates with stock prices). Thus, the bunching pattern is much noisier. Given that many corporate finance settings feature relatively small samples and noisy data, the Alvero and Xiao (2020) fuzzy bunching methodology used here can be fruitfully applied to future research in this area. ${ }^{11}$

\section{Data and Institutional Background}

\subsection{Data Sources}

The SEC uses public float to determine firms' compliance status with multiple regulations. Formally, it is defined as the market value of all outstanding common equity (voting and non-voting)

\footnotetext{
${ }^{11}$ Using the sharp bunching approach in a noisy data setting would lead to under-estimation (Alvero and Xiao, 2020). Indeed, Dharmapala (2019) applies sharp bunching to the SOX 404 threshold and finds very small bunching.
} 
held by non-affiliates at the end of the second fiscal quarter. ${ }^{12}$ Firms must disclose their public float according to this definition at the top of their 10-K. We collect public float data for all U.S. listed firms from 10-K filings (including 10-KSB, 10-KT, and 10-K405) using a customized web-crawling script. ${ }^{13}$. We restrict to all fiscal years from 1994 (the year EDGAR starts and financial statements are machine-readable) to 2018. We further require firms to have non-missing sales in Compustat and non-missing public float. These restrictions exclude shell and pink sheet companies. We match these firms to Jay Ritter's IPO database to identify the year a firm went public. ${ }^{14}$ To estimate the cost structure of regulatory costs, we obtain audit fees data from Audit Analytics and SOX 404 compliance costs data reported in a SEC survey SEC (2011). Lastly, we use a sample of VC-backed firms from VentureSource to study the impact of regulatory costs on IPO decisions. We also use a sample of public firms that went through going private transactions (identified using 13e-3 filings) to study the impact of regulatory costs on going private decisions.

\subsection{Institutional Background}

SEC regulations on public firms can be characterized into two major categories: disclosure and governance. In this section, we describe the institutional details surrounding several regulatory reliefs offered by the SEC in the past three decades, which helps shed light on regulatory costs faced by public firms. We focus on four types of regulatory reliefs: scaled disclosure, non-accelerated filing, exemption from SOX Section 404, and Emerging Growth Company benefits. These benefits apply to firms of different sizes as determined by their public float, and sometimes by their revenue. For each rule change, we also provide the SEC's original assessment of costs and benefits. Although our bunching estimation does not rely on the exogeneity of these regulatory changes, we detail their history and potential lobbying or anticipation in Appendix Section A.1.2.

\footnotetext{
${ }^{12}$ Before 2002, public float was computed within 60 days of $10-\mathrm{K}$ filing date. Rule 405 defines an affiliate as a "person that directly, or indirectly through one or more intermediaries, controls, is controlled by, or is under common control with" an issuer. Appendix Section A.1.1 provides more details on public float data.

${ }^{13}$ The data on public float is available here https://github.com/michaelewens/public_float_regulation.

${ }^{14}$ The data can be found here: https://site.warrington.ufl.edu/ritter/ipo-data/.
} 


\subsubsection{Scaled Disclosure}

Enacted in August of 1992, the SEC implemented a new set of rules centered on the SB-2 registration form and refined the class of companies called "Small Business Issuers" (SBI). ${ }^{15}$ These new rules refined Regulation S-K, a regulation about the information requirements in filings and the now defunct Form S-18. ${ }^{16}$ These regulatory changes significantly expanded the set of companies that could take advantage of scaled disclosure from Form S-18. Some of the scaled disclosures included pared down selected financial data, simplified description of business, limited executive compensation information, no disclosure on beneficial ownership and less extensive details provided in annual reports. Appendix Table A.1 provides the full list of scaled disclosure items.

The 1992 rule change resulted in the introduction of small business annual reports (10-KSB) and quarterly reports (10-QSB). In its simplest form, a company could use the new SBI definition if it had a public float less than $\$ 25 \mathrm{~m}$ and annual revenues less than $\$ 25 \mathrm{~m}$. Once a company began reporting with the SEC, it remained SBI until either its revenue or public float exceeded the $\$ 25 \mathrm{~m}$ threshold for two consecutive years (in its 10-KSB). In 2008, the scaled disclosure regulatory relief was expanded to a broader set of firms called "Smaller Reporting Companies" (SRC), defined as firms with less than $\$ 75 \mathrm{~m}$ public float and less than $\$ 50 \mathrm{~m}$ in revenues (see Appendix A.1.3 for details on SRC). With the introduction of SRC, the SEC eliminated all SBI filings as such as 10-KSB and 10-QSB. The $\$ 25 \mathrm{~m}$ threshold for scaled disclosure thus ends in 2008 .

As with all rule changes, the SEC assesses the costs and benefits of scaled disclosure. The SEC collected no data on expected costs and benefits from these changes, but did find some consensus from the majority of public commenters that the changes would result in cost savings for firms that chose the exemption (i.e., it would be costly to have more disclosure).

\subsubsection{Non-Accelerated Filer}

First proposed in 1998 and eventually enacted in April 2002, the SEC created a new category of registered firms called "Accelerated Filers." ${ }^{17}$ Such firms were required to file their finalized annual and quarterly reports within 75 and 35 days of the end of the fiscal period, respectively. Before

\footnotetext{
${ }^{15}$ See https://www.sec.gov/rules/final/6949.txt for the final rules.

${ }^{16}$ Form S-18 allowed qualified users with small offerings less than $\$ 7.5 \mathrm{~m}$ to avoid significant disclosures.

${ }^{17}$ The final rules are found here: https://www.sec.gov/rules/final/33-8128.htm.
} 
this change, all registered firms had to file these reports within 90 and 45 days. The stated goal was "modernizing the periodic reporting system and improving the usefulness of periodic reports to investors." (SEC, 2002, sec I.B) Importantly for our purposes, the SEC and public commenters recognized that the burden of accelerating filing may be higher for smaller firms. After the phasein period, the new rule applied to firms whose public float was $\$ 75$ million or more as of the last business day of its most recently completed second fiscal quarter, among other conditions that accelerated filers need to satisfy. ${ }^{18}$ Firms that did not satisfy these conditions are "Non-Accelerated Filers."

The SEC investigated the costs and benefits of this rule change using survey data from the American Society of Corporate Secretaries. The organization summarized the estimated costs provided by 46 of the surveyed companies with approximately $\$ 75 \mathrm{~m}$ float:

"These estimates ranged from $\$ 12,500$ to $\$ 5,000,000$, with a median value of $\$ 125,000$. $50 \%$ expected on-going annual costs to comply with the proposals. These estimates ranged from $\$ 27,500$ to $\$ 250,000$, with a median value of $\$ 90,000$. $11 \%$ of respondents expected both initial and on-going costs to comply with the proposals." 19

The SEC highlighted other potential costs including risk of lower quality information, increased audit fees, increased compliance costs (e.g. headcount), and general filing complications because there were no "best-practices" for report creation at the time of passage. The SEC weighed these costs against benefits to investors. Here, investors in accelerated filers would benefit because of improved timeliness and transparency of disclosures.

\subsubsection{SOX Section 404 Exemption}

The passage of the Sarbanes-Oxley (SOX) Act in 2002 introduced many new disclosure and governance rules for public companies. Section 404 concerns a firm's internal controls and is widely considered as the costliest part of SOX (Zhang, 2007; Gao et al., 2009). Expecting a disproportionate burden of this section on small firms, the law provided an initial 5-month extension to both

\footnotetext{
${ }^{18}$ These conditions include i) The company has been subject to the reporting requirements of Section 13 (a) or 15(d) of the Exchange Act for a period of at least 12 calendar months; ii) The company has previously filed at least one annual report pursuant to Section 13(a) or 15(d) of the Exchange Act; iii) The company is not eligible to use Forms 10-KSB and 10-QSB.

${ }^{19}$ These substantial numbers relative to the size of the surveyed firm (around $\$ 75 \mathrm{~m}$ float) highlight the potentially large upward bias in firms' self-reported compliance costs.
} 
part (a) and (b) to firms with public floats less than $\$ 75 \mathrm{~m}$ in 2002 . The former requires that firms provide a management's report on their internal controls, while the latter requires that the firm hire an outside auditor to attest to the firm's internal controls. Firms with floats above this threshold accelerated filers - had to comply with 404(a) and (b) on or after November 15, 2004. Firms whose public float did not exceed $\$ 75 \mathrm{~m}$ - non-accelerated filers - in 2002, 2003 or 2004 could choose to not comply with both parts of Section 404. These exemptions were later extended multiple times and then made permanent. ${ }^{20}$

Regulators were aware that these new rules would introduce costs on firms. Specifically, the SEC expected that compliance with 404(b) in particular would lead to increased auditing fees and labor hours preparing financial statements. In an August 2006 report, the SEC writes:

"Many public commenters have asserted that the internal control reporting compliance costs are likely to be disproportionately higher for smaller public companies than larger ones, and that the auditor's fee represents a large percentage of those costs. Furthermore, we have learned from public comments [...] that while companies incur increased internal costs in the first year of compliance as well due to "deferred maintenance" items (e.g., documentation, remediation, etc.), these costs may decrease in the second year."

A 2009 SEC survey (SEC, 2009) reports the estimated pre-2007 costs of 404 compliance for nonaccelerated filers to be an average (median) of $\$ 770 \mathrm{~K}(\$ 580 \mathrm{~K})$. Iliev (2010), Gao et al. (2009), Dey and Sullivan (2009), and Alexander et al. (2013) each provide empirical evidence for these costs, while arguing that they likely did not outweigh the benefits.

\subsubsection{Emerging Growth Companies}

The JOBS Act (2012) introduced the "Emerging Growth Company" (EGC) category for firms that went public after December 8, 2011. A company qualifies as an EGC if it has total annual gross revenues of less than $\$ 1$ billion ( $\$ 1.07$ billion after 2017 ) during its most recently completed fiscal year and, as of December 8, 2011, had not sold common equity securities under a registration statement. A company retains its EGC status until it crosses one of the following thresholds: 1)

\footnotetext{
${ }^{20}$ The delay in compliance was later extended in September 2005 to 2007 (SEC Release NOS. 33-8731; 34-54295; File No. S7-06-03). In August 2006, non-accelerated filers were given extensions of 404(a) to 2007 and 404(b) to 2008. The SEC notes in that report for both rules, these "deadline[s] could be further postponed." The exemption from 404(b) continued to be extended until non-accelerated filers were permanently exempt with the passage of the Dodd-Frank Act in 2010.
} 
reaching $\$ 1$ billion ( $\$ 1.07$ billion after 2017 ) in gross revenue, 2) past the fifth anniversary of its IPO, 3) issuing more than $\$ 1$ billion of non-convertible debt within a three-year period, 4) has more than $\$ 700$ million public float (i.e., becomes a large accelerate filer). We focus on the last public float threshold because it is more difficult to manipulate gross revenue and it is rare for new public firms to issue more than $\$ 1$ billion of non-convertible public debt in the first five years post-IPO. Notably, although a firm can transition out of the EGC status, it cannot transition into EGC if it did not elect EGC status during IPO filing.

There are several benefits of being an EGC, which are best summarized as a combination of scaled disclosure and relaxation of some internal governance rules. First, an EGC filer faces less extensive disclosure requirements in initial and subsequent registration statements, particularly in the description of executive compensation and the time periods covered by the MD\&A section; they also enjoy delayed filing of $10-\mathrm{K}$ and $10-\mathrm{Q}$ relative to large accelerated filers. Second, EGC filers need only provide two years' rather than three years' of audited financial statements in initial registration statement and subsequent annual reports. Third, EGC filers do not need to provide an auditor attestation of internal control under SOX 404(b). Fourth, these filers can delay compliance with new accounting standards. Lastly, EGC filers can use test-the-waters communications with qualified institutional buyers and institutional accredited investors when issuing securities. ${ }^{21}$

\subsection{Summary of Regulatory Thresholds}

Despite the above regulations' differences, they share a common eligibility criterion — public float. ${ }^{22}$ Panel A of Table 1 summarizes the various regulatory reliefs described above and the associated public float cutoffs. Panel B describes the set of regulatory benefits enjoyed by firms in different public float categories. In particular, the last column summarizes the key thresholds that can be exploited in each time period and the associated benefits if firms stay below the threshold. These variations in cutoffs and their effective periods give us a rich empirical setting to separately identify the value of different regulatory reliefs.

\footnotetext{
${ }^{21}$ Since 2007 , being below $\$ 700 \mathrm{~m}$ float also gives firms additional 15 days in filing $10-$ Ks and 10-Qs relative to large accelerated filers that are above $\$ 700 \mathrm{~m}$. However, as documented in both Alsabah and Moon (2020) and our Figure 1, there is no bunching in float below $\$ 700 \mathrm{~m}$ before 2012 when there was filing delay benefits but no other EGC benefits, suggesting that the value of this 15-day filing delay is negligible for firms around $\$ 700 \mathrm{~m}$ float.

${ }^{22}$ For regulations that also have a revenue-based threshold, we condition on firms being below the revenue threshold in forming our samples, so that public float is the only relevant margin for regulatory avoidance.
} 
Our empirical design exploits firms' bunching behavior around three public float cutoffs: $\$ 25 \mathrm{~m}$, $\$ 75 \mathrm{~m}$, and $\$ 700 \mathrm{~m} .{ }^{23}$ Panel C of Table 3 summarizes the thresholds and samples used to identify different sets of regulatory reliefs. Specifically, we use the period when the regulatory relief is in place as the bunching period, and the period before the relief is introduced (or after it expires) as the non-bunching period. The non-bunching period acts as the counterfactual distribution of firms' public float in the absence of bunching incentives. We use bunching around $\$ 25 \mathrm{~m}$ in $1994-2007$ to identify the value of scaled disclosure, bunching around $\$ 75 \mathrm{~m}$ in $2003-2007$ to identify the value of SOX 404 exemption and delayed filing, and bunching around $\$ 700 \mathrm{~m}$ in $2012-2018$ to identify the value of EGC benefits. Section 3.5 provides more details on the estimation samples.

\subsection{How Significant Are These Regulations?}

The regulations detailed above constitute important components of regulations faced by U.S. registered (i.e., public) firm. For example, the internal governance provisions of SOX only emerged with the law's passage, and is widely regarded as the costliest part of SOX (Zhang, 2007; Gao et al., 2009). The regulations studied here capture the two fundamental goals of the Securities Act of 1933: 1) requiring that investors receive financial and other significant information, and 2) prohibiting fraud and misrepresentations. ${ }^{24}$ However, quantifying the importance of these rules relative to all public firm regulations is challenging. That said, we attempt one quantification of a threshold regulation's scope using the Small Business Issuer (SBI) classification introduced in 1992. Because this rule allowed firms to simply provide less information in their reports, the quantity of interest is the difference in the amount of textual data in the financial filings. To do so, we collect all 10-Ks and 10-KSBs from 1994 (availability of EDGAR) to 2007 (when 10-KSBs were eliminated). Annual reports have four parts, each of which we summarize with a simple measure of string length. ${ }^{25}$ Table A.2 in the Appendix compares the length of annual reports for SBIs and non-SBIs, controlling for various firm characteristics and fixed effects. Column 1 shows that the average SBI annual report file size is $27 \%$ smaller than those of non-SBI filings. Specifically, SBI

\footnotetext{
${ }^{23}$ In certain periods, the $\$ 75 \mathrm{~m}$ and $\$ 700 \mathrm{~m}$ thresholds were also associated with a few alternative regulations. We discuss these regulations in Section ?? and show that they do not affect our estimates.

${ }^{24}$ See https://www.sec.gov/answers/about-lawsshtml.html.

${ }^{25}$ Although the content and details of each $10-\mathrm{K}$ section change over the sample period, we can summarize them as follows. Part I details the business, properties and legal proceedings. Part II contains financial data. Part III has information on management, compensation and insider transactions. Part IV contains exhibits and footnotes.
} 
10-KSBs have $21 \%$ shorter Part Is, $20 \%$ shorter Part IIs and $80 \%$ shorter Part IVs (columns 2, 3, 5). Columns 4 and 6 show that while SBIs have longer Part IIIs in their annual reports because they are much less likely to refer readers to DEF14A, their DEF14A filings are $25 \%$ smaller than those of non-SBIs. Given the likely costs in time, resources and transparency of disclosure in 10-Ks, the differences in size and length between the SBI and non-SBI annual reports are economically meaningful.

\subsubsection{Other public firm regulations}

Although the regulations we study capture the two fundamental aspects of the Securities Act of 1933, it is important to note that they do not encompass all regulations faced by public firms. For example, we do not study regulations related to securities exchange and trading, which are regulated by the Securities Exchange Act of 1934. We also do not study industry-specific regulations, such as regulations on financial institutions (e.g., Dodd-Frank Act) or mining safety regulations on mining companies. ${ }^{26}$ Lastly, our methodology precludes us from studying uniformly implemented regulations that are not threshold-based such as Reg FD and options expensing requirements. ${ }^{27}$

\section{Empirical Facts}

\subsection{Bunching at Regulatory Thresholds}

Figure 1 shows the distributions of firms' public float around the three regulatory thresholds detailed in Section 1.2. The left panels plot the CDFs and the right panels plot the histograms. If there is bunching in public float, the CDF should be steeper before the cutoff and flatter after the cutoff, leading to a bulge in the distribution relative to the counterfactual CDF without bunching. Further, the histogram should also show a sharp drop in density after the cutoff than before it. Figure 1 shows just such a pattern. For all three thresholds, the CDF in bunching years is more concave than that in non-bunching years, generating a clearly visible gap between the two. The histograms also show a sharp drop in the density of firms' public float after the cutoffs in bunching years and

\footnotetext{
${ }^{26}$ Many of these industry-specific regulations apply to both public and private firms and hence should not affect firms' public-vs-private choice, which we study in Section 5.

${ }^{27}$ Appendix Table A.3 provides a list of other major SEC regulations that are not threshold-based.
} 
a smooth density around the cutoffs in non-bunching years. These bunching patterns themselves suggest that the regulations triggered by these thresholds are on average costly for firms, so that they are willing to avoid them. ${ }^{28}$ In contrast, in Figure 2, we find no bunching nor differences in float distributions across bunching and non-bunching years around three placebo thresholds unrelated to any regulations. These placebo figures suggest that the float distribution in non-bunching years serves as a good counterfactual for the distribution in bunching years. ${ }^{29}$ Our bunching estimators exploit these bunching patterns to estimate the implied regulatory benefits associated with staying below the regulatory cutoffs.

\subsection{How Firms Manipulate Public Float}

In this section, we examine how firms manipulate their public float, which directly informs how we model the costs of bunching in Section 3.2. Firms can 1) reduce investment, 2) increase debt, or 3) increase inside ownership to fund the reduction in public float. The first margin concerns firms' operations while the latter two concern the financing side of firms' balance sheet. If a firm reduces equity without increasing debt, its operation (and thus investment) would need to shrink. On the other hand, if a firm keeps its operations constant, a shortfall in equity will need to be filled with debt, leading to higher leverage. Alternatively, firms could keep both leverage and investment constant and only adjust the fraction of shares held by insiders vis-à-vis public investors. ${ }^{30}$

To test the above margins, we compare the characteristics of firms just above and just below each threshold. If, for example, firms manipulate float by substituting debt for equity, we should observe that bunching firms on average have higher leverage than similar non-bunching firms. Given that bunching firms tend to concentrate just below the threshold, we should in turn observe that firms just below the threshold have higher leverage on average than firms just above it. One concern with the above comparison is that firms on the two sides of the threshold may be inherently different due to their size differences. To address this, we further compare the differences

\footnotetext{
${ }^{28}$ The bunching patterns do not imply that regulatory compliance is on net costly for all firms. For example, some firms may find it beneficial to voluntarily comply even if they are below the threshold. This may happen if the signaling value of voluntary compliance outweighs the costs of compliance.

${ }^{29}$ We examine alternative ways to estimate counterfactual float distribution in Section 6.3

${ }^{30}$ Theoretically firms can also manipulate their quarterly earnings to influence stock prices. However, second quarter earnings are typically announced after the end of the second quarter (i.e., when public float is computed), making such manipulation infeasible for most firms.
} 
in bunching and non-bunching years. In non-bunching years, any differences between firms above and below threshold should reflect their inherent differences, rather than the outcome of manipulation. Hence, we estimate the following specification on a small window of firms around each of the three thresholds:

$$
Y_{i, t}=\theta \times \text { Below threshold }_{i, t}+\beta \times \text { Below threshold }_{i, t} \times \text { Bunching years }_{t}+\boldsymbol{X}_{\boldsymbol{i}, \boldsymbol{t}}+\varepsilon_{i, t}
$$

where Below threshold ${ }_{i, t}$ indicates a firm's public float being below threshold, Bunching years indi- $^{-}$ cates treated years as in Table 3 , and $\boldsymbol{X}_{\boldsymbol{i}, \boldsymbol{t}}$ is a vector of controls that include industry fixed effects, year fixed effects, and the lagged dependent variable. The dependent variable $Y_{i, t}$ is book leverage, investment, or fraction of non-affiliated shares (i.e., one minus the fraction of closely-held shares). We do not include firm fixed effects because most firms show up only once in our narrow window sample. As such, our comparisons are largely cross-sectional rather than within-firm.

Table 2 reports the estimation results where each panel considers a different threshold. Column 1 shows that public float distortion leads to increases in book leverage. In contrast, the remaining columns show that firms neither alter their investment nor insider ownership around the threshold changes. Column 2 considers the standard CAPEX-based measure of investment. Columns 3 and 4 use alternative measures of investment that incorporate intangibles such as R\&D and SG\&A (Ewens et al., 2020). The signs are as predicted in some specifications, but lack statistical and economic significance. The final column reports the change in insider ownership result. The coefficient estimates are statistically and economically insignificant.

Table A.4 further examines whether firms change other aspects of their operations to avoid regulation. Using the same specification as Table 2, we find no significant changes in a wide variety of operational outcomes, including total assets, tangibility, asset turnover, and profitability, consistent with no changes in investment. We also examine how firms reduce their public float, regardless of how they fund these reductions. The most common way is to increase payouts, including dividends and repurchases. Column 5 of Table A.4 confirms this: in bunching years firms just below the thresholds have higher total payouts than firms just above. Alternatively, firms may strategically release bad news to depress stock prices. Using news data from RavenPack, we find 
that firms below the threshold in bunching years are more likely to release bad news in the second fiscal quarter, when public float is calculated, but not so in the third fiscal quarter (columns 6-7). ${ }^{31}$ Overall, these results together suggest that firms keep their public float below threshold through increasing payouts or releasing bad news, while using debt to fill the equity shortfall with unchanged operations. $^{32}$ In the following exercise, we infer the regulatory costs based on the adjustment of leverage.

\section{Bunching Estimator of Regulatory Costs}

This section lays out the bunching estimator that we use to quantify regulatory costs.

\subsection{A Primer for Bunching Estimation}

The public finance and labor economics literatures originally developed bunching estimation to analyze taxpayers' strategic response to changes in tax rates at tax brackets (Saez, 2010; Chetty et al., 2011; Kleven and Waseem, 2013). The key idea is simple: if a threshold-based policy results in a discrete change in the payoff function of rational agents, then some agents should bunch at the threshold, and the extent of bunching should reveal the underlying economic parameters about the policy or the payoff function.

Bunching estimation typically involves two steps. First, one estimates a behavioral response to the threshold using the bunching variable distribution. The goal here is to answer the question: how many agents choose to bunch? In the second step, the behavioral response is translated to a structural parameter through the lens of an economic model of the agent's payoff. The observed bunching is a result of two forces: (1) policy-induced payoff change (how costly it is to cross the threshold), and (2) the elasticity of the behavioral response (how costly it is to manipulate the bunching variable). Larger policy-induced payoff change or higher elasticity of the behavioral response will lead to greater observed bunching.

\footnotetext{
${ }^{31}$ It is unclear whether these news release are short-term or have a long-run impact on firms' equity value. If it is the latter case, firms will presumably need to fill the equity shortfall with debt to keep investment constant, as documented above.

${ }^{32}$ This is likely due to the fact investment is often lumpy and irreversible, while leverage can be adjusted in a more granular manner. Consistent with our finding, Weber and Yang (2020) and Alsabah and Moon (2020) also find leverage to be the main margin of adjustment around the $\$ 75 \mathrm{~m}$ and $\$ 700 \mathrm{~m}$ threshold, respectively.
} 
We adapt the existing bunching method to our setting in two ways. First, in the classic bunching setting, the policy-induced payoff change is known (e.g., changes in tax rate) and the goal is to estimate the elasticity of the behavioral change (e.g., labor supply elasticity). In our setting, the elasticity of the behavioral response is known (i.e., the leverage distortion cost for firms) and the goal is to estimate the unknown policy-induced payoff change (i.e., regulatory costs). Second, in a classic bunching setting, agents would only bunch at the regulatory threshold, creating a sharp spike at the regulatory threshold in the probability density function (PDF) (see Figure 4a). In our setting, firms cannot perfectly control their public float due to volatility in share price. Firms may also "overshoot" and bunch far below the threshold to avoid crossing the threshold due to share price appreciations. As a result, the bunching pattern is quite fuzzy, as shown in the right panel of Figure 1. We thus use the fuzzy bunching estimator developed by Alvero and Xiao (2020). Intuitively, bunching creates a bulge in the cumulative distribution function (CDF), as shown in Figure 4b. The fuzzy bunching estimator uses this bunching bulge's area to measure bunching. We detail this method in Section 3.4.

\section{2 $\quad$ Model}

We now describe the economic model of the payoff of the firms. Suppose there is a set of firms indexed by the optimal equity that they would like to choose in the absence of regulatory distortions, $z$. Since we find that firms do not manipulate insider ownership, we use equity and public float interchangeably in the model. Now a regulation imposes a cost of $k$ if a firm's equity is above $\underline{e}$. Firms choose the quantity of equity $e$ relative to the undistorted level $z$ to maximize its payoff:

$$
\max _{e}-\Phi(e-z)-k \mathbf{1}_{\{e \geq \underline{e}\}}
$$

The first term of the payoff function, $\Phi$, captures the costs that a firm incurs if its actual equity $e$ deviates from its undistorted optimum $z$. Motivated by the empirical findings in Section 2 that firms bunch by substituting debt for equity, $\Phi$ can be interpreted as the capital structure distortion 
costs. We obtain the functional form of $\Phi$ from Binsbergen et al. $(2010,2011):^{33}$

$$
\Phi(e-z)=\frac{1}{2} \beta \eta q z r^{2}\left(1-\frac{e}{z}\right)^{2}
$$

where $e$ is the actual equity; $z$ is the optimal equity in the absence of regulatory distortion; $\beta$ is the slope of marginal cost curve of debt, which is estimated to be 4.733 by Binsbergen et al. (2010, 2011); $\eta$ is public float-to-book asset ratio; $q$ is Tobin's $Q ; r$ is interest rate on debt. In Section A.4.4, we show that our estimates are robust to using an alternative leverage distortion cost function from Korteweg (2010).

The second term of the payoff function (2), $k \mathbf{1}_{\{e \geq \underline{e}\}}$, is the cost of regulation. If a firm's equity is above a regulatory threshold, $\underline{e}$, then the firm is subject to that regulation which imposes a cost of $k$. For now, $k$ is a constant parameter, which we allow to vary with firm size in Section 4.2.

Figure 3 shows the optimal choice of equity under different scenarios. Figure 3a shows that, in the absence of the regulation, firms choose the optimal equity amount $e=z$ to minimize capital structure distortion. However, after the regulation is introduced, the payoff function is shifted downward by $k$ in the region where the equity is above the regulatory threshold, as shown by Figure 3b. The discrete jump in regulatory costs creates an incentive to bunch. Specifically, firms just above the regulatory threshold find it more profitable to reduce their equity to $\underline{e}$ and avoid the regulatory costs. However, bunching is costly because of the costs from sub-optimal leverage, $\Phi(e-z)$. The loss in firm value is an increasing function of the undistorted equity because larger firms need to reduce more equity to bunch below the threshold, thus leading to larger loss in firm value. Figure 3c shows that if a firm's undistorted equity is far larger than the threshold, then it chooses not to bunch and to instead incur the regulatory costs, $k$. There exists a marginal firm that is indifferent between bunching and incurring regulatory costs, as shown in Figure 3d. The indifference condition of the marginal firm reveals the regulatory costs. Formally, regulatory costs

\footnotetext{
${ }^{33}$ Binsbergen et al. $(2010,2011)$ estimate marginal cost of debt functions for individual firm-years from variations in the tax benefits of debt. They then simulate the marginal benefit functions of debt according to the tax code. The cost of leverage distortion is the triangular area between the marginal cost and marginal benefit curves of leverage as shown in Figure 1 of Binsbergen et al. (2011), or $\frac{1}{2} \beta(\Delta I O B)^{2} v$, where IOB is interest over book assets $a$, and $v$ is firm value. Using the notations in this paper, the leverage distortion cost for a firm with optimal float $z$ bunching at $e$ is $\Phi(e-z)=\frac{1}{2} \beta(\Delta I O B)^{2} v=\frac{1}{2} \beta\left(\frac{r(e-z)}{a}\right)^{2} q a=\frac{1}{2} \beta r^{2} \frac{z}{a}\left(\frac{e}{z}-1\right)^{2} q z=\frac{1}{2} \beta r^{2} \eta q z\left(1-\frac{e}{z}\right)^{2}$.
} 
can be calculated as follows:

$$
k=\Phi(\underline{e}-\bar{e})
$$

where $\underline{e}$ is the regulatory threshold and $\bar{e}$ is the undistorted equity of the marginal firm that is indifferent between bunching or not bunching. If we know the size of the marginal firm $\bar{e}$, we can estimate the regulatory cost parameter $k$.

So far, our discussion holds the undistorted equity $z$ constant for each firm. However, the model also applies to a setting where $z$ grows over time. In this case, firms decide whether to bunch each year, depending on how far the undistorted optimal equity in that year is from the regulatory threshold. If the undistorted equity exceeds the regulatory threshold by a small amount, the firm will bunch at the threshold. The firm may stop bunching after a few years when the undistorted equity has grown much larger and it becomes too costly to bunch. The implicit assumption is that firms do not have to commit to a bunching decision. Instead, they can decide whether to bunch period by period. This assumption is reasonable because firms can adjust their public floats regularly by changing their payout policy. This assumption is also consistent with Figure A.1, which shows that most firms stay below the threshold for just a few years.

\subsection{Interpretation of $k$}

The parameter $k$ captures both the direct costs of regulation, including fees to lawyers and accountants and costs of investing in internal control system, and the indirect costs, including competition effect of disclosing proprietary information, productivity loss from diverting resources from operation to compliance, and any constraints regulations impose on firms' operating decisions. The indirect costs are typically difficult to measure because they are not recorded in financial statements. However, indirect costs affect firms' bunching decision, so they can be estimated via a revealed preference approach. The parameter $k$ may also include benefits of regulation for those in compliance. For instance, better disclosure can reduce a firm's cost of capital. Thus, the parameter $k$ should be interpreted as the net cost of regulation: compliance costs net of the benefits from compliance. We do not attempt to separately identify compliance costs and the benefits of compliance, because for firms' compliance decisions or their public-private choice, what matters is the net costs. 
Importantly, our net cost estimate does not incorporate the social benefits of regulations, such as the effects on competition, investor welfare, and other general equilibrium outcomes. Instead, our estimate provides a useful input for policy makers to compare against the social benefits of regulations.

\subsection{Estimation}

We use the Alvero and Xiao (2020) fuzzy bunching estimator. Intuitively, bunching creates a bulge in the CDF, as shown in Figure 4b. The fuzzy bunching estimator uses the area of this bunching bulge to infer the marginal firm $\bar{e}$. Formally, the bunching range $\Delta e \equiv \bar{e}-\underline{e}$ is given by:

$$
\widehat{\Delta e}=\sqrt{\frac{2 A}{f_{0}(\underline{e})}},
$$

where $A \equiv \int\left(F(e)-F_{0}(e)\right) d e$ is the bunching area, and $F$ and $F_{0}$ are the actual and counterfactual CDFs, respectively. ${ }^{34}$

In many bunching settings, agents face optimization frictions such as switching costs, inattention, and inertia. Ignoring such frictions may bias the bunching estimates (Chetty, 2012). In the estimation, we follow Kleven and Waseem (2013) to introduce a parameter $\alpha$ to account for optimization frictions. This parameter can be interpreted as the fraction of non-optimizing firms that are not responding to bunching incentives. $\alpha$ can be estimated from the probability mass in the dominated region $[\underline{e}, \bar{e}]$ using the following formula:

$$
\hat{\alpha}=\frac{2(F(\bar{e})-F(\underline{e}))}{f_{0}(\underline{e})(\bar{e}-\underline{e})}-1 .
$$

The bunching range $\Delta e$ adjusted for optimization frictions is given by:

$$
\widehat{\Delta e}=\sqrt{\frac{2 A}{(1-\alpha) f_{0}(\underline{e})}} .
$$

\footnotetext{
${ }^{34}$ The intuition of the fuzzy bunching estimator is the following: the bunching area can be approximated by a triangle with a height of $f_{0} \Delta e$ and a base of $\Delta e$. The area of the triangle is then $A=f_{0}(\Delta e)^{2} / 2$, from which we can then solve for the bunching range $\Delta e$.
} 


\subsection{Estimation Samples}

We estimate the above bunching model on samples of firms around each of our three regulatory thresholds. For each threshold, we use the years since its introduction as the "bunching sample" and examine the distribution of firms' public float around that threshold. We also construct the "non-bunching sample" using years before the threshold's introduction or after its expiration, which provides the counterfactual distribution of firms' public float in the absence of bunching incentives. ${ }^{35}$

Specifically, to analyze firms' bunching below the $\$ 25 \mathrm{~m}$ threshold, we focus on firms that were Small Business Issuers (SBI) in the previous fiscal year and will be eligible this year if public float stays below $\$ 25 \mathrm{~m}$. These are the firms with less than $\$ 25 \mathrm{~m}$ gross revenue in the current and previous fiscal years and whose public float is less than $\$ 25 \mathrm{~m}$ in the previous fiscal year. The sample period to construct the bunching distribution (bunching period) is 1994 to 2007. Since scaled disclosure was extended from firms below $\$ 25 \mathrm{~m}$ float to those below $\$ 75 \mathrm{~m}$ in 2008 , the $\$ 25 \mathrm{M}$ cutoff no longer applies after 2008. The sample period to construct the counterfactual distribution (non-bunching period) is thus 2009 to $2018 .{ }^{36}$

To exploit the $\$ 75 \mathrm{~m}$ threshold, we focus on non-accelerated filer firms that had less than $\$ 75 \mathrm{~m}$ public float in the previous fiscal year. We focus on the bunching period of 2003 to 2007 to identify the combined value of SOX 404 internal control exemption plus delayed filing of 10-Ks and 10-Qs. Our non-bunching period is 1994 to 2002.

Last, we analyze firms' bunching around the $\$ 700 \mathrm{~m}$ threshold for Emerging Growth Company status. We obtain all IPOs from 1997 to 2018 from Jay Ritter's website (Ritter, 2020), the KenneyPatton IPO Database (Kenney and Patton, 2013), and SDC. We restrict the sample to U.S. issuers with a positive public float after IPO. Because firms cannot transition back into EGC after transitioning out, we restrict to firms that were EGC-eligible in the previous year, i.e., firm-years with less than $\$ 1$ billion gross revenue in the previous and current fiscal years, ${ }^{37}$ and with less than

\footnotetext{
${ }^{35}$ Figure 2 shows that the float distribution in non-bunching years provides a good counterfactual to the distribution in bunching years. Alternatively, we can construct the counterfactual distribution by fitting a smooth polynomial to the CDF in the bunching sample after excluding observations around the threshold. In Section 6.3, we demonstrate the results' robustness to this alternative estimation of counterfactual distributions.

${ }^{36}$ We exclude the transitioning year 2008 from our non-bunching period because firms could still choose to file as a Small Business Issuer in 2008 if their fiscal year ends after December 15th. Theoretically, we could also use the years before the introduction of this threshold (i.e., pre-1992) as the non-bunching period, but this precedes the introduction of EDGAR, which precludes from collecting public float data.

${ }^{37}$ The gross revenue threshold was adjusted to $\$ 1.07$ billion from 2017 onward.
} 
$\$ 700 \mathrm{~m}$ public float in the previous fiscal year. Additionally, we restrict to the first three years after IPO since firms have the strongest incentives to bunch for EGC benefits when they are newly public (Alsabah and Moon, 2020). Our bunching period is from 2012 to 2018 and our non-bunching period is from 1997 to 2011.

We use firms that are just above the float of the marginal bunching firm in the bunching period to parameterize the cost of capital structure distortion, $\Phi$. In Section 6.4, we show that our estimates are similar if we use firms around the float of the marginal bunching firm to obtain these parameters. We do not use data in non-bunching period because these financial ratios can vary significantly with market conditions.

\section{Estimation Results}

\subsection{Baseline Results}

Table 3 reports the bunching estimates of regulatory costs for each of the three thresholds. We first examine the $\$ 25 \mathrm{~m}$ threshold in column 1, which identifies the costs of enhanced disclosure. We find that the marginal firm that is indifferent between bunching and not bunching has a $\$ 27 \mathrm{~m}$ undistorted public float. Bunching of this marginal firm leads to an increase in leverage ratio of 5.6 percentage points. The indifference condition of this marginal firm implies that the annual regulatory costs associated with enhanced disclosure are around $\$ 0.026$ million per year. The present value of these regulatory costs account for $0.62 \%$ of the marginal bunching firm's firm value $^{38}$ The share of non-optimizing agents, $\alpha$, is 0.48 , suggesting a fair amount of optimization frictions. For comparison, the optimization friction parameter estimated by Kleven and Waseem (2013) in a taxpayer sample ranges from 0.51 to 0.86 .

Column 2 reports the estimation for the $\$ 75 \mathrm{~m}$ threshold in the 2003-2007 period. This threshold relates to the regulatory costs of SOX 404 and accelerated filing deadlines. Here, the marginal bunching firm has an undistorted float of $\$ 95 \mathrm{~m}$. Bunching of this marginal firm leads to an increase in leverage ratio of 10.8 percentage points. The indifference condition of this marginal firm implies that the annual regulatory costs associated with SOX 404 compliance and accelerated filing are

\footnotetext{
${ }^{38}$ Throughout this paper, we use a $7 \%$ discount rate to discount the constant perpetuity of annual regulatory costs.
} 
$\$ 0.122$ million per year. The present value of these annual regulatory costs account for $0.73 \%$ of the marginal bunching firm's firm value.

Lastly, column 3 reports the estimates for the $\$ 700 \mathrm{~m}$ threshold, which identifies regulatory costs of losing EGC status. The estimates show that the marginal bunching firm has an undistorted float of $\$ 838 \mathrm{~m}$. Bunching of this marginal firm leads to an increase in leverage ratio of 7.3 percentage points. The magnitude of this leverage change is close to that documented in Alsabah and Moon (2020). The indifference condition of this marginal bunching firm implies that the annual regulatory costs associated with losing EGC benefits are around $\$ 0.71$ million per year. The present value of these annual regulatory costs represents $0.77 \%$ of the marginal bunching firm's firm value.

To further facilitate the interpretation of the magnitude of our estimated regulatory costs, we benchmark these costs against the total assets and profits of the marginal bunching firm. Table 4 report the results. For the marginal firm that bunches for the $\$ 25 \mathrm{~m}$ threshold, annual enhanced disclosure costs around $0.18 \%$ of its total assets and $7.8 \%$ of EBITDA. For the marginal firm bunching for the $\$ 75 \mathrm{~m}$ threshold, annual SOX 404 compliance and accelerated filing cost $0.1 \%$ of its total assets, $1.3 \%$ of EBITDA, and $6.3 \%$ of net income. Finally, for the newly public marginal firm bunching for the $\$ 700 \mathrm{~m}$ threshold, the annual cost of losing all EGC benefits (a combination of disclosure and internal control reliefs) amounts to $0.13 \%$ of its total assets, $2.3 \%$ of EBITDA, and $7.1 \%$ of net income. These results suggest that small firms as well as newly public firms face particularly high regulatory costs as a percentage of their size and profit.

\subsection{Extrapolation}

Our approach provides an estimate of the regulatory costs facing the marginal bunching firms. In this section, we extrapolate these estimates to other firms. The extrapolation exploits the extent to which each of these regulatory costs are variable (i.e., proportional to size) versus fixed. If the regulatory costs are all fixed costs, then all firms have the same regulatory costs as the marginal firm regardless of firm size. However, if the regulatory costs are all variable, then the regulatory costs should scale proportionally with firm size. Formally, we can extrapolate the regulatory costs 
from the marginal bunching firm to a firm of public float $e$ using the following equation:

$$
\ln k=\ln \bar{k}+\kappa(\ln e-\ln \bar{e})
$$

where $\bar{e}$ is the float of the marginal bunching firm, $\bar{k}$ is the regulatory costs of the marginal firm estimated in Table 3 , and $\kappa$ is the elasticity of regulatory costs to the public float. ${ }^{39}$

We estimate $\kappa$ using two sets of data. First, we use surveyed SOX 404 compliance costs from the SEC study (SEC, 2011) to estimate their relationship with firms' public float. ${ }^{40}$ Note that we do not require firms to truthfully report compliance costs in the survey data - the self-reported costs could be biased. We simply require that firms do not bias the variable and fixed components differentially, which is a much weaker assumption. We also do not require these alternative data to capture full compliance costs - we simply use them to estimate cost structure. Second, we use the relationship between pre-SOX audit fees from Audit Analytics and firms' public float to estimate the cost structure of disclosure compliance. Pre-SOX audit fees mainly capture financial reporting costs and does not include internal control costs. Third, we use the relationship between post-SOX audit fees, which capture both disclosure and internal control costs, and firms' public float to approximate the cost structure of EGC benefits. ${ }^{41}$ We estimate the following relationship between reported regulatory costs and firms' public float:

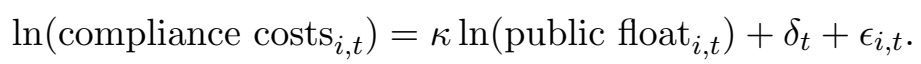

Table 5 reports the estimates based on equation (9). Panel A reports the results for surveyed SOX 404 compliance costs. Column 1 estimates the elasticity of 404(b) audit fees to public float to be 0.432 . We obtain an estimate of 0.456 when looking at the total SOX 404 compliance costs in column 5, which we use as our estimate of $\kappa$. Columns 1 and 2 of Panel B reports the relationship between pre-SOX audit fees and public float. Based on the coefficient for audit fees in column 1, we estimate the elasticity of disclosure cost to public float to be 0.412 . Although we do not have

\footnotetext{
${ }^{39}$ We use a log-on-log model to extrapolate because data shows that compliance costs and float follow this relationship (see Figure A.2).

${ }^{40}$ The SEC study only reports the average itemized compliance costs by public float interval and time period. We treat each float interval-period as one observation and weight the observations by the number of responding firms.

${ }^{41}$ In both cases, we exclude from Audit Analytics data firm-years that are exempted from the relevant regulation.
} 
data on reported values of EGC benefits, we can approximate its cost structure using post-SOX audit fees, which capture both disclosure and internal control costs. Column 2 of Panel B reports the relationship between post-SOX audit fees and public float. The coefficient estimate implies an elasticity of combined disclosure and internal control cost to public float of 0.423 , which reassuringly lies between the elasticities for disclosure costs and internal control costs.

\subsection{Regulatory Costs across Firms and Over Time}

Using the above extrapolation, we can compute the regulatory costs for companies of any public float in any year in our data. For the median U.S. firm with a public float of $\$ 102 \mathrm{~m}$, it faces annual enhanced disclosure costs of $\$ 0.045 \mathrm{~m}$, SOX 404 compliance costs of $\$ 0.126 \mathrm{~m}$, and combined costs of disclosure and internal governance captured by EGC benefits of $\$ 0.293 \mathrm{~m}$. The present value of these costs together translates to $4.1 \%$ of the median firms' public float. ${ }^{42}$ These regulatory costs are therefore economically meaningful for an average US public company.

The extrapolation also allows a comparison of the cost estimates across the three thresholds. For example, we can extrapolate the values of scaled disclosure and SOX 404 exemption from the corresponding thresholds to the marginal firm bunching for $\$ 700 \mathrm{~m}$ for EGC benefits. This yields a combined value of $\$ 0.44 \mathrm{~m}$ for the marginal EGC bunching firm. This value is lower than the estimated total EGC benefits of $\$ 0.71 \mathrm{~m}$. Such a difference can be attributed to the fact that EGC benefits include not only scaled disclosure, 404(b) exemption and delayed filing, but also shorter financial history disclosure in registration statement, delayed compliance with new accounting rules, and the ability to use test-the-waters communications with investors when issuing securities. Our estimates suggest that these latter benefits could be highly valuable for newly public firms.

We next examine the variations of the estimated regulatory costs across firms and over time. Figure 5 shows a heatmap of annual regulatory costs as a percentage of firm's EBITDA. We find that smaller firms face heavier regulatory burden than larger firms in the early sample period. ${ }^{43}$ For example, at the beginning of our sample period, firms with $\$ 10 \mathrm{~m}$ float spend $10.5 \%$ of their

\footnotetext{
${ }^{42}$ We obtain $4.1 \%$ based on a $7 \%$ discount rate assuming constant perpetuity. The true realized percentage may be different for two reasons: 1) regulations and thresholds can change over time; 2) firms trigger more regulations as they grow larger, yet conditional on the same regulations (i.e., not crossing any thresholds), larger firms bear lower costs relative to their size.

${ }^{43}$ Similar patterns hold when we scale regulatory costs by firms' public float as shown in Figure A.3.
} 
EBITDA on regulatory costs per year. In contrast, firms around $\$ 1$ billion float spend $0.13 \%$ of EBITDA on regulatory costs. After SOX in 2002 , medium-sized firms $(\$ 75 \mathrm{~m}-\$ 700 \mathrm{~m})$ experienced a large jump in regulatory costs relative to their size and profit. The regulatory burden on medium and small firms were greatly lifted by the 2012 JOBS Act.

Next, we aggregate our identified regulatory costs across all public firms in the U.S. and plot out the aggregate trends. Figure 6 shows the time series for aggregate regulatory costs in dollar and as a percentage of aggregate EBITDA. We find that the aggregate regulatory costs increased from $\$ 2$ billion in late 1990s to almost $\$ 4$ billion in 2018 . There is a substantial jump after SOX, followed by a dip during financial crisis. Regulatory costs as a percentage of EBITDA increased from $0.15 \%$ before SOX to $0.23 \%$ after SOX. Since 2005, there has been a steady decline. Interestingly, JOBS Act did not lead to a noticeable decline in aggregate regulatory costs, likely because it only affects a small number of newly public firms. By 2018, regulatory costs relative to EBITDA have dropped to their pre-SOX levels.

\subsection{Comparing with Existing Estimates}

How do our estimates compare with existing estimates from surveys and previous research? We note a few caveats before any such comparison. First, existing evidence is limited due to the challenge in accurately identifying regulatory costs, so it is often difficult to find an exact counterpart for our estimate. Second, some existing evidence is based on surveys on firms or CEOs. As shown by Parker (2018) and Alvero et al. (2020), firms may have incentives to over-report their compliance costs in surveys in order to seek regulatory relief. Third, our bunching estimator estimates the net costs of regulation (i.e., compliance costs minus the benefits of compliance due to lower costs

of capital). In contrast, existing databases or research often report the gross compliance costs. Last, our estimates incorporate the indirect costs of compliance in addition to direct costs, while most existing estimates only capture direct costs. With these caveats in mind, Section A.3 in the Appendix provides four comparisons to alternative methods of regulatory cost estimation. Overall, our results compare as expected given the differences in regulations, data inputs, and modeling assumptions. 


\subsection{How Regulators Can Use Our Estimates}

Our estimates are of interest to regulators, who routinely conduct cost-benefit analysis on existing regulations. For example, regulators can compare our net cost estimate with the social benefits of a regulation to gauge its optimality. Our bunching approach complements existing methods to estimate regulatory costs, such as firm surveys or reduced-form regression analysis of firms' financial data. Because the bunching approach estimates regulatory costs from firms' revealed preference, it is not prone to misreporting concerns in surveys; it also captures all net costs relevant to firms, including indirect costs. Furthermore, the bunching approach applies to settings in which reducedform regressions may be biased by firms' strategic responses to regulations. Our estimates can also inform the rule-making of new regulatory proposals when the new rules bear similarity to existing ones, or when regulators conduct pilot experiments on a subset of firms. That said, for brand new regulations without precedents or any reference data from experiments, the bunching approach cannot be used for ex-ante cost-benefit analysis.

\section{Regulatory Costs and the Disappearing Public Firms}

In this section, we examine how much our estimated regulatory costs can explain the disappearing public firms puzzle. We explore both the entry to and exit from public market. Doidge et al. (2017) show that each margin accounts for roughly half of the disappearing public firms since the 1990s.

\subsection{Regulatory Costs and the IPO Volume}

We model the probability that firm $i$ goes public in year $t$ using a logit model:

$$
\operatorname{Pr}(\mathrm{IPO})_{i, t}=\frac{\exp \left(\beta \ln k_{i, t}+\gamma X_{i, t}\right)}{1+\exp \left(\beta \ln k_{i, t}+\gamma X_{i, t}\right)}
$$

where $k_{i, t}$ is the regulatory costs borne by firm $i$ in year $t$ if it chooses to go public. The vector $X_{i, t}$ contains firm characteristics that affect the net benefits of IPO. The model is based on Chemmanur, He, and Nandy (2010), except that we add regulatory costs as an additional explanatory variable.

We estimate the above logit model using maximum likelihood on a panel of 21,066 U.S. 
venture capital(VC)-backed firms from 1992 to 2018, of which 1,957 went public. To ensure a clean risk-set of potential IPOs, we track startups from their first VC round until exit or failure. As VC-backed startups are an important source of IPOs (e.g. Ritter, 2020), this sample provides a reasonable risk-set of private firm-years that face going public decisions. We estimate public float upon IPO from last round valuation using the following equation: Public Float $t_{i, t}=$ Last valuation $_{i, t} \times \operatorname{Avg}\left(\frac{\text { Primary share } \times \text { Share price }}{\text { Pre-money valuation }}\right)_{t} \times \operatorname{Avg}\left(\frac{\text { Secondary shares }+ \text { Primary shares }}{\text { Primary shares }}\right)_{t}$. We obtain the average ratio of raised amount to pre-money valuation from VentureSource and the average ratio of tradable shares (i.e., primary plus secondary) to primary shares from SDC. Both ratios are estimated at the yearly level. If a startup's valuation is missing in a given year, we linearly extrapolate using two known valuations. Startups with no reported valuations are excluded from the sample. We control for total financing raised, years since first VC round, and dummies for firms' headquarter state. We also include industry-year fixed effects to absorb sectoral shocks and changes in regulations that apply uniformly to all firms.

Given that we control for public float and the imputed regulatory cost depends on public float, our identifying variation comes from discontinuous changes in regulatory costs over time for a given firm size and across size thresholds for a given year, as induced by regulatory changes. This allows us to exploit the more exogenous variations in regulatory costs. Different from prior papers that study a particular reform, we use all regulatory changes to estimate the elasticity of IPO to the dollar cost of regulations, rather than to a regulatory change itself. Our use of imputed public float also makes sure that our regression is not subject to the endogeneity concern from float manipulation.

Table 6 presents the estimated results. Columns 1 and 2 present the logit coefficients and the marginal effects, respectively. We find that a one-standard-deviation increase in our estimated regulatory costs is associated with a $7 \%$ decrease in the probability of a VC-backed firm going public in a year. We also find that years since first round negatively predicts IPO likelihood. The result that regulatory costs significantly impact private firms' decision to go public echoes the findings in Lowry et al. (2017), Aghamolla and Thakor (2019), and Breuer (2021). However, this is the first sensitivity estimation of the IPO decision to the dollar value of regulatory costs, rather than its response to a specific regulatory reform. 
Using the estimated model, we conduct a set of counterfactual analyses of IPO outcomes by varying the regulatory costs $k_{i, t}$ after 2000, the period that witnessed dramatically lower numbers of IPOs. Columns 1 and 2 of Table 7 present the IPO outcomes before and after 2000 in the data. Columns 3 to 5 present the IPO outcomes after 2000 in three counterfactual scenarios. First, we consider a counterfactual scenario without SOX. ${ }^{44}$ Column 3 shows that there is a slight increase in the probability of IPO and IPO volumes. In particular, removing SOX only increases average annual IPO likelihood post 2000 from $0.95 \%$ to $0.96 \%$. The result may appear surprising given that the costs of SOX 404 are substantial. However, further investigation reveals that, in our sample, $82 \%$ of VC-backed firm would have a public float below SOX 404 exemption threshold upon IPO, which suggests that most VC-backed firms would be exempted from SOX 404 if going public. This finding is also consistent with Gao et al. (2013) and Doidge et al. (2013), who argue that the decline in IPOs is unlikely to be driven by SOX.

Prior research such as Dambra et al. (2015) finds that the IPO market partially recovered after 2012 passage of the JOBS Act. We examine how much of the recovery in IPOs can be explained by the reduction in the regulatory costs. To this end, we consider a scenario where the JOBS Act is absent in column 4 of Table 7. We show that, had JOBS Act not passed, the average annual IPO likelihood among VC-backed firms after 2000 would decrease from $0.95 \%$ to $0.74 \%$. Further, the total number of VC-backed IPOs after 2000 would drop from 912 to 711, and the aggregate public float of these IPO firms decrease from $\$ 339 \mathrm{~b}$ to $\$ 314 \mathrm{~b}$. The decline in the number of IPOs translates to an average 28.7 fewer IPOs per year over the period of 2012 to 2018, when JOBS Act was in effect. This estimate is somewhat larger than that of Dambra et al. (2015), who show that JOBS Act has led to 21 additional IPOs per year using a very different empirical methodology.

Finally, column 5 of Table 7 considers a scenario where all regulatory costs in Table 3 are zero post-2000. Removing these regulatory costs would increase post-2000 IPO likelihood among VC-backed firms from $0.95 \%$ to $1.4 \%$. The average yearly number of VC-backed IPOs over 20002018 would increase from 50.2 to 70.6 . While the effects are substantial, they would not offset the dramatic decrease in IPO volume after 2000. Removing all identified regulations increases average annual IPO likelihood post 2000 by $0.445 \%$, which, compared with the $6 \%$ drop in IPO likelihood

\footnotetext{
${ }^{44}$ Panel B of Table A.6 summarizes the regulatory burden borne by firms in different size group under this scenario.
} 
from before to after 2000, explains only $7.4 \%$ of the decline in IPO likelihood. Similarly, removing all regulatory costs after 2000 increases the average yearly number of IPOs over this period by 20.4, which offsets only $22 \%$ of the decrease in yearly IPO volume from pre-2000 to post-2000.

Figure 7 shows our yearly counterfactual estimates for average regulatory costs facing potential IPO firms, annual IPO probability, and yearly number of IPOs. They confirm the limited role played by SOX and the significant impact of JOBS Act on IPO volumes after 2012. Further, Panels B and $\mathrm{C}$ of Figure 7 demonstrate that even removing all identifiable post-2000 regulatory costs does not remove the strong declining trend in IPO likelihood and volume. Thus, regulatory cost itself is unlikely to explain the full magnitude of IPO declines in the U.S. over the past two decades. ${ }^{45}$ Nonregulatory factors, such as decline in business dynamism (Decker et al., 2016), shifting investment to intangibles (Kahle and Stulz, 2017; Doidge, Kahle, Karolyi, and Stulz, 2018), abundant private equity financing (Ewens and Farre-Mensa, 2020), changing economies of scale and scope (Gao, Ritter, and Zhu, 2013), and changing acquisition behavior (Gao, Ritter, and Zhu, 2013; Eckbo and Lithell, 2021) are likely to play a more important role.

\subsection{Regulatory Costs and the Going Private Transactions}

We also estimate the effect of regulatory costs on public firms' decision to go private. We model the probability of going private using the following logit specification, following Lehn and Poulsen (1989) and Engel et al. (2007):

$$
\operatorname{Pr}(\text { GoingPrivate })_{i, t}=\frac{\exp \left(\beta \ln k_{i, t}+\gamma X_{i, t}\right)}{1+\exp \left(\beta \ln k_{i, t}+\gamma X_{i, t}\right)}
$$

where $k_{i, t}$ is the regulatory costs borne by firm $i$ in year $t$ if it stays public. The vector $X_{i, t}$ contains lagged firm characteristics that affect the net benefits of going private, including log public float, book leverage, log total assets, ROA, investment-to-asset ratio, log sales growth, market-to-book ratio, annual stock return, log number of analysts, and institutional ownership. We also include state fixed effects as well as industry-year fixed effects to absorb industry-level shocks and nonthreshold-based regulatory changes that apply to all firms.

\footnotetext{
${ }^{45}$ Section 6.6 shows that these results are similar if firms make IPO decisions based on the present value of future regulatory costs.
} 
We estimate the above logit model of going private decisions on a panel of 4,217 U.S. public firms from 1995 to 2017. Following Bharath and Dittmar (2010), we identify going private transactions using 13e-3 filings. Sample inclusion requires that these filings are followed by a filing of Form 15 or Form 25 within the next two years to ensure that the security was indeed de-registered. This yields 949 going private transactions, out of which 674 can be matched to Compustat firms with non-missing control variables.

Table 8 presents the logit regression results. Consistent with the prior literature, lower market cap, growth, valuation, stock return, analyst coverage, and institution ownership predict higher probability of going private, while lower leverage and profitability predict the opposite. However, we do not find regulatory costs to be a significant factor in public firms' going private decisions. Instead, the sign of the coefficient is the opposite: higher regulatory costs slightly reduces the probability of going private. This null result echoes the mixed findings in prior literature on the effect of SOX on going private transactions (Engel et al., 2007; Leuz, 2007; Leuz et al., 2008; Bartlett III, 2009), and could be explained by the fact that some of the regulatory costs are upfront and irreversible (e.g., setting up internal control system). Hence, these costs will be sunk costs for public firms' going private decisions but will enter into private firms' going public decisions. Further, many PE deals are motivated by financial or operational engineering reasons (Kaplan, 1989; Guo et al., 2011; Bernstein and Sheen, 2016), rather than avoidance of regulatory costs.

\subsection{Summary}

Overall, our estimated regulatory costs affect firms' public-vs-private choice mainly through their going public rather than going private decisions. However, regulatory costs only explain a small fraction of the disappeared IPOs, in contrast to the popular claim by practitioners. Instead, our results are consistent with the view of Gao et al. (2013) and Doidge et al. (2013), who suggest that the regulatory changes in the early 2000s did not cause the disappearance of public firms.

These results come with three caveats. First, our results concern the effects of thresholdbased regulations identifiable in our bunching estimation. Our counterfactual analysis leaves out regulations that are not threshold-based as reviewed in Table A.3. Nevertheless, our analysis covers the major regulatory changes that are often attributed to the decline in public firms, such as 
SOX. Second, the counterfactual analysis offers useful comparative statics on the relation between regulatory costs and IPO volumes. However, these regulations may generate social benefits to the overall public market. Our counterfactual analysis should not be interpreted as a welfare analysis of these regulations on the overall IPO market because we only vary the (net) costs of regulation but not their social benefits. Third, our IPO counterfactuals use a sample of VC-backed firms, which represent around $50 \%$ of all IPOs. Non-VC-backed firms may have different sensitivity to regulatory costs when making their IPO decisions. Caveats aside, the counterfactual exercises provide informative results on the debate on the cause of the disappearing IPO puzzle.

\section{Robustness and Further Analyses}

In this section, we show the results are robust to a variety of alternative assumptions, sampling choice, or consideration of alternative regulations. Appendix Section A.4 provides details on each of these additional investigations.

\subsection{Alternative Regulations Around the $\$ 75 \mathrm{~m}$ and $\$ 700 \mathrm{~m}$ Thresholds}

In addition to the regulations discussed in Section 1.2 , the $\$ 75 \mathrm{~m}$ and $\$ 700 \mathrm{~m}$ thresholds were also associated with some benefits in security issuance in certain periods if firms are above these thresholds. The $\$ 75 \mathrm{~m}$ threshold was also briefly associated with an exemption from Say-on-Pay in 2010 and 2011. Appendix Section A.4.1 shows that these alternative regulations do not significantly bias our estimates.

\subsection{Heterogeneity}

Our main analyses include firms in all industries. In Appendix Section A.4.2 we examine heterogeneity of regulatory costs along different industry cuts or firm characteristics by conducting subsample analyses. The findings demonstrate the expected differences by industry and proprietary levels. 


\subsection{Alternative Counterfactual Distributions}

One might be concerned about firms' anticipation of threshold regulations, or whether the firm size distribution in non-bunching period is a good counterfactual for the distribution in the bunch-

ing period. Appendix Section A.4.3 presents alternative tests and counterfactual distributions to address these concerns. The results are quantitatively similar.

\subsection{Alternative Parameter Choices}

Appendix Section A.4.4 demonstrates that our results are robust to alternative parameter values and alternative cost function for estimating the leverage distortion cost.

\subsection{Agency Issues}

Our model assumes that managers choose whether to bunch to maximize firm value. One may worry that this assumption may be violated for firms with substantial agency issues. A priori, the bias from agency issues can be either positive or negative. On the one hand, entrenched managers may be averse to taking on additional debt to bunch, leading to a downward bias in our estimates. On the other hand, regulatory compliance may be more costly to managers than to shareholders, leading to an upward bias. To address this concern, we re-estimate the regulatory costs excluding firms that may have severe agency issues. In particular, we drop firms in the bottom decile of institutional ownership and firms in the bottom decile of board independence. The results are reported in Table A.14. The estimates are similar to our baseline estimates.

\subsection{Dynamic Considerations in IPO Analysis}

In our baseline estimation, we relate the IPO decision to the immediate regulatory cost a firm faces when it goes public. We show in Appendix Section A.4.5 that our IPO results are robust to firms' dynamic expectations about future regulatory costs. 


\section{Conclusion}

This paper studies the connection between regulatory costs and firms' public-vs-private choice by exploiting a regulatory quirk: many rules trigger when a firm's public float exceeds a threshold. We find that firms increase their leverage to move their public float below the thresholds. We estimate regulatory costs from the extent of this avoidance using a revealed preference approach. The regulatory costs of being a public firm are substantial: various disclosure and internal governance rules lead to a total compliance cost of $4.1 \%$ of the market capitalization for a median U.S. public firm. Regulatory costs have greater impact on private firms' IPO decisions than on public firms' going private decisions. However, heightened regulatory costs only explain a small fraction of the decline in the number of public firms over the last two decades. Our results suggest that nonregulatory factors likely played an more important role in explaining the decline in the number of U.S. public firms. 


\section{References}

Aghamolla, C. and R. T. Thakor (2019). Do mandatory disclosure requirements for private firms increase the propensity of going public? Available at SSRN 3428780.

Al-Ubaydli, O. and P. A. McLaughlin (2017). Regdata: A numerical database on industry-specific regulations for all united states industries and federal regulations, 1997-2012. Regulation $\mathscr{G}$ Governance 11(1), 109-123.

Alexander, C. R., S. W. Bauguess, G. Bernile, Y.-H. A. Lee, and J. Marietta-Westberg (2013). Economic effects of sox section 404 compliance: A corporate insider perspective. Journal of Accounting and Economics 56(2-3), 267-290.

Alsabah, K. and S. K. Moon (2020). IPO regulation and initial capital structure: Evidence from the JOBS Act. Working paper.

Alvero, A., S. Ando, and K. Xiao (2020). Watch what they do, not what they say: Estimating regulatory costs from revealed preferences. Working paper.

Alvero, A. and K. Xiao (2020). Fuzzy bunching. Available at SSRN 3611447.

Amadxarif, Z., J. Brookes, N. Garbarino, R. Patel, and E. Walczak (2019). The language of rules: textual complexity in banking reforms.

Amirapu, A. and M. Gechter (2020). Labor regulations and the cost of corruption: Evidence from the indian firm size distribution. Review of Economics and Statistics 102(1), 34-48.

Antill, S. (2020). Are bankruptcy professional fees excessively high? Available at SSRN 3554835.

Bachas, N., O. S. Kim, and C. Yannelis (2020). Loan guarantees and credit supply. Journal of Financial Economics.

Bachas, N., E. Liu, and D. Morrison (2020). Market power in small business lending: A two dimensional bunching approach.

Ballew, H., M. Iselin, and A. Nicoletti (2021). Accounting-based thresholds and growth decisions in the banking industry. Review of Accounting Studies, 1-43.

Barth, M. E., W. R. Landsman, and D. J. Taylor (2017). The JOBS Act and information uncertainty in IPO firms. The Accounting Review 92(6), 25-47.

Bartlett III, R. P. (2009). Going private but staying public: Reexamining the effect of SarbanesOxley on firms' going-private decisions. U. Chi. L. Rev. 76, 7.

Bernard, D., D. Burgstahler, and D. Kaya (2018). Size management by european private firms to minimize proprietary costs of disclosure. Journal of Accounting and Economics 66(1), 94-122.

Bernstein, S. and A. Sheen (2016). The operational consequences of private equity buyouts: Evidence from the restaurant industry. Review of Financial Studies 29(9), 2387-2418.

Bharath, S. T. and A. K. Dittmar (2010). Why do firms use private equity to opt out of public markets? Review of Financial Studies 23(5), 1771-1818. 
Bindal, S., C. H. Bouwman, S. A. Johnson, et al. (2020). Bank regulatory size thresholds, merger and acquisition behavior, and small business lending. Journal of Corporate Finance 62, 101519.

Binsbergen, J. H. v., J. R. Graham, and J. Yang (2010). The cost of debt. Journal of Finance 65(6), 2089-2136.

Binsbergen, J. H. v., J. R. Graham, and J. Yang (2011). An empirical model of optimal capital structure. Journal of Applied Corporate Finance 23(4), 34-59.

Bouwman, C. H., S. A. Johnson, et al. (2018). Differential bank behaviors around the dodd-frank act size thresholds. Journal of Financial intermediation 34, 47-57.

Breuer, M. (2021). How does financial-reporting regulation affect industry-wide resource allocation? Journal of Accounting Research 59(1), 59-110.

Calomiris, C. W., H. Mamaysky, and R. Yang (2020, June). Measuring the Cost of Regulation: A Text-Based Approach. SSRN Scholarly Paper ID 3550922, Social Science Research Network, Rochester, NY.

Chaplinsky, S., K. W. Hanley, and S. K. Moon (2017). The JOBS Act and the costs of going public. Journal of Accounting Research 55(4), 795-836.

Chemmanur, T. J., S. He, and D. K. Nandy (2010). The going-public decision and the product market. The Review of Financial Studies 23(5), 1855-1908.

Chetty, R. (2012). Bounds on elasticities with optimization frictions: A synthesis of micro and macro evidence on labor supply. Econometrica 80(3), 969-1018.

Chetty, R., J. N. Friedman, T. Olsen, and L. Pistaferri (2011). Adjustment costs, firm responses, and micro vs. macro labor supply elasticities: Evidence from danish tax records. Quarterly Journal of Economics 126(2), 749-804.

Cheynel, E. and M. Liu-Watts (2020). A simple structural estimator of disclosure costs. Review of Accounting Studies, 1-45.

Clinton, S. B., J. T. White, and T. Woidtke (2014). Differences in the information environment prior to seasoned equity offerings under relaxed disclosure regulation. Journal of Accounting and Economics 58(1), 59-78.

Coates, J. C. and S. Srinivasan (2014, September). SOX after ten years: A multidisciplinary Review. Accounting Horizons 28(3), 627-671.

Coates, J. C. I. (2007). The goals and promise of the Sarbanes-Oxley Act. Journal of economic perspectives 21(1), 91-116.

Dagostino, R. (2018). The impact of bank financing on municipalities' bond issuance and the real economy. Working Paper, University of Rochester.

Dambra, M., L. C. Field, and M. T. Gustafson (2015). The JOBS Act and IPO volume: Evidence that disclosure costs affect the IPO decision. Journal of Financial Economics 116(1), 121-143.

Dambra, M. and M. Gustafson (2020). Do the burdens to being public affect the investment and innovation of newly public firms? Management Science. 
Decker, R. A., J. Haltiwanger, R. S. Jarmin, and J. Miranda (2016). Declining business dynamism: What we know and the way forward. American Economic Review 106(5), 203-07.

DeFusco, A. A., S. Johnson, and J. Mondragon (2020). Regulating household leverage. The Review of Economic Studies 87(2), 914-958.

DeFusco, A. A. and A. Paciorek (2017). The interest rate elasticity of mortgage demand: Evidence from bunching at the conforming loan limit. American Economic Journal: Economic Policy 9(1), $210-40$.

Dey, R. and M. Sullivan (2009). What will non-accelerated filers have to pay for the section 404 internal control audit. Working Paper.

Dharmapala, D. (2019). Estimating Firms' Responses to Securities Regulation Using a Bunching Approach.

Doidge, C., K. M. Kahle, G. A. Karolyi, and R. M. Stulz (2018). Eclipse of the public corporation or eclipse of the public markets? Journal of Applied Corporate Finance 30(1), 8-16.

Doidge, C., G. A. Karolyi, and R. M. Stulz (2013). The US left behind? Financial globalization and the rise of IPOs outside the US. Journal of Financial Economics 110(3), 546-573.

Doidge, C., G. A. Karolyi, and R. M. Stulz (2017). The US listing gap. Journal of Financial Economics 123(3), 464-487.

Eckbo, B. E. and M. Lithell (2021). Merger-driven listing dynamics. Working paper.

Ederer, F. and G. Manso (2013). Is pay for performance detrimental to innovation? Management Science 59(7), 1496-1513.

Engel, E., R. M. Hayes, and X. Wang (2007). The Sarbanes-Oxley Act and firms' going-private decisions. Journal of Accounting and Economics 44(1-2), 116-145.

Ewens, M. and J. Farre-Mensa (2020). The deregulation of the private equity markets and the decline in IPOs. Review of Financial Studies 33(12), 5463-5509.

Ewens, M., R. H. Peters, and S. Wang (2020). Measuring intangible capital with market prices. Working paper.

Fagereng, A. and M. A. K. Ring (2021). Financial frictions and the non-distortionary effects of delayed taxation. Available at SSRN 3791384.

Gao, F., J. S. Wu, and J. Zimmerman (2009). Unintended consequences of granting small firms exemptions from securities regulation: Evidence from the Sarbanes-Oxley Act. Journal of Accounting Research 47(2), 459-506.

Gao, X., J. R. Ritter, and Z. Zhu (2013). Where have all the IPOs gone? Journal of Financial and Quantitative Analysis 48(6), 1663-1692.

Giroud, X. and H. M. Mueller (2010). Does corporate governance matter in competitive industries? Journal of financial economics 95(3), 312-331. 
Gong, K. and C. Yannelis (2018). Measuring the impact of regulation on firms. Review of Financial Studies, RER.

Guo, S., E. S. Hotchkiss, and W. Song (2011). Do buyouts (still) create value? Journal of Finance 66(2), 479-517.

Gustafson, M. T. and P. Iliev (2017). The effects of removing barriers to equity issuance. Journal of Financial Economics 124(3), 580-598.

Hoberg, G. and G. Phillips (2016). Text-based network industries and endogenous product differentiation. Journal of Political Economy 124(5), 1423-1465.

Iliev, P. (2010). The effect of SOX Section 404: Costs, earnings quality, and stock prices. Journal of Finance 65(3), 1163-1196.

Iliev, P. and S. Vitanova (2019). The effect of the say-on-pay vote in the United States. Management Science 65(10), 4505-4521.

Jackson, H. E. (2007). The impact of enforcement: a reflection. U. Pa. L. Rev. PENNumbra 156, 400.

Kahle, K. M. and R. M. Stulz (2017). Is the US public corporation in trouble? Journal of Economic Perspectives 31(3), 67-88.

Kalmenovitz, J. (2019). Regulatory intensity and firm-specific exposure. NYU Stern School of Business.

Kaplan, S. (1989). Management buyouts: Evidence on taxes as a source of value. Journal of Finance 44(3), 611-632.

Kenney, M. and D. Patton (2013). Firm database of emerging growth initial public offerings (IPOs) from 1990 through 2010.

Kleven, H. J. (2016). Bunching. Annual Review of Economics 8, 435-464.

Kleven, H. J. and M. Waseem (2013). Using notches to uncover optimization frictions and structural elasticities: Theory and evidence from pakistan. Quarterly Journal of Economics 128(2), 669723.

Korteweg, A. (2010). The net benefits to leverage. The Journal of Finance 65(6), 2137-2170.

Lehn, K. and A. Poulsen (1989). Free cash flow and stockholder gains in going private transactions. the Journal of Finance 44(3), 771-787.

Leuz, C. (2007). Was the Sarbanes-Oxley Act of 2002 really this costly? A discussion of evidence from event returns and going-private decisions. Journal of Accounting and Economics 44(1-2), 146-165.

Leuz, C., A. Triantis, and T. Y. Wang (2008). Why do firms go dark? Causes and economic consequences of voluntary SEC deregistrations. Journal of Accounting and Economics 45(2-3), 181-208. 
Leuz, C. and P. D. Wysocki (2016). The economics of disclosure and financial reporting regulation: Evidence and suggestions for future research. Journal of Accounting Research 54(2), 525-622.

Lewis, C. M. and J. T. White (2020). Deregulating innovation capital: The effects of the JOBS Act on biotech startups. Available at SSRN 3640852.

Liu, L. Y. (2020). Long-run economic consequences of firms' avoidance behavior in the threshold regulation: Evidence from the Sarbanes-Oxley Act. Working paper.

Lowry, M., R. Michaely, and E. Volkova (2017). Initial public offerings: A synthesis of the literature and directions for future research. Foundations and Trends in Finance, forthcoming.

Manso, G. (2011). Motivating innovation. The journal of finance 66(5), 1823-1860.

Morgenstern, M. and P. Nealis (2004). The impact of Sarbanes-Oxley on mid-cap issues. https://www.sec.gov/info/smallbus/mmorgensternmidcap.pdf .

Parker, R. (2018). Hyping the cost of regulation. The Regulatory Review.

Porta, R. L., F. Lopez-de Silanes, A. Shleifer, and R. W. Vishny (1998). Law and finance. Journal of political economy 106(6), 1113-1155.

Register, F. (1993). Federal register.

Ritter, J. (2020). Initial public offerings: Updated statistics. Data retrieved from https://site.warrington.ufl.edu/ritter/ipo-data/.

Saez, E. (2010). Do taxpayers bunch at kink points? American Economic Journal: Economic Policy 2(3), 180-212.

Schivardi, F. and R. Torrini (2008). Identifying the effects of firing restrictions through sizecontingent differences in regulation. Labour Economics 15(3), 482-511.

SEC (1992). Small Business Initiative.

SEC (2002). Acceleration of Periodic Report Filing Dates and Disclosure Concerning Website Access to Reports.

SEC (2008a). Changeover to the sec's new smaller reporting company system by small business issuers and non-accelerated filer companies: A small entity compliance guide.

SEC (2008b). Smaller reporting company regulatory relief and simplification.

SEC (2009). Study of the Sarbanes-Oxley Act of 2002 Section 404 Internal Control over Financial Reporting Requirements. Technical report, Office of Economics Analysis, U.S. Securities and Exchange Commission.

SEC (2011). Study and Recommendations on Section 404(b) of the Sarbanes-Oxley Act of 2002 For Issuers With Public Float Between $\$ 75$ and $\$ 250$ Million. Technical report, Staff of the Office of the Chief Accountant, U.S. Securities and Exchange Commission.

Simkovic, M. and M. B. Zhang (2020). Regulation and technology-driven entry: Measurement and micro-evidence. Available at SSRN 3205589. 
Weber, D. P. and Y. S. Yang (2020). The debt-equity choice when regulatory thresholds are based on equity values: Evidence from sox 404. The Accounting Review 95(2), 339-364.

Weild, D. (2011). How to revive small-cap IPOs. Wall Street Journal.

Zhang, I. X. (2007). Economic consequences of the Sarbanes-Oxley Act of 2002. Journal of Accounting and Economics $44(1-2), 74-115$. 
Figure 1: CDFs and Histograms for Public Float around Regulatory Thresholds

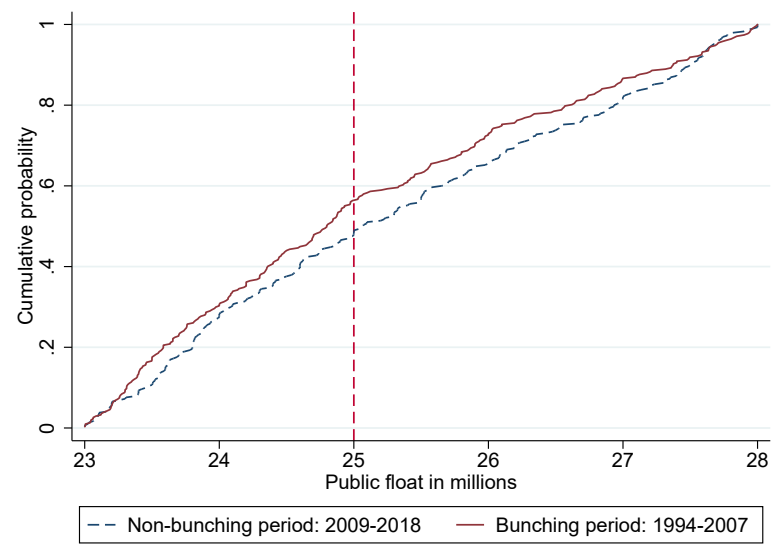

(a) CDF: $\$ 25$ mil

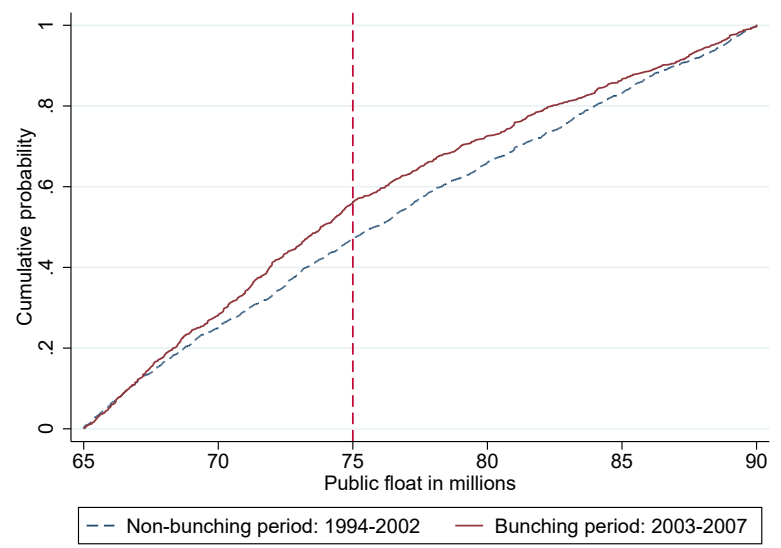

(c) CDF: $\$ 75$ mil

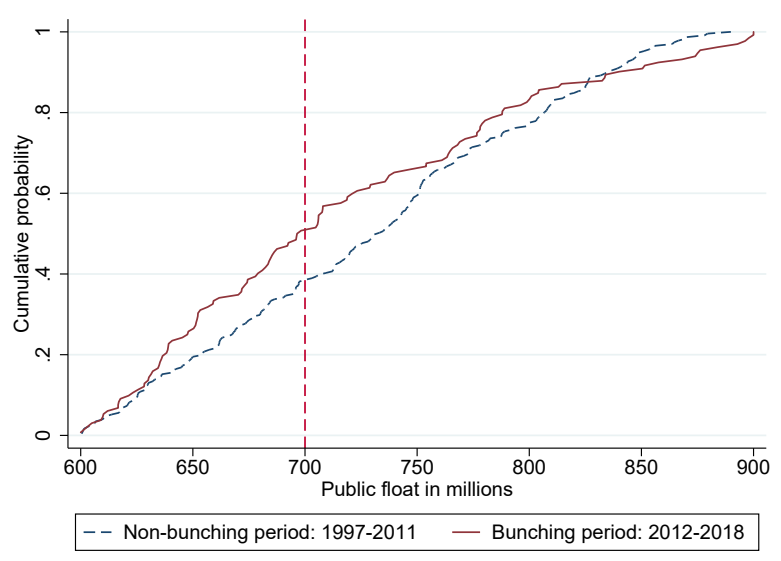

(e) CDF: $\$ 700$ mil

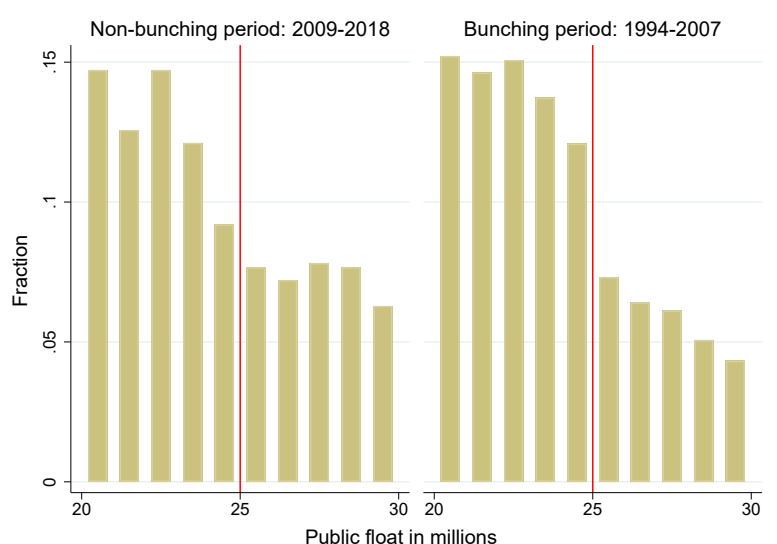

(b) Histogram: $\$ 25$ mil

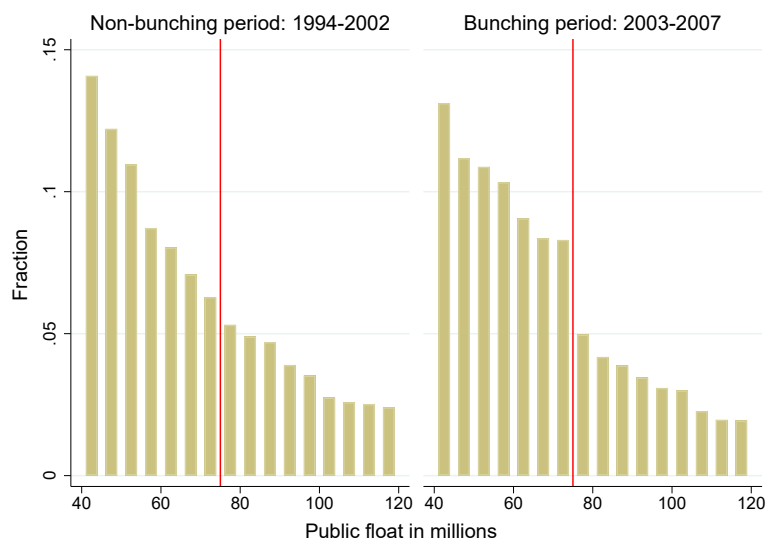

(d) Histogram: $\$ 75$ mil

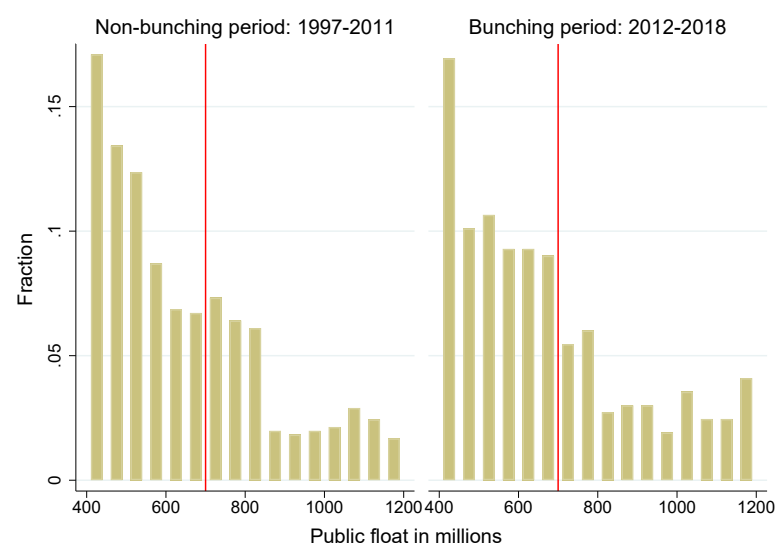

(f) Histogram: $\$ 700$ mil

These figures show the cumulative distribution functions and histograms for firms' public float around regulatory thresholds in bunching and non-bunching years. Bunching years are years when the threshold-based regulation is in place. Non-bunching years are years before the regulation is introduced or after it expires. 
Figure 2: CDFs and Histograms for Public Float around Placebo Thresholds

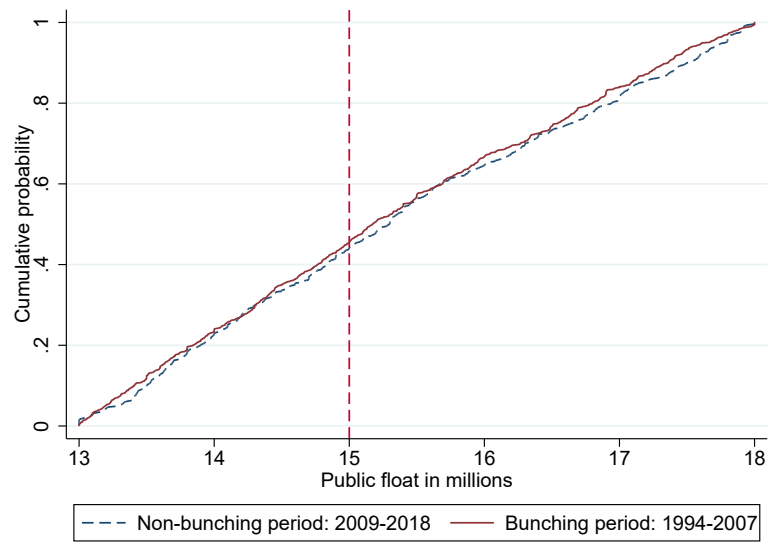

(a) CDF: $\$ 15$ mil

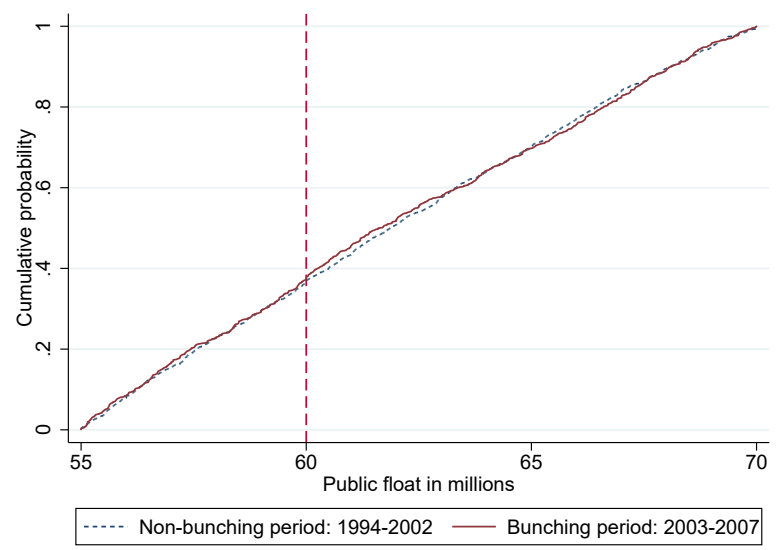

(c) CDF: $\$ 60$ mil

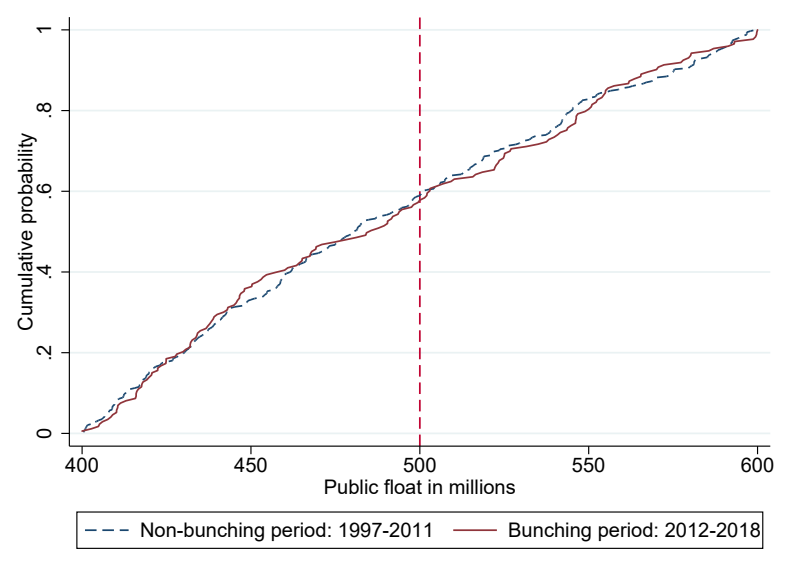

(e) CDF: $\$ 500$ mil

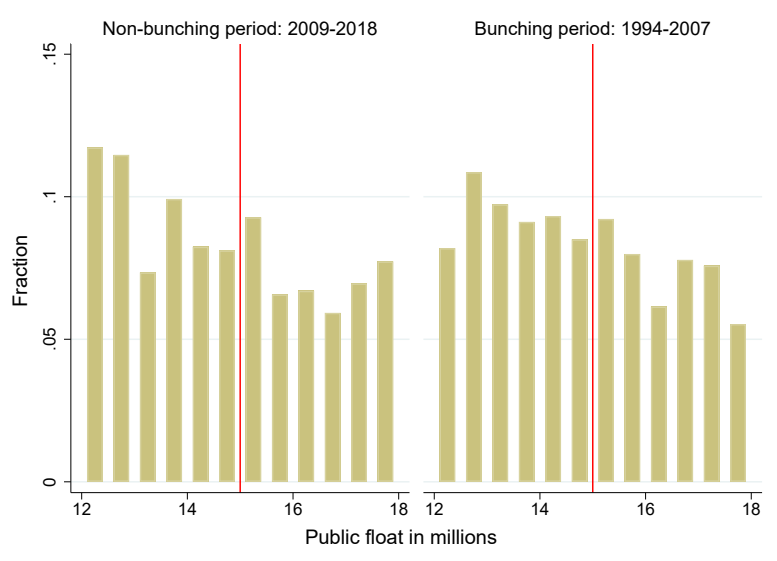

(b) Histogram: $\$ 15$ mil

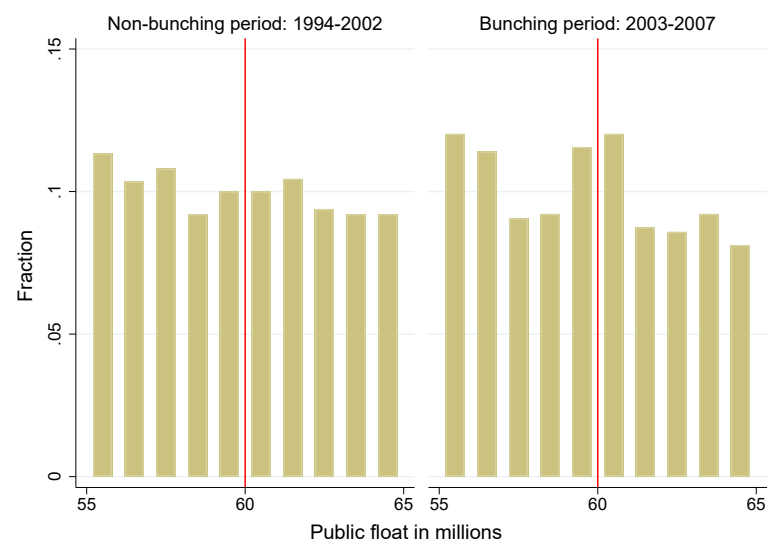

(d) Histogram: $\$ 60$ mil

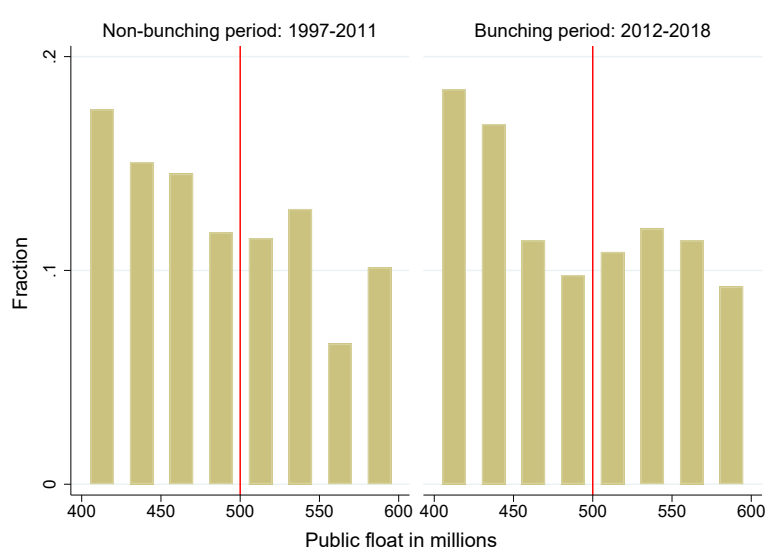

(f) Histogram: $\$ 500$ mil

These figures show the cumulative distribution functions and histograms for firms' public float around three placebo thresholds that are below our actual regulatory thresholds: $\$ 15 \mathrm{M}, \$ 60 \mathrm{M}$, and $\$ 500 \mathrm{M}$. The samples are based on the same sample periods and filters as for our main samples, except for public float range. 
Figure 3: Firm Payoff as a Function of Public Float

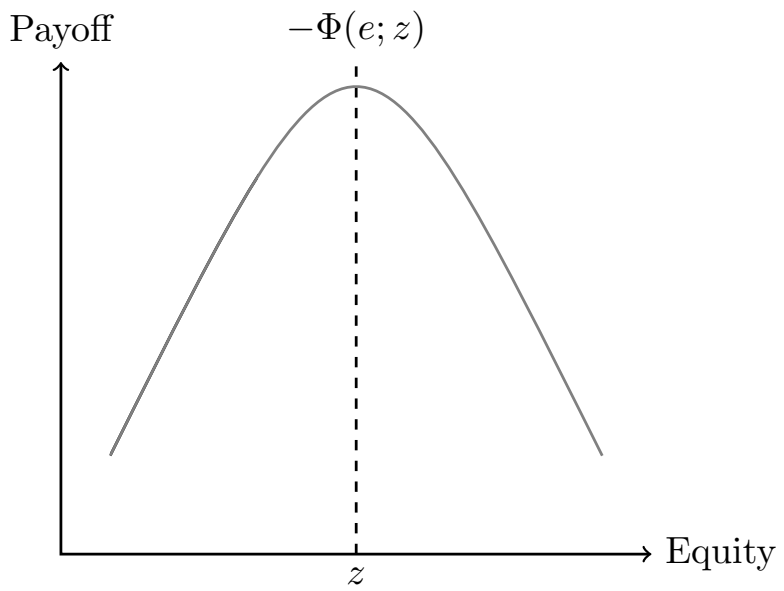

(a) No regulatory threshold

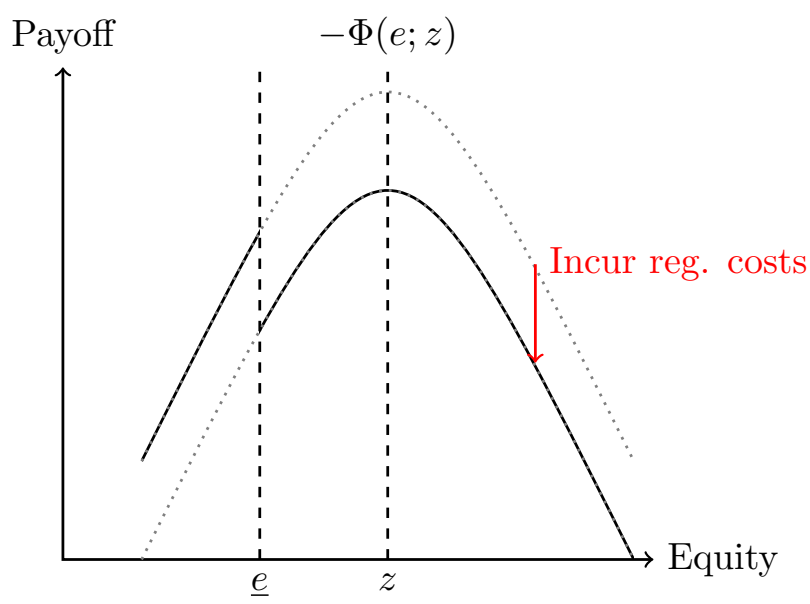

(c) Not bunching

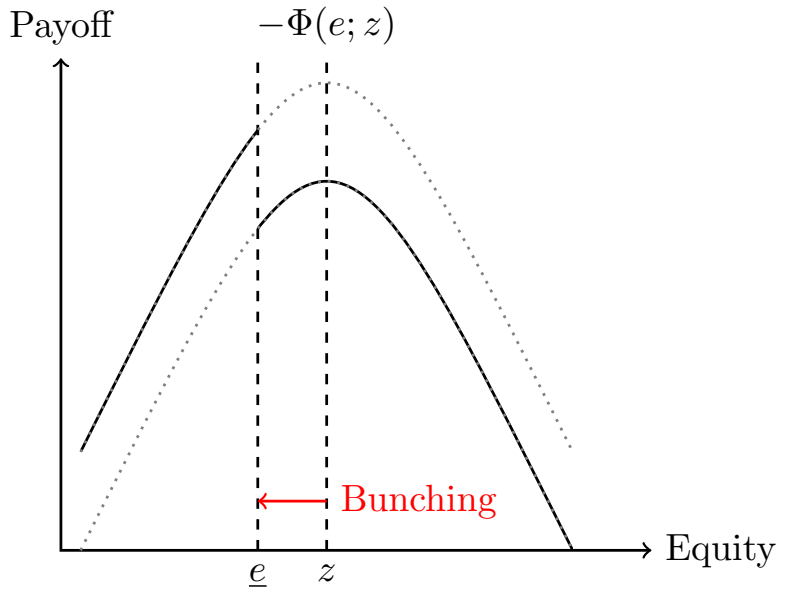

(b) Bunching at regulatory threshold

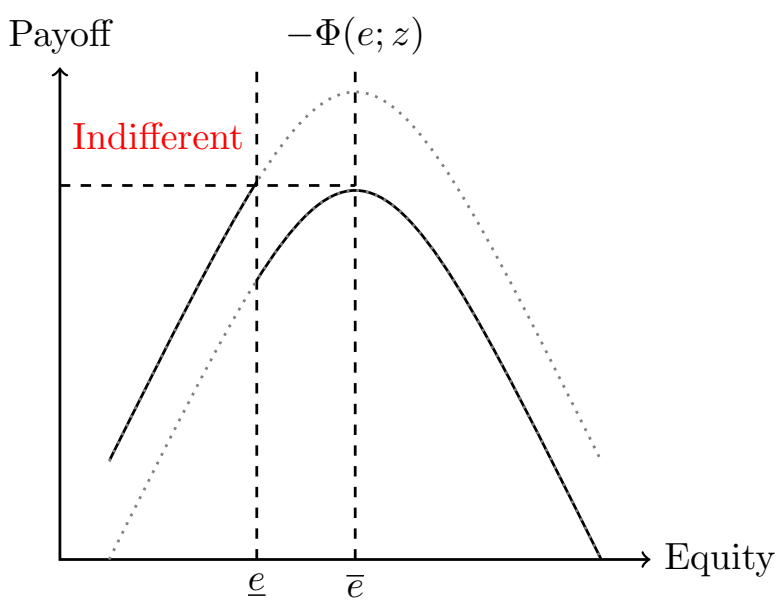

(d) Marginal buncher

This figure illustrates the shape of a firm's payoff as a function of the public float $e$. Panel (a) illustrates a concave payoff function in the absence of a regulatory threshold. Panel (b) shows a new payoff function when a regulatory threshold is introduced at $\underline{e}$. The discontinuity in the payoff induces firms whose public float was somewhat above the threshold to bunch. Panel (c) shows a firm whose undistorted optimal float is way above the regulatory threshold and therefore chooses not to bunch. Panel (d) shows a payoff function for the marginal bunching firm who is indifferent between bunching and not bunching. 
Figure 4: Moments of Distribution Functions Used in Bunching Estimator

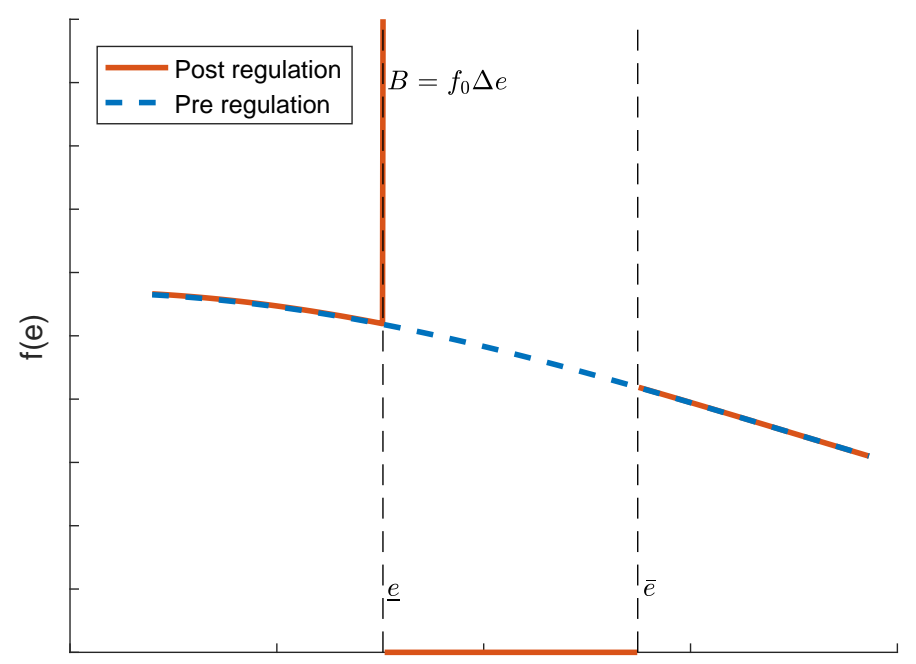

(a) Probability density function

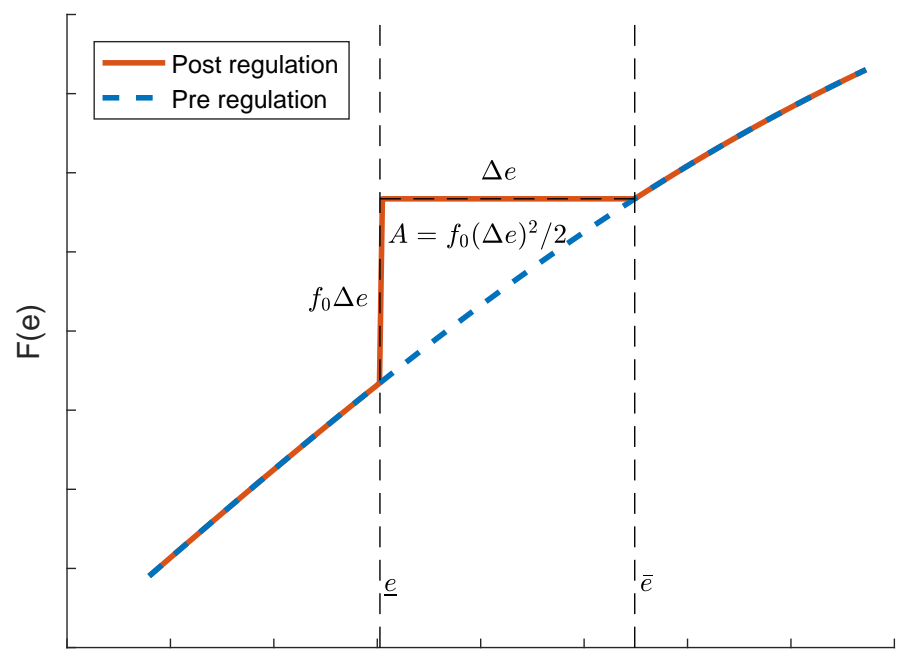

(b) Cumulative distribution function

This figure shows the probability density function (upper panel) and the cumulative distribution function (lower panel) of public float in the presence of bunching. $\underline{e}$ is the regulatory threshold. $\bar{e}$ is the float of the marginal bunching firm. $\Delta e$ is the bunching range from $\underline{e}$ to $\bar{e}$. $B$ is the excess mass at $\underline{e}$. $A$ is the area between the cumulative distribution functions before and after the regulation. $f_{0}$ is the probability density at $\underline{e}$. 
Figure 5: Estimated Regulatory Costs Scaled by EBITDA

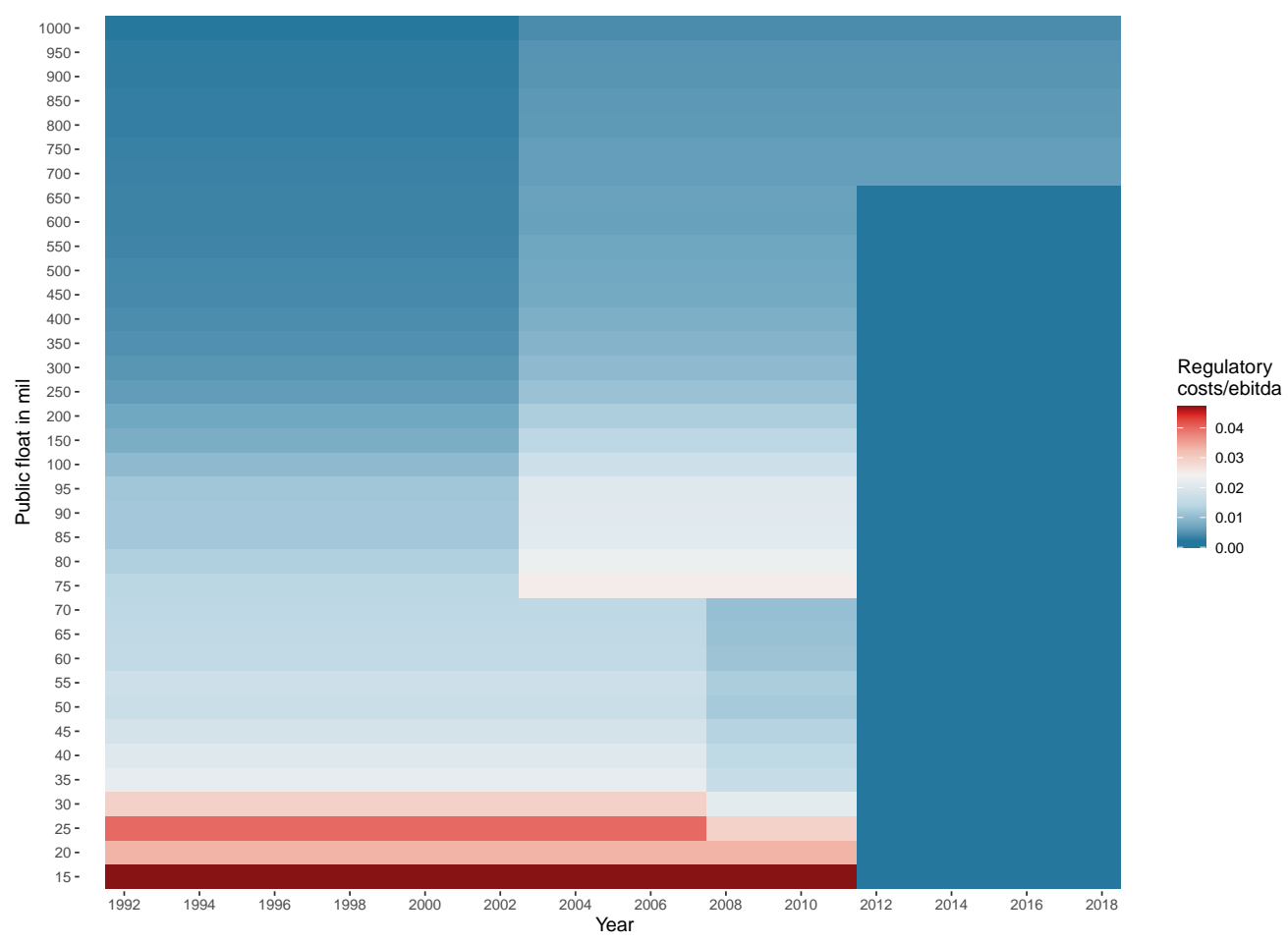

(a) Firms with public age $<=5$

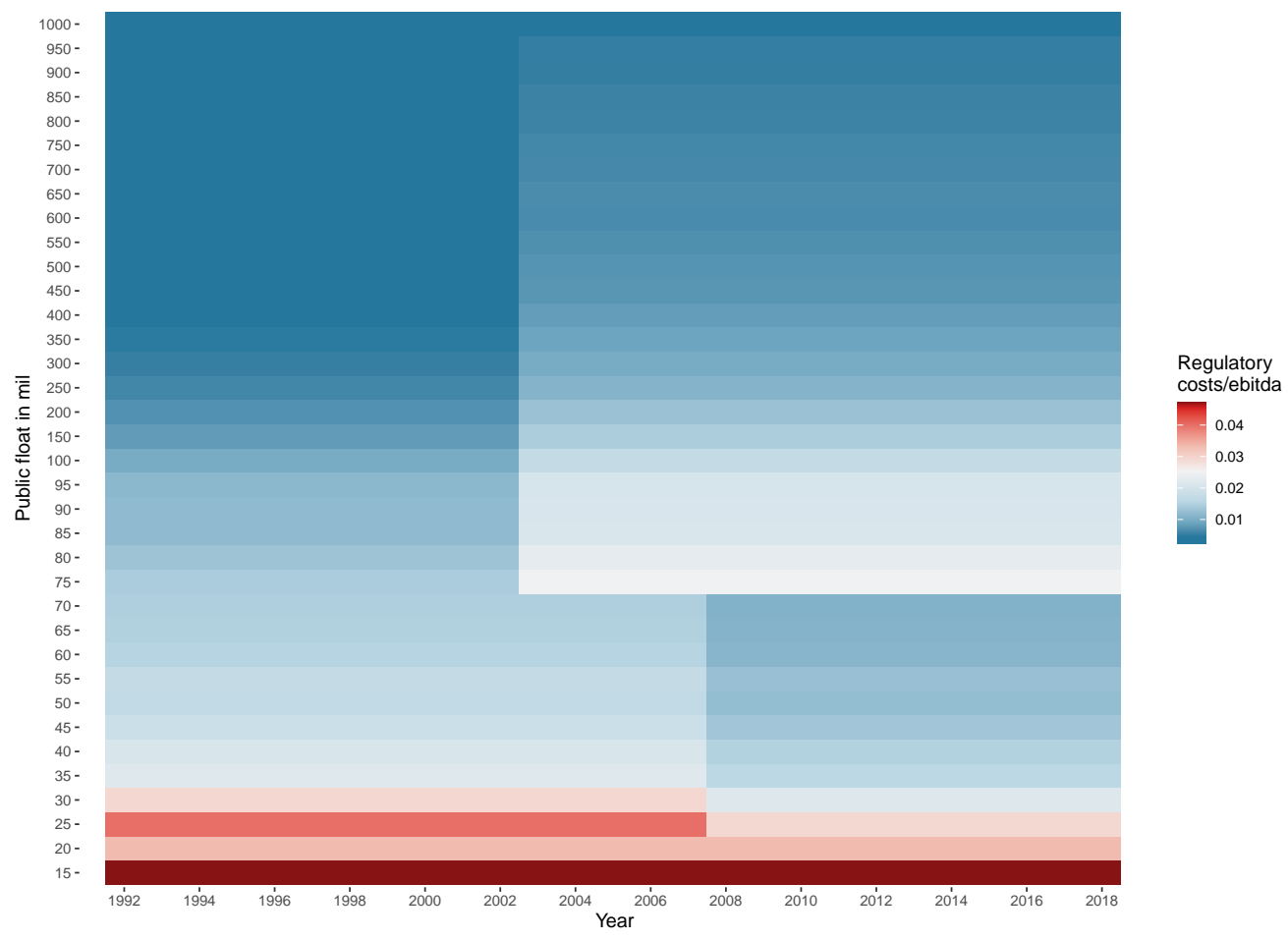

(b) Firms with public age $>5$

These figures show, by public float and year, the estimated total annual regulatory costs scaled by firms' EBITDA. Panel A shows it for firms that went public less than 5 years ago (hence JOBS Act would apply after 2012). Panel B shows it for firms that went pulfic more than 5 years ago. 
Figure 6: Estimated Aggregate Regulatory Costs

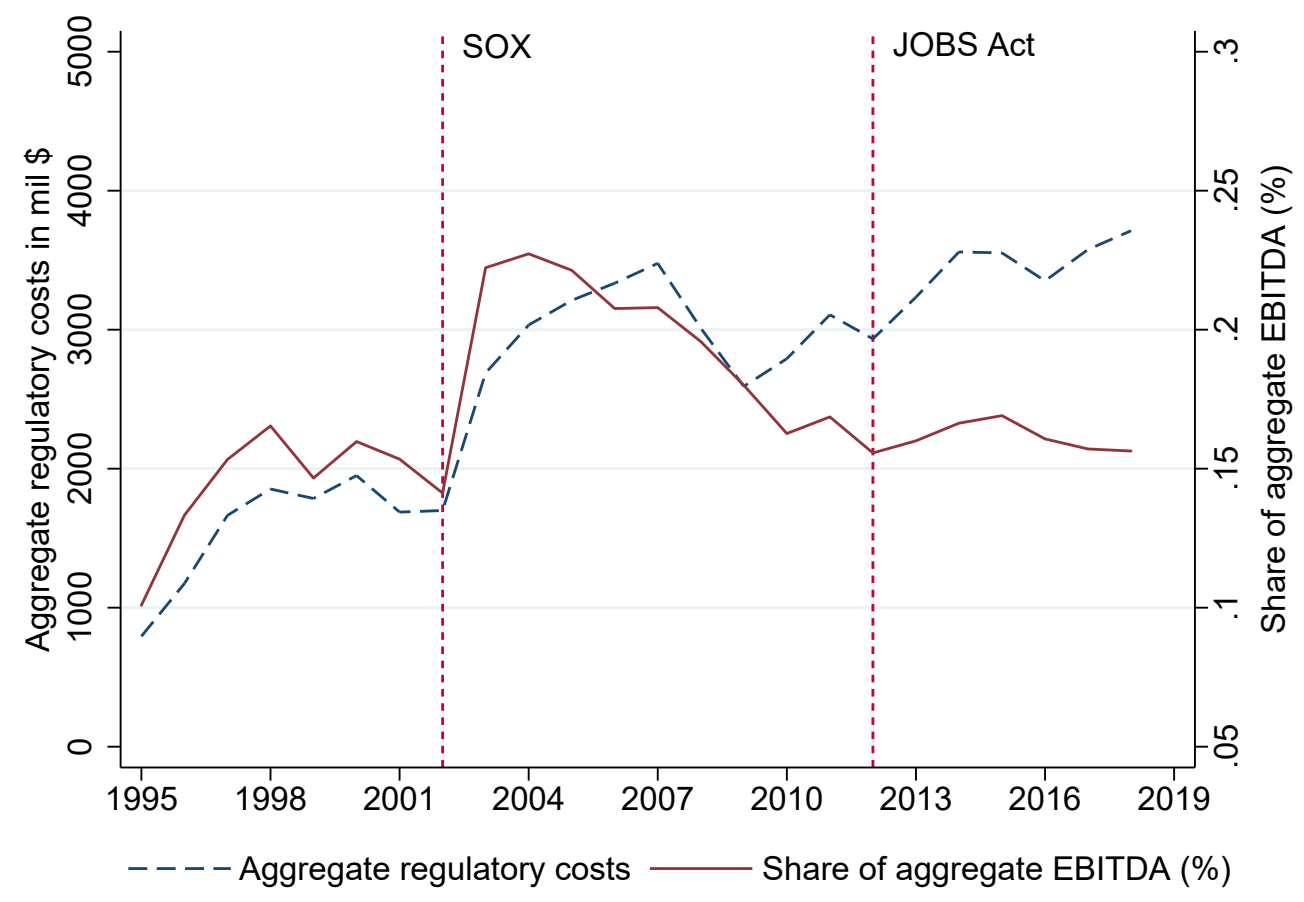

This figure shows the estimated aggregate regulatory costs over time for all public firms with a non-zero public float. The dashed line shows the dollar costs in millions of USD. The solid line shows the percentage share of aggregate regulatory costs relative to aggregate EBITDA. 
Figure 7: IPO Counterfactual Simulations

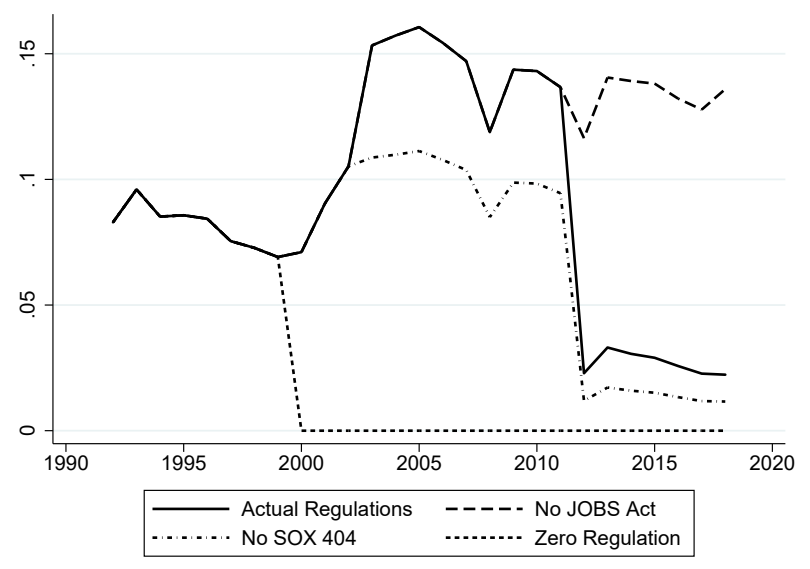

(a) Regulatory costs for potential IPO firms $(\$ \mathrm{~m})$

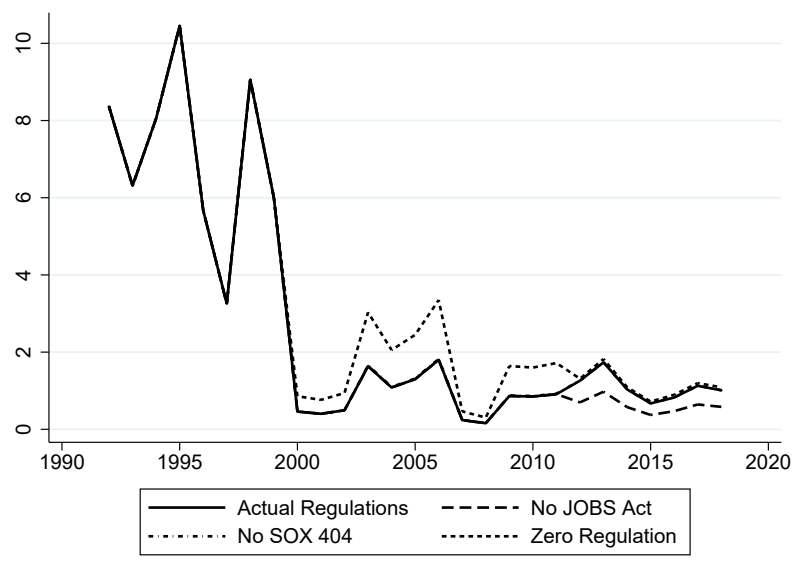

(b) IPO likelihood

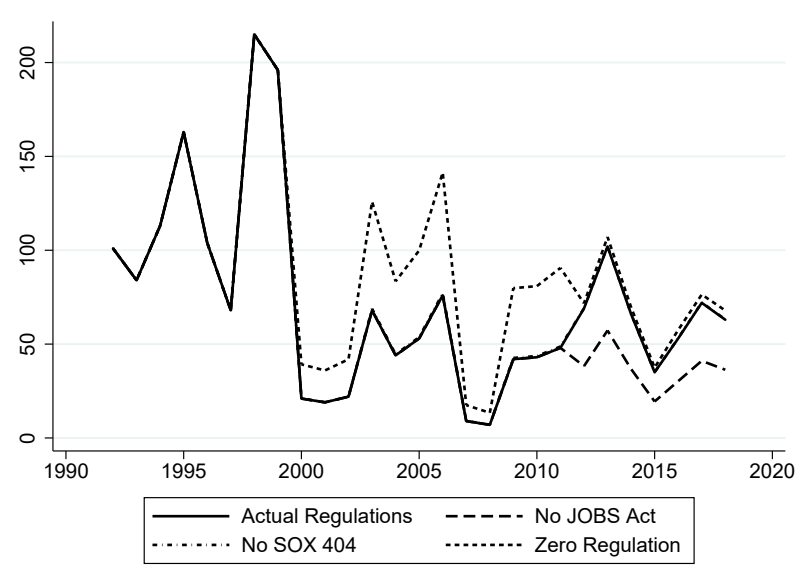

(c) Yearly no. of IPOs

These figures show counterfactual regulatory costs facing potential IPO firms (Panel A), annual IPO likelihood (Panel B), and the annual number of IPOs (Panel C) for four regulatory scenarios after 2000: 1) actual, 2) no JOBS Act, 3) no SOX 404, and 4) zero regulation costs. Estimations are based on the model in Table 6 and counterfactual regulation costs in Tabylgs A.5 and A.6. 
Table 1: Summary of Regulatory Thresholds

Panel A: Key Public Float Thresholds

\begin{tabular}{lllll}
\hline Time period & Scaled Disclosure & $\begin{array}{l}\text { Non-accelerated filer } \\
(\mathrm{NAF})\end{array}$ & $\begin{array}{l}\text { Exempt from SOX } \\
\text { Section } 404\end{array}$ & $\begin{array}{l}\text { Emerging Growth } \\
\text { Company (EGC) }\end{array}$ \\
\hline $1992-2002$ & $<\$ 25 \mathrm{mil}$ & & & \\
$2003-2007$ & $<\$ 25 \mathrm{mil}$ & $<\$ 75 \mathrm{mil}$ & $<\$ 75 \mathrm{mil}$ & \\
$2008-2011$ & $<\$ 75 \mathrm{mil}$ & $<\$ 75 \mathrm{mil}$ & $<\$ 75 \mathrm{mil}$ & \\
$2012-2018$ & $<\$ 75 \mathrm{mil}$ & $<\$ 75 \mathrm{mil}$ & $<\$ 75 \mathrm{mil}$ & $<\$ 700 \mathrm{mil}$ \\
\hline
\end{tabular}

Panel B: Public Float Intervals and Associated Regulatory Benefits

\begin{tabular}{|c|c|c|c|c|c|}
\hline Time Period & $<25$ mil & $25-75 \mathrm{mil}$ & $75-700$ mil & $>700 \mathrm{mil}$ & Binding Thresholds \\
\hline $1992-2002$ & Scaled disclosure & $\mathrm{N} / \mathrm{A}$ & $\mathrm{N} / \mathrm{A}$ & $\mathrm{N} / \mathrm{A}$ & 25 for SD \\
\hline 2003-2007 & $\begin{array}{l}\text { Scaled disclosure } \\
+ \text { filing delay }+404 \text { exempt }\end{array}$ & filing delay +404 exempt & $\mathrm{N} / \mathrm{A}$ & $\mathrm{N} / \mathrm{A}$ & $\begin{array}{l}25 \text { for SD } \\
75 \text { for } 15 d+404\end{array}$ \\
\hline 2008-2011 & \multicolumn{2}{|c|}{ Scaled disclosure + filing delay +404 exempt } & $\mathrm{N} / \mathrm{A}$ & $\mathrm{N} / \mathrm{A}$ & 75 for $\mathrm{SD}+$ delay +404 \\
\hline
\end{tabular}

This table summarizes regulatory thresholds used in our paper. Panel A presents the time-varying threshold for each type of regulatory benefits. Panel B summarize the set of regulatory benefits enjoyed by firms in each public float interval. The last column of Panel B summarizes key exploitable thresholds in each time period and the associated benefits each threshold identifies. 
Table 2: How Firms Manipulate Public Float

\begin{tabular}{lccccc}
\hline Dep. var. & $\begin{array}{c}\text { Book leverage } \\
(1)\end{array}$ & $\begin{array}{c}\text { Investment1 } \\
(2)\end{array}$ & $\begin{array}{c}\text { Investment2 } \\
(3)\end{array}$ & $\begin{array}{c}\text { Investment3 } \\
(4)\end{array}$ & $\begin{array}{c}\text { Non-aff. own. } \\
(5)\end{array}$ \\
\hline & \multicolumn{2}{c}{ Panel A. $\$ 25 \mathrm{~m}$ threshold } \\
\hline Below $\$ 25 \mathrm{~m} \times$ Bunching years & $0.119^{*}$ & 0.019 & 0.019 & 0.025 & -0.012 \\
& {$[0.058]$} & {$[0.026]$} & {$[0.027]$} & {$[0.034]$} & {$[0.049]$} \\
Year FE and SIC2 FE & Yes & Yes & Yes & Yes & Yes \\
N & 1593 & 1463 & 1456 & 1389 & 800 \\
Adj. R-sq & 0.430 & 0.187 & 0.226 & 0.261 & 0.083 \\
Mean of dep. var. & 0.247 & 0.059 & 0.132 & 0.197 & 0.746 \\
\hline & \multicolumn{7}{c}{ Panel B. $\$ 75 \mathrm{~m}$ threshold } & -0.021 \\
\hline Below $\$ 75 m \times$ Bunching years & $0.011^{* *}$ & -0.005 & -0.008 & -0.010 & {$[0.015]$} \\
Year FE and SIC2 FE & {$[0.005]$} & {$[0.007]$} & {$[0.007]$} & {$[0.010]$} & Yes \\
N & Yes & Yes & Yes & Yes & 2791 \\
Adj. R-sq & 3788 & 3675 & 3651 & 3470 & 0.22 \\
Mean of dep. var. in level & 0.511 & 0.329 & 0.397 & 0.397 & 0.724 \\
\hline & 0.171 & 0.051 & 0.096 & 0.140 & \\
\hline Below \$700m $\times$ Bunching years & $0.068^{* *}$ & -0.012 & -0.003 & -0.007 & -0.016 \\
Year FE and SIC2 FE & {$[0.029]$} & {$[0.014]$} & {$[0.025]$} & {$[0.035]$} & {$[0.017]$} \\
N & Yes & Yes & Yes & Yes & Yes \\
Adj. R-sq & 235 & 233 & 227 & 227 & 200 \\
Mean of dep. var. & 0.688 & 0.585 & 0.5 & 0.526 & 0.370 \\
\hline
\end{tabular}

This table examines how firms manipulate public float around regulatory thresholds. Specifically, we compare book leverage, investment, and nonaffiliated ownership between firms just above and those just below the threshold, in bunching and non-bunching years. The three panels correspond to samples around the $\$ 25 \mathrm{M}, \$ 75 \mathrm{M}$, and $\$ 700 \mathrm{M}$ thresholds, respectively. Book leverage is total debt divided by total assets; Investment 1 is capex divided by lagged total assets; Investment 2 is (capex $+\mathrm{R} \& \mathrm{D})$ divided by lagged (total assets + knowledge capital); Investment3 is (capex + $\mathrm{R} \& \mathrm{D}+\gamma^{*} \mathrm{SG} \& \mathrm{~A}$ ) divided by lagged (total assets + knowledge capital + organizational capital), where $\gamma$, knowledge capital, and organizational capital are from Ewens et al. (2020); Non-aff. own. is the fraction of shares held by public investors. Samples in the top (middle) (bottom) panel focuses on firms with a public float between $\$ 20 \mathrm{M}$ and $\$ 30 \mathrm{M}(\$ 60 \mathrm{M}$ and $\$ 90 \mathrm{M})$ ( $\$ 630 \mathrm{M}$ and $\$ 770 \mathrm{M})$. Bunching and non-bunching years are defined in Table 3. All panels include year fixed effects, industry (2-digit SIC) fixed effects, and the lagged dependent variable in year $t-1$. Robust standard errors clustered by industry and year are in parentheses. ${ }^{*}$ indicates statistical significance at the $10 \%$ level, $* *$ at the $5 \%$ level, and $* * *$ at the $1 \%$ level. 
Table 3: Bunching Estimates of Regulatory Costs

\begin{tabular}{|c|c|c|c|}
\hline Threshold & $\begin{array}{c}\$ 25 \text { mil } \\
(1)\end{array}$ & $\begin{array}{c}\$ 75 \text { mil } \\
(2)\end{array}$ & $\begin{array}{c}\$ 700 \mathrm{mil} \\
(3)\end{array}$ \\
\hline & \multicolumn{3}{|c|}{ Panel A. Estimates } \\
\hline Marginal firm $(\bar{e})(\$ \mathrm{~m})$ & $\begin{array}{l}27.044 \\
{[0.283]}\end{array}$ & $\begin{array}{l}94.493 \\
{[2.380]}\end{array}$ & $\begin{array}{c}838.313 \\
{[5.349]}\end{array}$ \\
\hline Regulatory costs $(k)(\$ \mathrm{~m})$ & $\begin{array}{c}0.026 \\
{[0.006]}\end{array}$ & $\begin{array}{c}0.122 \\
{[0.025]}\end{array}$ & $\begin{array}{c}0.713 \\
{[0.049]}\end{array}$ \\
\hline PV(regulatory costs)/Firm value (\%) & $\begin{array}{c}0.622 \\
{[0.153]}\end{array}$ & $\begin{array}{c}0.725 \\
{[0.147]}\end{array}$ & $\begin{array}{c}0.772 \\
{[0.053]}\end{array}$ \\
\hline Non-bunching fraction $(\alpha)$ & $\begin{array}{c}0.480 \\
{[0.119]}\end{array}$ & $\begin{array}{c}0.780 \\
{[0.047]}\end{array}$ & $\begin{array}{c}0.530 \\
{[0.114]}\end{array}$ \\
\hline \multirow[t]{2}{*}{$\Delta$ Leverage } & $\begin{array}{c}0.056 \\
{[0.008]}\end{array}$ & $\begin{array}{c}0.108 \\
{[0.013]}\end{array}$ & $\begin{array}{c}0.073 \\
{[0.003]}\end{array}$ \\
\hline & \multicolumn{3}{|c|}{ Panel B. Parameters } \\
\hline Public float/Assets $(\eta)(\%)$ & 2.000 & 0.880 & 1.572 \\
\hline Tobin's Q $(q)$ & 2.720 & 1.680 & 3.570 \\
\hline \multirow[t]{2}{*}{ Interest rate $(r)$} & 0.115 & 0.093 & 0.049 \\
\hline & \multicolumn{3}{|c|}{ Panel C. Samples } \\
\hline Bunching sample & $1994-2007$ & $2003-2007$ & $2012-2018$ \\
\hline Non-bunching sample & 2009-2018 & $1994-2002$ & $1997-2011$ \\
\hline Identified regulation & $\begin{array}{c}\text { Scaled } \\
\text { disclosure }\end{array}$ & $\begin{array}{l}\text { SOX } 404+ \\
\text { filing delay }\end{array}$ & $\begin{array}{c}\text { EGC } \\
\text { benefits }\end{array}$ \\
\hline
\end{tabular}

This table presents the bunching estimation results. Marginal firm is the public float of the firm that is indifferent between bunching and not bunching. Regulatory costs are the estimated annual costs of regulation $k$ and are in $\$$ million. $P V$ (regulatory costs)/Firm value is the percentage of the present value of future regulatory costs over firm value. The present value is estimated using a $7 \%$ discount rate on a constant perpetuity. Bootstrapped standard errors are reported in brackets. 
Table 4: Benchmarking Estimated Regulatory Costs

\begin{tabular}{lccc}
\hline Threshold & $\begin{array}{c}\$ 25 \text { mil } \\
(1)\end{array}$ & $\begin{array}{c}\$ 75 \text { mil } \\
(2)\end{array}$ & $\begin{array}{c}\$ 700 \text { mil } \\
(3)\end{array}$ \\
\hline Regulatory costs $(\mathrm{k})$ & 0.026 & 0.122 & 0.713 \\
Identified regulations & Scaled & SOX $404+$ & EGC \\
& disclosure & filing delay & benefits \\
\hline Total assets & 14.67 & 126.39 & 556.74 \\
EBITDA & 0.33 & 9.31 & 31.05 \\
Net income & -0.73 & 1.94 & 10.00 \\
\hline k/Total assets & $0.18 \%$ & $0.10 \%$ & $0.13 \%$ \\
k/EBITDA & $7.78 \%$ & $1.31 \%$ & $2.30 \%$ \\
k/Net income & $-3.58 \%$ & $6.29 \%$ & $7.13 \%$ \\
\hline
\end{tabular}

This table benchmarks the estimated annual regulation costs $k$ against the marginal bunching firms' total assets, EBITDA, and net income. All numbers are in millions of USD except percentages. 
Table 5: Cost Structure Estimation

Panel A: SOX 404 Compliance Costs from SEC Survey

\begin{tabular}{lccccc}
\hline & $404(\mathrm{~b})$ audit & Internal labor & $\begin{array}{c}\text { Non-labor } \\
(1)\end{array}$ & $\begin{array}{c}\text { Outside labor } \\
(2)\end{array}$ & $\begin{array}{c}\text { Total } \\
(3)\end{array}$ \\
\hline Public float (in \$mil) & $0.432^{* * *}$ & $0.519^{* * *}$ & $0.355^{* * *}$ & $0.337^{* * *}$ & $0.456^{* * *}$ \\
& {$[0.014]$} & {$[0.032]$} & {$[0.018]$} & {$[0.023]$} & {$[0.028]$} \\
Intercept & $10.476^{* * *}$ & $10.516^{* * *}$ & $9.467^{* * *}$ & $10.365^{* * *}$ & $11.554^{* * *}$ \\
& {$[0.089]$} & {$[0.200]$} & {$[0.115]$} & {$[0.145]$} & {$[0.176]$} \\
\hline Period FE & Yes & Yes & Yes & Yes & Yes \\
N & 12 & 12 & 12 & 12 & 12 \\
Adj. R-sq & 0.813 & 0.85 & 0.946 & 0.833 & 0.852 \\
\hline Dep. var. mean & 13.2 & 13.8 & 11.7 & 12.5 & 14.4 \\
\hline
\end{tabular}

Panel B: Audit Fees from Audit Analytics

Pre-SOX audit fees

(1)

\begin{tabular}{lcc}
\hline Public float (in \$mil) & $0.412^{* * *}$ & $0.423^{* * *}$ \\
Intercept & {$[0.027]$} & {$[0.019]$} \\
& $4.393^{* * *}$ & $5.091^{* * *}$ \\
Year FE & {$[0.562]$} & {$[0.354]$} \\
$\mathrm{N}$ & Yes & Yes \\
Adj. R-sq & 6836 & 60889 \\
\hline Dep. var. mean & 0.426 & 0.616 \\
\hline
\end{tabular}

This table estimates the cost structure of regulatory compliance costs by relating these costs to firm size, proxied by public float. All dependent and independent variables are log transformed from dollar values. Panel A presents the estimated relationship between firms' public float and self-reported SOX 404 compliance costs based on survey data from SEC (2009) and SEC (2011). Each observation is a size group-period. Panel B presents the estimated relationship between firms' public float and audit fees from Audit Analytics. Each observation is a firm-year. Column 1 focuses on the pre-SOX period during which audit fees only capture financial auditing costs. The sample includes all firm-years before 2002, except those who benefit from scaled disclosure (i.e. with less than $\$ 25$ mil in public float). Column 2 focuses on the post-SOX period during which audit fees cover both financial auditing costs and internal control attestation costs. The sample includes all firm-years after 2002 except those who benefit from scaled disclosure or 404(b) exemption, i.e. those with less than $\$ 75$ mil in public float between 2003 and 2011, and those with less than $\$ 700$ mil in public float and age from IPO less than 5 years after 2012 (eligible for EGC status). Standard errors are clustered by period in Panel A and clustered by 2-digit SIC code in Panel B. 
Table 6: Regulatory Costs and IPOs

\begin{tabular}{lcc}
\hline & \multicolumn{2}{c}{ IPO } \\
\cline { 2 - 3 } & $(1)$ & Marginal Effects \\
\hline Regulatory costs $(\ln )$ & Coefficients & $-0.00021^{* * *}$ \\
& {$\left[0.05607^{* * *}\right.$} & {$[0.00006]$} \\
Imputed public float $(\ln )$ & & \\
& $0.23825^{* * *}$ & $0.00089^{* * *}$ \\
Total funding raised $(\ln )$ & {$[0.02493]$} & {$[0.00011]$} \\
& $0.87704^{* * *}$ & $0.00328^{* * *}$ \\
Years since founding & {$[0.03149]$} & {$[0.00015]$} \\
& & $-0.00025^{* * *}$ \\
Industry-Year FE & $-0.06631^{* * *}$ & {$[0.00003]$} \\
State FE & {$[0.00833]$} & Yes \\
Observations & Yes & Yes \\
\hline
\end{tabular}

This table estimates a logit model of the IPO decision on a panel of VC-backed private firms. The sample is a panel of 21,066 VC-backed firms from first VC round to the year before exit or failure from 1992 to 2018. Columns 1 and 2 present the logit coefficients and the marginal effects, respectively. Regulatory costs is the compliance costs estimated from Table 3 and extrapolated to all firm sizes. Imputed public float is the imputed public float upon IPO based on the most recent round of VC valuation (see Section 5.1 for details on imputation). Total funding raised is the cumulative sum of funding raised from VC. We control for state and industry-year fixed effects. Standard errors are clustered by firm. 
Table 7: Counterfactual Simulation of Regulatory Costs and IPOs

\begin{tabular}{|c|c|c|c|c|c|}
\hline & $\begin{array}{c}\text { Actual regulation } \\
\text { (1) }\end{array}$ & $\begin{array}{c}\text { Actual regulation } \\
(2)\end{array}$ & $\begin{array}{c}\text { No SOX } \\
\quad(3)\end{array}$ & $\begin{array}{c}\text { No JOBS Act } \\
(4)\end{array}$ & $\begin{array}{c}\text { Zero regulation } \\
(5)\end{array}$ \\
\hline & Pre-2000 & \multicolumn{4}{|c|}{ Post-2000 } \\
\hline Regulatory costs $(\$ \mathrm{~m})$ & 0.079 & 0.085 & 0.061 & 0.132 & 0.000 \\
\hline Regulatory costs / Public float (\%) & 0.509 & 0.274 & 0.266 & 0.509 & 0.000 \\
\hline IPO probability ( $\%)$ & 6.933 & 0.954 & 0.961 & 0.744 & 1.399 \\
\hline Yearly no. of IPOs & 141.4 & 50.2 & 50.5 & 37.5 & 70.6 \\
\hline Total no. of IPOs & 1044.0 & 912.0 & 918.5 & 711.4 & 1337.9 \\
\hline Total IPO public float $(\$ b)$ & 105.5 & 339.4 & 347.5 & 314.0 & 572.6 \\
\hline
\end{tabular}

Column 1 shows the actual IPO outcomes before 2000 and columns 2 to 5 show counterfactual IPO outcomes under different regulatory scenarios after 2000. Actual regulation is the baseline scenario based on actual regulations. No SOX estimates are based on regulatory costs without SOX (see Panel A of Table A.6). No JOBS Act estimates are based on regulatory costs without JOBS Act (see Panel B of Table A.6). Zero regulation estimates are based on zero regulatory costs after 2000. Regulatory costs is the average annual regulatory costs facing potential IPO firms (i.e., VC-backed firms) in the corresponding period. Regulatory costs / Public Float is the average ratio of annual regulatory costs relative to public float for a potential IPO firm in the corresponding period. IPO probability is the average predicted probability that a potential IPO candidate will go public in the corresponding period. Yearly no. of IPOs is the average yearly predicted total number of IPOs, obtained by summing up predicted IPO probabilities in each year and take the yearly average over the corresponding period. Total no. of IPOs is the predicted total number of IPOs, obtained by summing up predicted IPO probabilities across the sample in the corresponding period. Total IPO public float is the predicted aggregate public float of IPO firms over the corresponding period, obtained by weighted summing the public float of potential IPO firms weighted by IPO probabilities. 
Table 8: Regulatory Costs and Going Private Transactions

\begin{tabular}{|c|c|c|}
\hline & \multicolumn{2}{|c|}{ Going Private } \\
\hline & $\begin{array}{c}(1) \\
\text { Coefficients }\end{array}$ & $\begin{array}{c}(2) \\
\text { Marginal Effects }\end{array}$ \\
\hline Regulatory costs (ln) & $\begin{array}{l}-0.0422 \\
{[0.0294]}\end{array}$ & $\begin{array}{l}-0.0003 \\
{[0.0002]}\end{array}$ \\
\hline Public float (ln) & $\begin{array}{c}-0.1546^{* * *} \\
{[0.0195]}\end{array}$ & $\begin{array}{c}-0.0010^{* * *} \\
{[0.0002]}\end{array}$ \\
\hline Leverage & $\begin{array}{c}0.5919^{* * *} \\
{[0.1276]}\end{array}$ & $\begin{array}{c}0.0038^{* * *} \\
{[0.0009]}\end{array}$ \\
\hline Total assets (ln) & $\begin{array}{c}0.0117 \\
{[0.0288]}\end{array}$ & $\begin{array}{c}0.0001 \\
{[0.0002]}\end{array}$ \\
\hline ROA & $\begin{array}{c}0.6926^{* * *} \\
{[0.1418]}\end{array}$ & $\begin{array}{c}0.0044^{* * *} \\
{[0.0009]}\end{array}$ \\
\hline Investment-to-assets & $\begin{array}{l}-0.6522 \\
{[0.4899]}\end{array}$ & $\begin{array}{l}-0.0042 \\
{[0.0031]}\end{array}$ \\
\hline Sales growth & $\begin{array}{c}-0.3860^{* * *} \\
{[0.0991]}\end{array}$ & $\begin{array}{c}-0.0025^{* * *} \\
{[0.0006]}\end{array}$ \\
\hline $\mathrm{M} / \mathrm{B}$ & $\begin{array}{c}-0.0141^{* *} \\
{[0.0057]}\end{array}$ & $\begin{array}{c}-0.0001^{* *} \\
{[0.0000]}\end{array}$ \\
\hline Stock return & $\begin{array}{c}-0.2915^{* * *} \\
{[0.0677]}\end{array}$ & $\begin{array}{c}-0.0019^{* * *} \\
{[0.0004]}\end{array}$ \\
\hline No. of analysts (ln) & $\begin{array}{c}-0.1631^{*} \\
{[0.0834]}\end{array}$ & $\begin{array}{c}-0.0010^{*} \\
{[0.0005]}\end{array}$ \\
\hline Institutional ownership & $\begin{array}{c}-1.1131^{* * *} \\
{[0.2513]}\end{array}$ & $\begin{array}{c}-0.0071^{* * *} \\
{[0.0016]}\end{array}$ \\
\hline $\begin{array}{l}\text { Industry-Year FE } \\
\text { State FE } \\
\text { Observations }\end{array}$ & $\begin{array}{c}\text { Yes } \\
\text { Yes } \\
43,437\end{array}$ & $\begin{array}{c}\text { Yes } \\
\text { Yes } \\
43,437\end{array}$ \\
\hline
\end{tabular}

This table estimates a logit model of going private decisions on a panel of public firms from 1995 to 2017 . The sample includes 674 firms that went private during our sample period and 3,543 firms that were public as of 2018. The dependent variable is a dummy equal to one if a firm goes private in the next year. Columns 1 and 2 present the logit coefficients and the marginal effects, respectively. Regulatory costs is the compliance costs estimated from Table 3 and extrapolated to all firm sizes. We control for industry (SIC 1-digit)-year fixed effects and state fixed effects. Standard errors are clustered by firm. 


\section{Appendix}

\section{A.1 Data and Institutional Details}

\section{A.1.1 Public Float Data}

The regulations we study all use public float to determine eligibility. Under the Securities Exchange Act of 1934, this number is required to be precisely disclosed on the fist page of firms' 10-K filings. Formally, public float is defined as the aggregate worldwide market value of a firm's voting and non-voting common equity held by non-affiliates (i.e., large shareholder or top management). ${ }^{46}$ It is computed by multiplying the aggregate worldwide number of shares of voting and non-voting common equity held by non-affiliates by the price at which the common equity was last sold, or the average of the bid and asked prices of the common equity, in the principal market for the common equity.

Before 2002, public float was computed within 60 days of their filing date in accordance with the SEC RIN 3235-AG82. ${ }^{47}$ Since the introduction of accelerated filing in 2002 (SEC RIN 3235AI33), all companies except small business issuers are required to compute public float as of the last business day of a firm's most recently completed second fiscal quarter. ${ }^{48}$ This amendment was to give companies enough time to prepare for a potential change in filing status. In particular, a company will be able to determine its public float by looking back at the last business day of its most recently completed second fiscal quarter. This allows companies to know further in advance whether they will become an accelerated filer at the end of their fiscal year and allow them to begin making the appropriate preparations.

We scrape public float information from firms' 10-K filings (including 10-KSB, 10-KT, and 10K405) using a proprietary Python script custom developed for us. This script locates the sentence disclosing public float using keywords and formatting syntax. The script was adjusted to account for different reporting formats over different time periods. We also extract the date on which

\footnotetext{
${ }^{46}$ Rule 405 defines an affiliate as a "person that directly, or indirectly through one or more intermediaries, controls, is controlled by, or is under common control with," an issuer. The term "control" is defined in Rule 405 under the Act as "the possession, direct or indirect, of the power to direct or cause the direction of the management and policies of a person, whether through the ownership of voting securities, by contract, or otherwise."

${ }^{47}$ https://www.sec.gov/rules/final/33-7419.txt

${ }^{48}$ https://www.sec.gov/rules/final/33-8128.htm
} 
public float was computed. We then manually check the scraped numbers against the original filings to verify the accuracy of our data and to further correct a small number of idiosyncratic discrepancies. To the best of our knowledge, this is the largest sample of public float data collected in the literature.

\section{A.1.2 Potential Lobbying and Anticipation of Regulations}

Scaled Disclosure and Small Business Issuer. The history of this rule change provides no evidence that the impacted companies significantly lobbied for the new rules well before enactment or during the comment period. The discussion about the changes began in early 1992 when the SEC proposed "Small business initiative." In fact, the SEC itself proposed legislation to both the House and Senate called the Small Business Incentive Act of 1992. The Act ${ }^{49}$ was never passed, but the SEC used its power to update the regulations in the spirit of this act. As with all rule changes, the SEC had an open comment period. In response to the comments, the SEC increased the original revenue threshold but otherwise "Regulation S-B is adopted in substantially the same form as proposed." (SEC, 1992, p. 13)

Non-accelerated Filer. Our study of this rule change's history does not show that any of the firms directly effected lobbied for the change, nor were there specific firms or firm types targeted. It was not implemented in response to legislation and instead stemmed from a standard rule-making change the SEC often performs. The SEC proposed the rule first in 1998, but only in April 2002 was the final rule proposal presented to the public. The rule received over 300 public comments from a range of investors and advocacy groups. The SEC's assessment of these comments was general disapproval:

Most of these commenters believed that any incremental benefit from the speed and extent of acceleration proposed was insufficient to warrant the added burdens on registrants and the risk of diminished disclosure quality, although these commenters generally did not analyze the benefits from the perspective of users of the reports. [...] The most common concern was that the proposed deadlines would negatively affect the quality and accuracy of reports. [...] According to one professional association, two-thirds of its survey respondents expected a reduction in the precision of reported information under the original proposals.

\footnotetext{
${ }^{49}$ See https : //www . congress . gov/bill/102nd-congress/house-bill/4938?s=1\&r=25
} 
In response to these comments, the SEC lengthened the disclosure windows for annual reports from an original 60 to 75 days and 30 to 35 days for quarterly reports. The fundamental condition of the accelerated filer definition based on public float did not change and in fact was an artifact of the $\$ 75 \mathrm{~m}$ float threshold implemented in an amendment to the Form S-3 registration in 1992 (Register, 1993).

Emerging Growth Companies. The timeline of the JOBS Act proposal to passage reveals no concerns regarding endogenous timing. The Act was born out of a host of bills passed by the House in November 2011 (e.g. Small Company Capital Formation (H.R. 1070) and Entrepreneur Access to Capital (H.R. 2930)). The Senate followed the passage of one of the House bills with their own proposals focused on crowdfunding. Each sat in the Senate Banking Committee until March 2012. Only in December 2011 did the ECG features emerge in a bill in the House. In March 2012, all the previously passed bills were consolidated into the JOBS Act, which was signed into law in April 2012. We found no evidence of previous attempts to pass this collection of laws.

\section{A.1.3 Smaller Reporting Companies}

Another major regulatory change is the introduction of the "smaller reporting company" SRC in 2008 (SEC, 2008b). Originally proposed in 2005, this new category of registered companies had their own scaled disclosure rules. This rule change was a simplification and consolidation of the scaled disclosure regime and Regulation S-B passed in 1992 (see Section 1.2.1). The simplification came in two parts. First, the SEC eliminated all the "SB" filings such as 10-KSB and SB-1s. Next, the commission moved 12 non-financial scaled disclosure requirements from Regulation SB into the existing Regulation S-K (e.g. executive compensation, use of proceeds, description of business, etc.). Companies with less than $\$ 75 \mathrm{~m}$ public float and $\$ 50 \mathrm{~m}$ in revenue had the option to label themselves a smaller reporting company and selectively disclose the 12 items. ${ }^{50}$ Among many limited disclosure options, such reporting companies need only provide 3 (rather than 5) years of business development activities, only provide compensation information on the CEO and two top-paid executives and produce only three of the seven compensation tables required of larger reporting companies. Smaller reporting companies had less stringent disclosure rules about policies

\footnotetext{
${ }^{50}$ See Table A.1 for the list of scaled disclosure items. Item 404 of Regulation S-K is the only place where the scaled requirements can be more rigorous for SRC than for larger companies.
} 
for related party transactions.

This SEC rule change (not legislation) was the part of a multi-year initiative "to provide responsive solutions addressing the special characteristics and needs of smaller companies and their investors." 51 This longer term feature of the rule change mitigates concerns about any lobbying on behalf of the affected firms.

In its report on the rule change, the SEC argued that there would be significance savings in lower compliance costs for smaller reporting companies. The SEC calculated that among those eligible firms that choose to because such a reporting company, the average firm will save over $\$ 60,000 /$ year in "internal burden hours and costs." ${ }^{2}$ Besides these quantifiable costs, the SEC believed that investors in smaller reporting companies may struggle with determining whether a particular firm has changed its information disclosure. As with the other rule changes, the SEC expected benefits such as streamlining regulation, reducing investor confusion about firm reporting type and "providing flexibility to [...] smaller reporting companies to tailor their disclosure to their investors' needs" would weigh against these costs.

\footnotetext{
${ }^{51}$ See https://www.sec.gov/rules/final/2007/33-8876.pdf

${ }^{52}$ The SEC writes:

We assume that approximately $50 \%$ of the 1,581 companies (or 790 companies) will use the scaled disclosure requirements. For purposes of the Paperwork Reduction Act, we estimate that these 790 smaller reporting companies may save 356,290 internal burden hours and costs in the amount of $\$ 47,479,000$ by using the scaled disclosure requirements.
} 


\section{A.2 Estimate Leverage Distortion Cost Based on Korteweg (2010)}

This section discusses an alternative approach to translate the extent of bunching to the regulatory cost based on Korteweg (2010). Korteweg (2010) estimates the net benefits to debt financing as a fraction of firm value as the following function of leverage $L$ :

$$
\text { NetBenefits }(L)=a \times L^{2}+b \times L+c
$$

where $a, b$, and $c$ are linear functions of several covariates of the marginal bunching firm, which we list in Panel B of Table A.13. Korteweg (2010) estimates the parameters of the above model using a Markov Chain Monte Carlo (MCMC) method and obtains the following results (based on column 4 of his Table III): $a=-0.346-0.203 P R O F+1.655 D E P R-0.184 V O L+0.149 P P E-0.063 M B-$ 0.052D_RECESS-0.006LN $(T A), b=0.143+0.539 P R O F-1.940 D E P R-0.086 V O L+0.353 P P E+$ $0.002 M B-0.037 D \_R E C E S S-0.003 L N(T A)$, and $c=-0.012+0.150 P R O F-0.288 D E P R-$ $0.075 V O L+0.078 P P E-0.001 M B+0.004 D \_R E C E S S+0.001 L N(T A)$, where PROF is EBITDA over sales; DEPR is depreciation over book assets; VOL is the standard deviation of PROF growth; $P P E$ is property, plant, and equipment divided by book assets; $M B$ is equity market capitalization divided by book equity; $D \_R E C E S S$ is a dummy indicating NBER recession; $L N(T A)$ is the natural logarithm of total assets in millions; and $L$ is the leverage ratio (i.e., net debt divided by the sum of net debt and market value of equity), bounded below by zero. We calibrate these covariates to the marginal firms and their values are in Panel B of Table A.13.

The regulatory cost as a fraction of firm value is given by the leverage distortion cost of the marginal bunching firm:

$$
\frac{k}{v}=\operatorname{NetBenefits}\left(L^{*}\right)-N \text { etBenefits }\left(L^{*}+\frac{\Delta e}{v}\right)
$$

where $L^{*} \equiv \max \left(0,-\frac{b}{2 a}\right)$ is the optimal leverage, and $\frac{\Delta e}{v}$ is the distortion in leverage when the marginal firm bunches at the regulatory threshold. 


\section{A.3 Comparison with Existing Estimates}

Our regulatory cost estimates can be compared to four previous estimations. We first examine the regulatory costs of the scaled disclosure. Using a structural model, Cheynel and Liu-Watts (2020) estimates an average disclosure costs of about $0.26 \%$ of total assets. When applied to the marginal bunching firm's total assets of $\$ 14.7 \mathrm{~m}$, this translates to an annual disclosure costs of $\$ 0.038 \mathrm{~m}$ comparable to our estimate of $\$ 0.026 \mathrm{~m}$. Next, the Audit Analytics data provides pre-SOX audit fees, which we use as a proxy for the direct costs of financial disclosure. We focus on the pre-SOX era because audit fees in that period capture expense for financial auditing and not costs for post-SOX internal control compliance. For firms with asset size of the marginal bunching firms, the median audit fee is $\$ 0.078 \mathrm{~m}$. Our estimate of $\$ 0.026 \mathrm{~m}$ for the value of scaled disclosure has the same order of magnitude as these alternative estimates. Our number is smaller because scaled disclosure does not cover all disclosure items. ${ }^{53}$ In addition, our estimate captures the net disclosure cost after taking into account the potential benefits of enhanced disclosure available to firms.

Second, we estimate the net benefits of SOX 404 exemption to be $\$ 0.122 \mathrm{~m}$ per year for the marginal bunching firm with a $\$ 94.5 \mathrm{~m}$ float. Survey results from the SEC (2011) report and Alexander et al. (2013) show that firms with public float between $\$ 75 \mathrm{~m}$ and $\$ 250 \mathrm{~m}$ face a median SOX 404 compliance cost of $\$ 0.51 \mathrm{~m}$, out of which $\$ 0.15 \mathrm{~m}$ are 404 (b) audit fees. Alternatively, we can use within-firm increase in audit fees around SOX as another proxy of direct internal control costs. For firms around the size of the marginal bunching firm, the median audit fee increases from 2000-2001 to 2003-2007 is $\$ 0.14$ m. Using a fuzzy regression discontinuity design, Iliev (2010) finds that SOX 404 increased audit fees by $98 \%$, which, applied to the median pre-SOX audit fees of $\$ 0.135 \mathrm{~m}$ for firms of similar size to the marginal bunching firm, translates to $\$ 0.132 \mathrm{~m}$. Overall, these numbers are larger but have the same order of magnitude as our estimates.

Third, we estimate the net benefits of EGC status to be $\$ 0.713 \mathrm{~m}$ per year for a marginal bunching firm of $\$ 838 \mathrm{~m}$ float. Unfortunately, there are no existing estimates of EGC benefits from surveys or research. The closest is the Lewis and White (2020) survey of a small group of biotech

\footnotetext{
${ }^{53}$ One could use our estimate in Table A.2 to scale up our enhanced disclosure cost: All else equal, SBI filers have 10-Ks and DEF14As that are about 25\% shorter than non-SBI filers. Assuming homogeneous disclosure cost for all disclosure items, the full disclosure cost for our marginal bunching firm is around $\$ 0.1 \mathrm{~m}$ per year, or about $2.5 \%$ of firm value based on present value. This value is likely a lower bound as it does not incorporate overhead costs that are invariant to disclosure length.
} 
firms that lost their EGC status. They report an average 404 (b) compliance cost of $\$ 0.8 \mathrm{~m}$, with $\$ 0.41 \mathrm{~m}$ in audit fees, $\$ 0.19 \mathrm{~m}$ in external consultant fees, and $\$ 0.2 \mathrm{~m}$ in internal labor. Given that 404(b) exemption is a subset of the benefits enjoyed by EGCs (though an important component), our estimate of $\$ 0.713 \mathrm{~m}$ can be considered as lower, which could again be explained by our measure capturing net benefits and/or firms over-reporting regulatory costs in surveys.

Lastly, we compare our estimates with regulation indices from Kalmenovitz (2019), who measure regulation intensity from regulatory text on Federal Register. We first correlate our firm-yearlevel total regulatory cost estimates with his firm-year-level RegIn_Dollar measure based on 112,831 firm-years from 1994 to $2018 .{ }^{54}$ We find an overall correlation of 0.234 and a within-year correlation of 0.247 . This is a strong positive correlation given that his measure captures all regulations by all federal agencies, not just those by the SEC. Figure A.4 compares the time series of our aggregate regulatory costs with the SEC regulation intensity index from Kalmenovitz (2019). Despite our measure capturing a subset of SEC regulations, our time series looks very similar to that from Kalmenovitz (2019). This suggests that our measure captures important SEC regulatory changes post 1990 s.

\footnotetext{
${ }^{54}$ To arrive at this measure, Kalmenovitz (2019) obtains regulation-level total paperwork costs estimated by each federal agency, then allocates them to industries based on textual similarity and then further allocates to firms based on firms' industry sales.
} 


\section{A.4 Robustness and Further Analysis}

\section{A.4.1 Alternative Regulations Around the $\$ 75 \mathrm{~m}$ and $\$ 700 \mathrm{~m}$ Thresholds}

First, since December 1, 2005, firms above $\$ 700 \mathrm{~m}$ float enjoy the Well-Known Seasoned Issuer (WKSI) status (Clinton et al., 2014), which allows for streamlined and faster security issuance. This rule may again create a reverse bunching incentive and a potential downward bias in our estimate. However, our estimate for EGC benefits from the $\$ 700 \mathrm{~m}$ threshold is unlikely to be affected because we focus on newly public firms that have little immediate need for a seasoned equity offering. Indeed, Figure A.5 Panel A shows no bunching above $\$ 700 \mathrm{~m}$ from 2006 to 2011, the period of WKSI and pre-EGC (relative to 1997-2005). This result suggests that any WKSI benefits for newly public firms are minimal and in turn, that our EGC benefit estimate is unlikely to be biased.

Second, before 2008 , firms above $\$ 75 \mathrm{~m}$ float enjoyed shelf registration, which streamlines and accelerates security issuance (Gustafson and Iliev, 2017). However, this cutoff was eliminated in 2008 when SEC extended shelf registration to all firms. ${ }^{55}$ Hence, before 2008, shelf registration may introduce an incentive to bunch above $\$ 75 \mathrm{~m}$, leading to a potential downward bias in our estimate. To address this, we use $2008-2018$ as an alternative bunching period for the $\$ 75 \mathrm{~m}$ threshold. One complication is that "Smaller Reporting Companies" were also introduced in 2008, which extended scaled disclosure from firms below $\$ 25 \mathrm{~m}$ to those below $\$ 75 \mathrm{~m}$. Therefore, relative to the period of 2003-2007, 2008-2018 additionally identifies the value of scaled disclosure, but without a downward bias from shelf registration. Given we already know the value of scaled disclosure, we can back out the residual value of shelf registration and examine whether it is economically meaningful.

Table A.7 reports the estimates for the $\$ 75 \mathrm{~m}$ threshold using the alternative bunching period of 2008-2018. We find that, over this period, the regulatory costs associated with being above $\$ 75 \mathrm{~m}$ is $\$ 0.156 \mathrm{~m}$ per year. This is $\$ 0.034 \mathrm{~m}$ higher than our estimate of $\$ 0.122 \mathrm{~m}$ over the $2003-2007$ period. Extrapolating our estimate of scaled disclosure to firms bunching for $\$ 75 \mathrm{~m}$ yields a value of scaled disclosure of $\$ 0.044 \mathrm{~m}$. This implies that, for firms around $\$ 75 \mathrm{~m}$, the value of shelf registration is $-\$ 0.01 \mathrm{~m}(=0.034-0.044)$ per year, which is economically and statistically insignificant. This suggests

\footnotetext{
${ }^{55}$ See the final rule titled "Revisions to the Eligibility Requirements for Primary Security Offerings on Form S-3 and F-3," SEC Release No. 33-8878, December 19, 2007.
} 
that shelf registration has a minimal impact on our estimate.

Finally, the Dodd-Frank Act introduced Say-on-Pay in 2010, which are advisory shareholder votes on executive compensation. Say-on-Pay was initially exempted for Smaller Reporting Companies (i.e., float less than $\$ 75 \mathrm{~m}$ ) for a temporary two-year period of 2010-2011 (Iliev and Vitanova, 2019). Since our baseline analysis uses 2003-2007 as the bunching period, our estimate is not affected by Say-on-Pay regulations. For our robustness test in Table A.7 which uses 2008-2018 as the bunching period, we show that there is no additional bunching below $\$ 75 \mathrm{~m}$ for $2010-2011$ relative to other years over 2008-2018 (Figure A.5 Panel B); if anything, we find slight bunching above. This is likely because the exemption was temporary and brief. Another potential reason is that the benefits of Say-on-Pay may be large relative to its costs (Iliev and Vitanova, 2019).

\section{A.4.2 Heterogeneity}

Table A.8 reports the results of sub-sample cuts and reveals three findings: 1) Firms facing higher competition bear higher regulatory costs than those facing lower competition, consistent with competition increasing the proprietary cost of disclosure, as well as the limited benefits of internal governance when external governance is strong (Giroud and Mueller, 2010). 2) Non-manufacturing (low-tangibility) firms face higher regulatory costs than manufacturing (high-tangibility) firms. This result is consistent with non-manufacturing or low-tangibility firms facing higher proprietary costs of disclosure due to greater intellectual properties or organization capital; it is also consistent with strong internal governance hurting innovation incentives (Manso, 2011; Ederer and Manso, 2013). 3) Compared with firms in other industries, financial and utility firms have lower disclosure costs but higher SOX 404 compliance costs and costs of losing EGC benefits.

\section{A.4.3 Alternative Counterfactual Distributions}

This section addresses two potential concerns with counterfactual distributions. First, although bunching estimator itself does not rely on the assumption that the threshold-based regulatory change is unanticipated, anticipation may affect the counterfactual distribution of the running variable estimated from the non-bunching period. To address this concern, we investigate whether our results are robust to dropping the two years before each of the three regulatory changes. 
Specifically, for the $\$ 75 \mathrm{~m}$ and $\$ 700 \mathrm{~m}$ thresholds, we drop the two years before the thresholds were introduced. For the $\$ 25 \mathrm{~m}$ threshold, we drop the last two years before the $\$ 25 \mathrm{~m}$ threshold expires. Table A.9 presents the results. We find that the estimates are very similar to our main results, with slightly smaller disclosure cost and EGC benefits, and a slightly higher 404 compliance cost.

Second, one might be concerned that the firm size distribution might be different in the nonbunching period than in the bunching period. In Figure 2, we showed that the distributions of public float are almost identical across bunching and non-bunching periods around placebo thresholds unrelated to any regulations. This suggests that the float distribution in the non-bunching period provides a reasonably good counterfactual. To further address the concern about counterfactual distribution, we follow the bunching literature to estimate an alternative counterfactual distribution using only the post-regulation period (i.e., the bunching period) (Kleven, 2016). Specifically, we fit a smooth polynomial to the distribution after excluding the observations around the regulatory threshold. Table A.10 presents the results. The estimates are similar to our main results.

\section{A.4.4 Alternative Parameter Choices}

Our main estimation uses firms just above the float of the marginal bunching firm in the bunching period to obtain the undistorted parameters of $\eta, q$, and $r$. Although these firms are uncontaminated by potential bunching incentives because they are above the marginal bunching firm, one could argue that they are slightly larger than the marginal bunching firm. In Table A.11, we show that our estimates are similar if we use firms around the float of the marginal bunching firm to obtain these parameters, though the estimate for EGC benefits is somewhat larger.

We also demonstrate the robustness of our results to alternative estimates of $\beta$ - the marginal

cost of debt. Our baseline $\beta$ value comes from Binsbergen et al. (2010), who estimate it for all Compustat firms. One may be concerned that firms in our bunching samples may have very different $\beta$. We thus re-estimate $\beta$ following the methodology in Binsbergen et al. (2010) on subsamples of firms around the three thresholds. As shown in Table A.12, the local $\beta$ is 4.637, 5.130 and 6.192 for firms around each of the three thresholds. These values are not too different from our baseline $\beta$ value of 4.733 .

Relatedly, our main estimation relies on the marginal cost of debt function from Binsbergen 
et al. (2010) to estimate leverage distortion costs. To demonstrate robustness, we show that our estimates are similar if we instead use the net benefits to leverage function from Korteweg (2010) to compute leverage distortion costs. Korteweg (2010) estimates the net benefits of debt as a function of leverage and covariates by generalizing the Modigliani-Miller beta levering and firm valuation formulas and exploiting observed variation in stock and bond betas and valuations. Despite the different approach, Korteweg (2010) estimates similar net benefits to leverage as Binsbergen et al. (2010). Table A.13 presents our bunching estimates based on Korteweg (2010). Specifically, we obtain parameters from firms just above our marginal bunching firms and feed them into the net benefits to leverage function estimated in Korteweg (2010). The leverage distortion cost is then calculated as the decrease in the net benefits to leverage as one moves from the optimal leverage to the distorted leverage (Appendix A.2 provides more details). As shown in Panel A of Table A.13, our regulatory cost estimates are similar to those in Table 3.

\section{A.4.5 Dynamic Considerations in IPO Analysis}

How important are firms' dynamic expectations about future regulatory costs for our main results? In Panel A of Table A.15, we reproduce the IPO predictive regression using the present value of future regulatory costs, rather than annual costs upon IPO. We project the public float of potential IPO firms for seven years (the average duration IPO firms stay public in our sample) after IPO, using float growth rates estimated from newly public firms. We then calculate yearly regulatory costs based on the corresponding float and the regulations prevailing in the potential IPO year. ${ }^{56}$ Last, we compute the present value of these yearly regulatory costs using a $7 \%$ discount rate to arrive at the variable $P V$ of regulatory costs. Panel B of Table A.15 shows the simulated IPO counterfactuals. We find results similar to those in Tables 6 and 7. A one-standard-deviation increases in the present value of regulatory costs reduces IPO likelihood by $7.5 \%$ relative to the mean. Removing SOX continues to have a minimal effect on IPO volumes while JOBS Act significantly boosted IPOs after 2012. Removing all regulatory costs explains $9.4 \%$ of the post-2000 decline in IPO likelihood.

\footnotetext{
${ }^{56}$ Hence, we assume firms extrapolate the current regulations into the future.
} 


\section{A.5 Appendix Figures and Tables}

Figure A.1: Distribution of the Number of Years Firms are Consistently Below Threshold
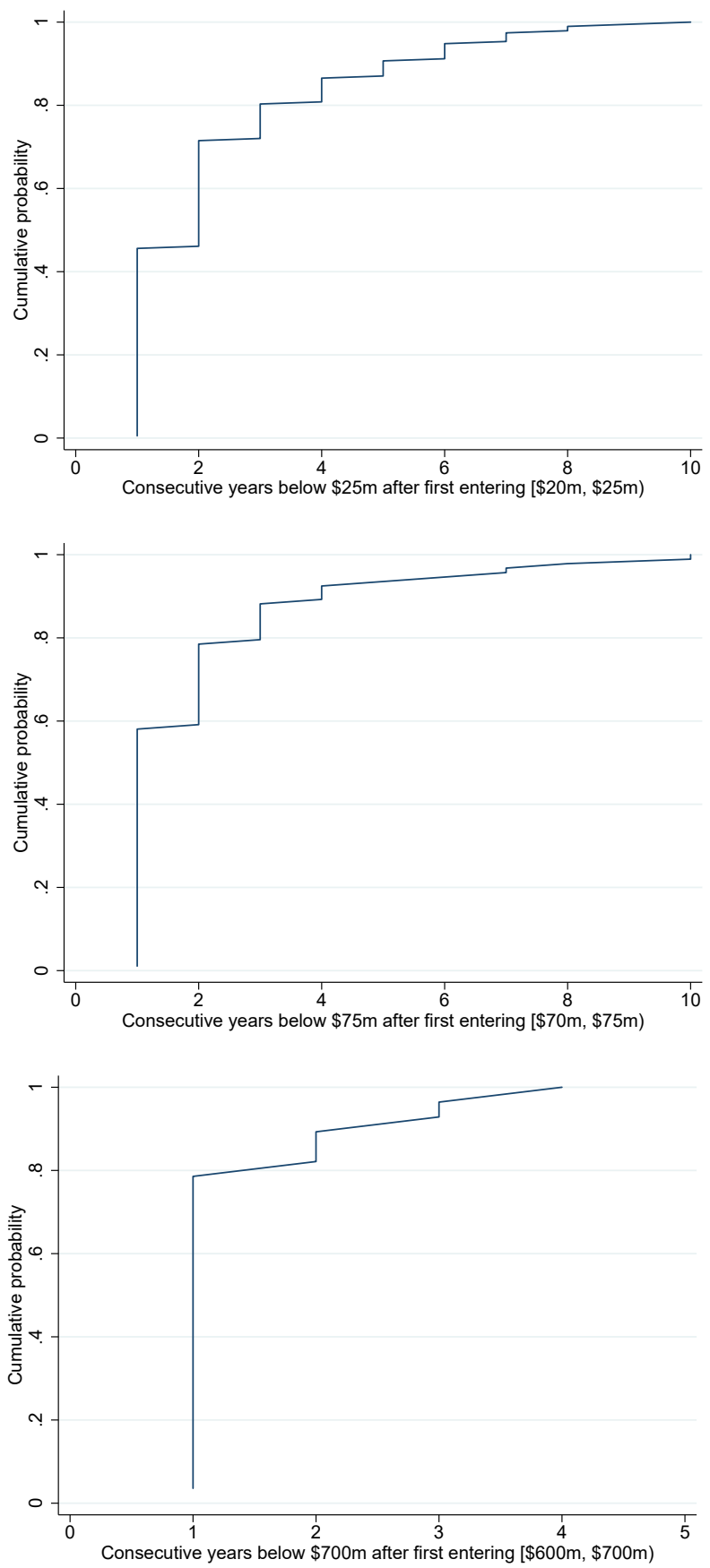

These figures show the cumulative distribution function for the number of years firms are consistently below a threshold, after they first enter a small range below the threshold during bunching years. 
Figure A.2: Non-Parametric Relationship Between Audit Fees and Public Float

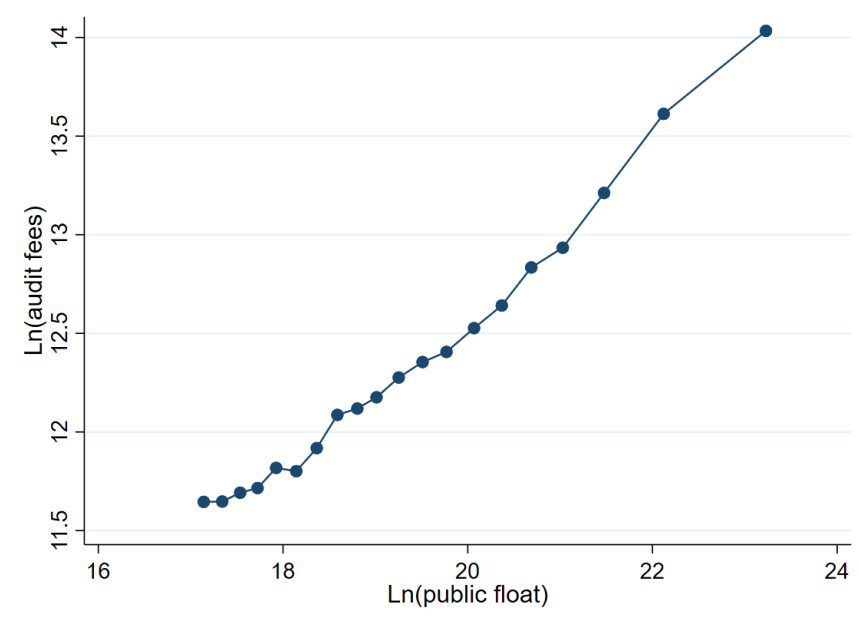

(a) $\ln$ (audit fees) and $\ln$ (public float) before SOX

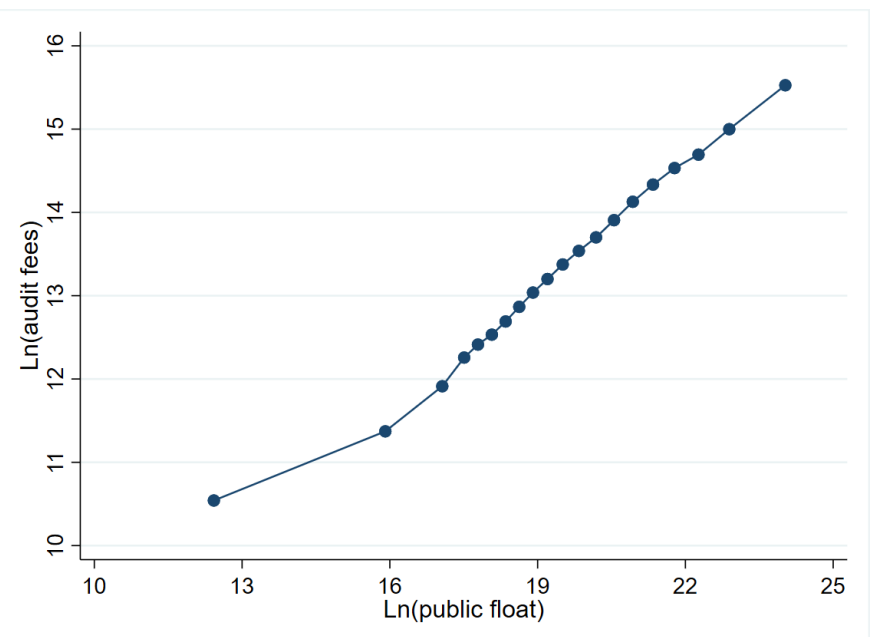

(b) $\ln$ (audit fees) and $\ln$ (public float) after SOX

These figures show the non-parametric bin-scatter relationship between log audit fees and log public float for both the pre-SOX and the post-SOX periods, removing year fixed effects. Firm-years that are eligible for scaled disclosure, 404(b) exemption, or EGC status are excluded. 
Figure A.3: Estimated Regulatory Costs Scaled by Public Float

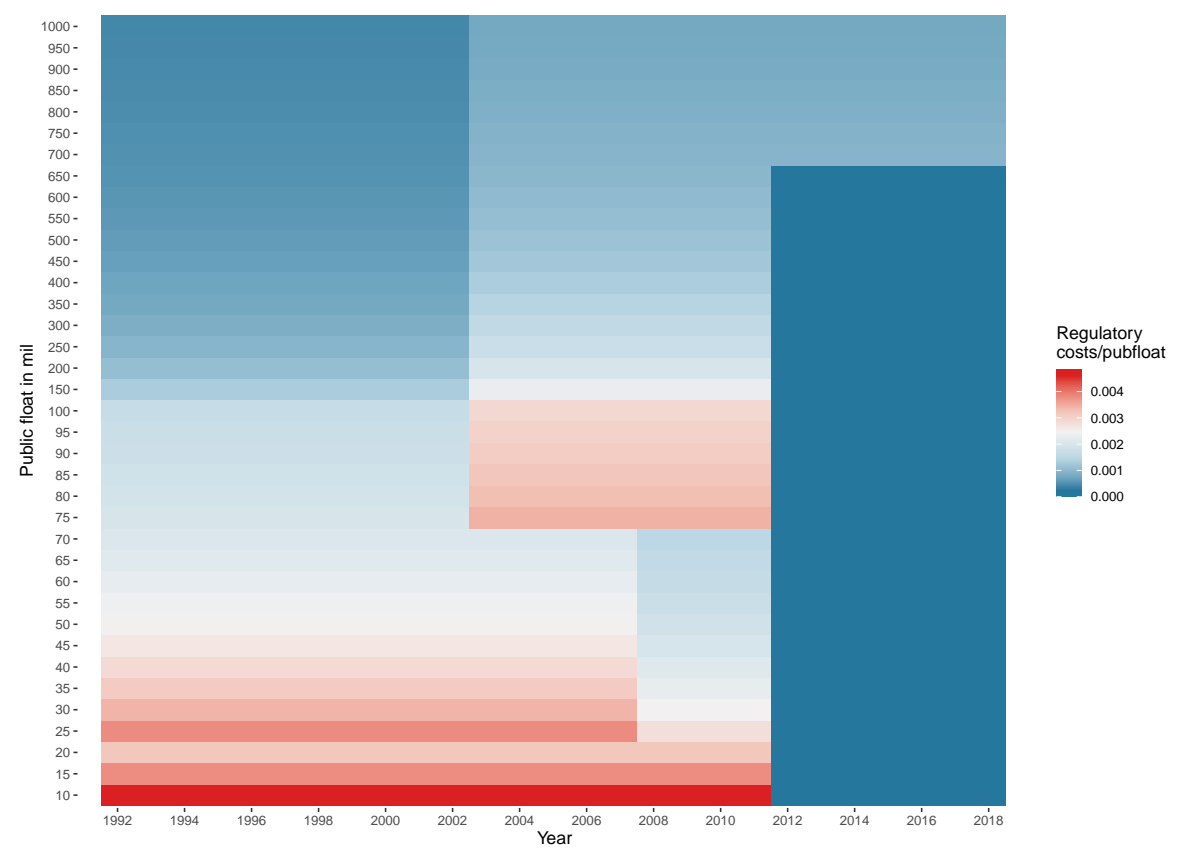

(a) Firms with public age $<=5$

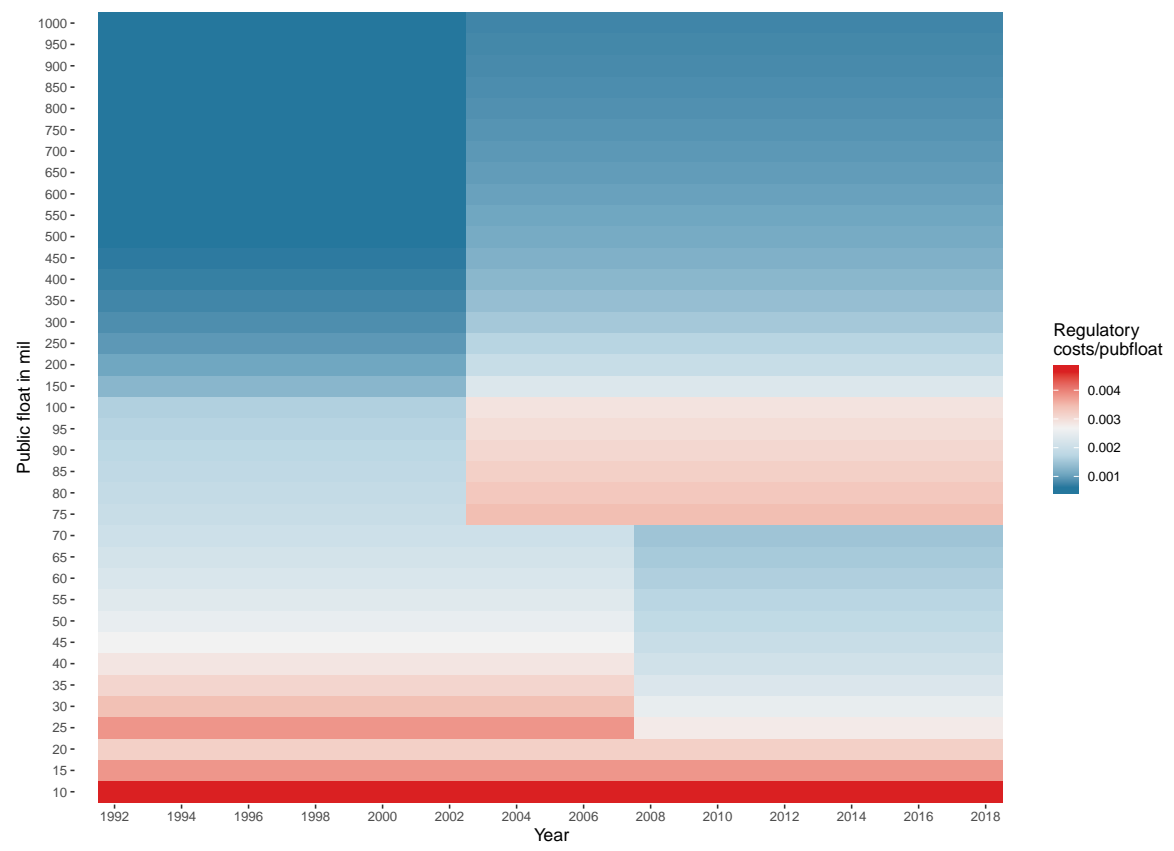

(b) Firms with public age $>5$

These figures show, by public float and year, the estimated total regulatory costs scaled by firms' public float. Panel A shows it for firms that went public less than 5 years ago. Panel B shows it for firms that went public more than 5 years ago. 
Figure A.4: Our Aggregate Estimate vs SEC Regulation Intensity from Kalmenovitz (2019)

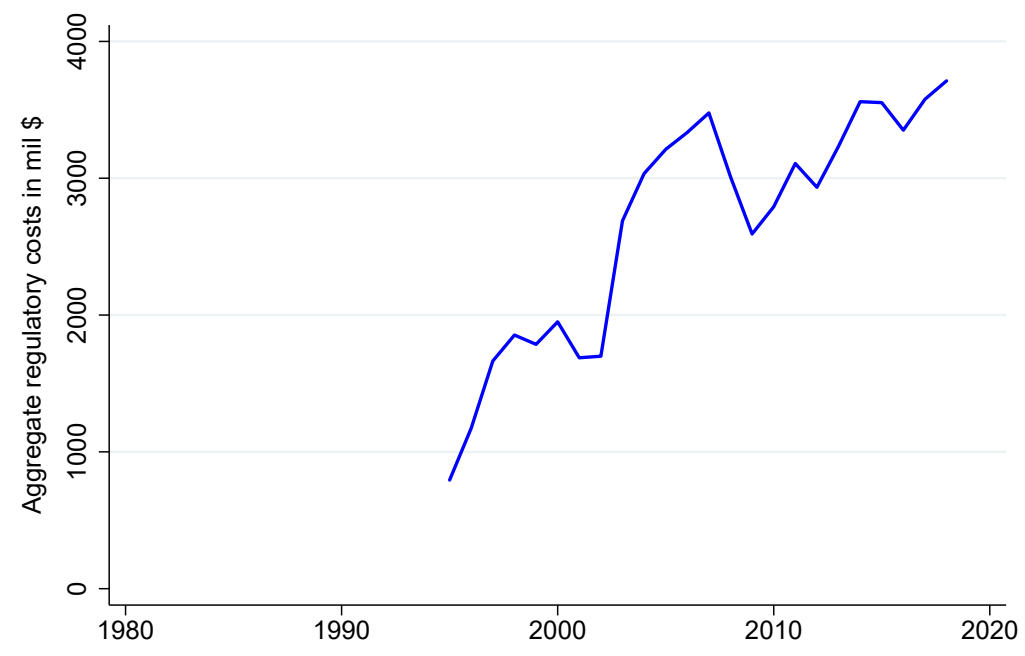

(a) Our Estimated Aggregate Regulatory Costs

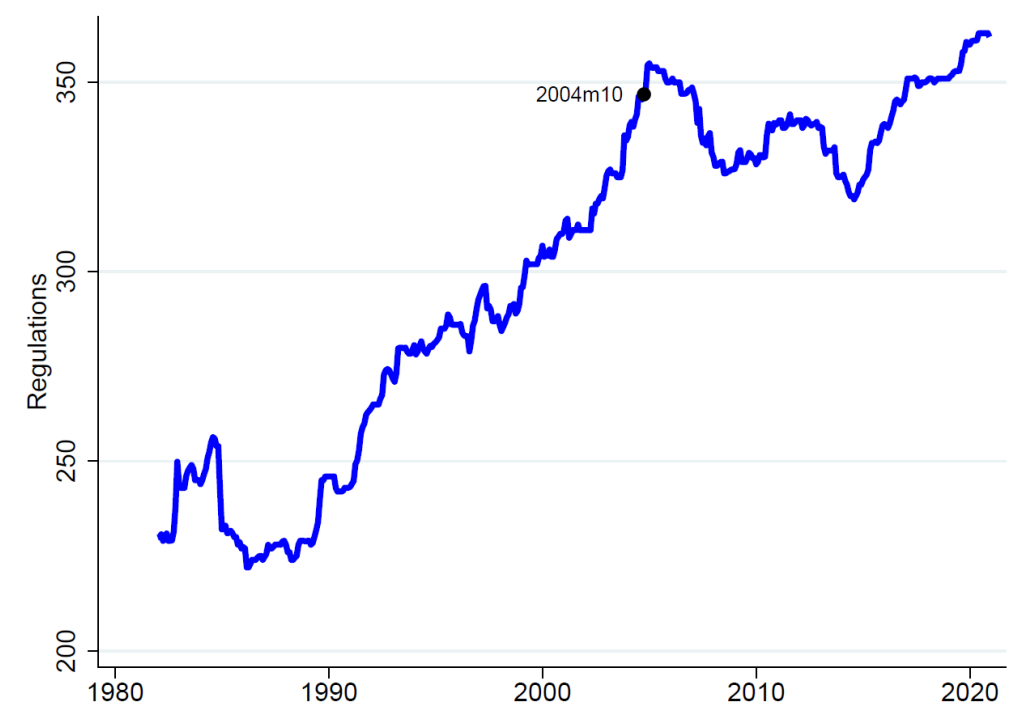

(b) SEC regulation intensity from Kalmenovitz (2019)

This figure compares the time series of our estimated aggregate regulatory costs with the time series of SEC regulation intensity from Kalmenovitz (2019) (Figure 6, Panel A). The horizontal axes are aligned to facilitate comparison. 
Figure A.5: Rule out the Effects of WKSI and Say-on-Pay

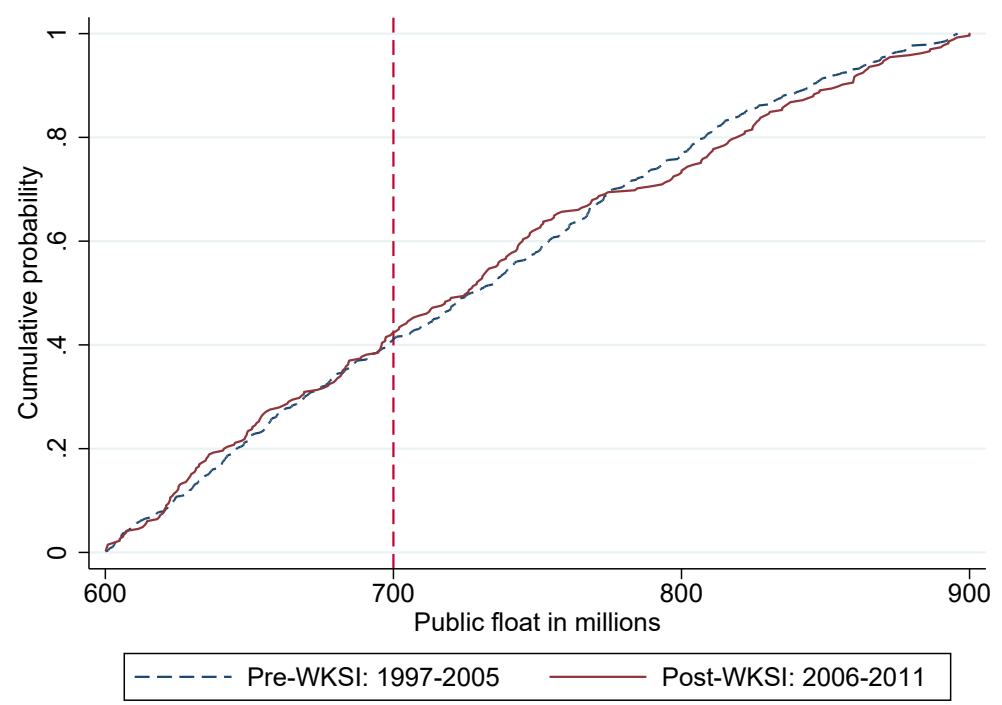

(a) WKSI did not trigger bunching above the $\$ 700 \mathrm{~m}$ threshold

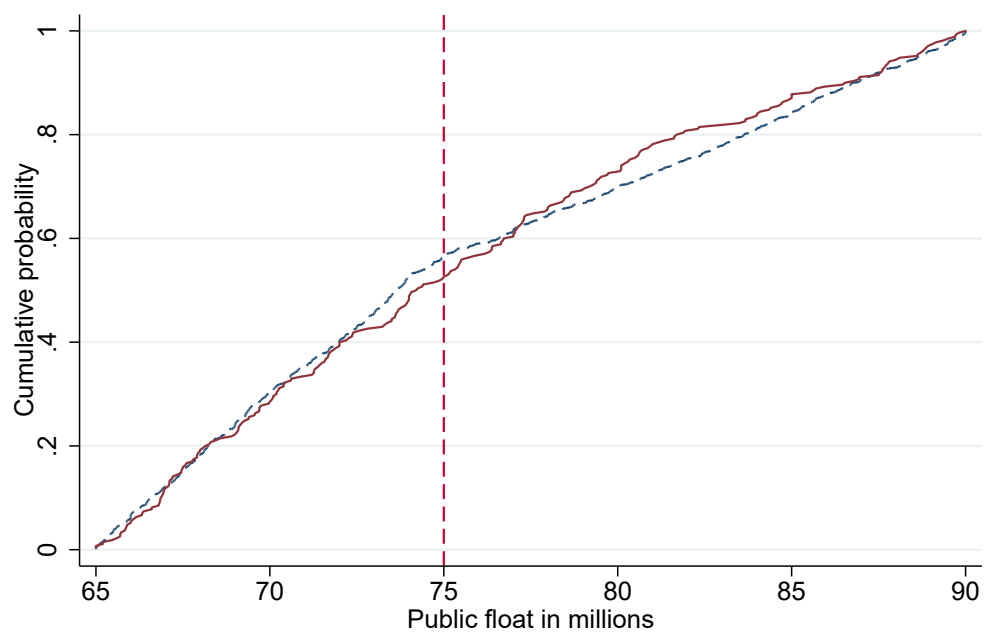

---- Other years in 2008-2018 - Say-on-Pay period: $2010-2011$

(b) Say-on-Pay did not trigger additional bunching below the $\$ 75 \mathrm{~m}$ threshold

Panel A shows that WKSI did not trigger bunching above the $\$ 700 \mathrm{~m}$ threshold. Panel B shows that Sayon-Pay did not trigger additional bunching below the $\$ 75 \mathrm{~m}$ threshold; if anything, there is slight bunching above. Panel A plots the CDF of firms' public float around the $\$ 700 \mathrm{~m}$ threshold for firms with public age less than 5 years old. The pre-WKSI period corresponds to years before WKSI ("Well-Kown Seasoned Issuers") was introduced in December 2005. The post-WKSI period corresponds to years after WKSI was introduced but before JOBS Act in 2012. Panel B plots the CDF of firms' public float around the $\$ 75 \mathrm{~m}$ threshold. The Say-on-Pay period corresponds to 2010-2011 when Small Reporting Companies were temporarily exempted from Say-on-Pay votes. The control period are other years in the 2008-2018 period. 
Table A.1: Scaled Disclosure Items

Reg S-K Items:

Item 101

Item 105

Description of business

Item 201

Risk factors

Market price of and dividends on registrant's common equity and related

stockholder matters

Item 301

Selected financial data

Item 302

Supplementary financial information

Item 303

Management's discussion and analysis of financial condition and results of operations

Item 305

Quantitative and qualitative disclosures about market risk

Item 402

Executive compensation

Item 404

Transactions with related persons, promoters and certain control persons

Corporate governance

Item 407

Item 503

Item 504

Prospectus summary, risk factors, and ratio of earnings to fixed charges

Item 601

Use of proceeds

Exhibits

Reg S-X Items:

Shorter financial history

Relaxed requirement on pro forma and interim financial statements

This table presents the scaled disclosure items for small business issuers (1992-2007) and small reporting companies (2008-). These companies may choose to comply with scaled or non-scaled financial and non-financial item requirements on an item-by-item basis in any one filing. Where the scaled reporting requirement is more rigorous, however, the company must meet the more rigorous standard. Item 404 of Regulation S-K is the only place where the scaled requirements can be more rigorous than the larger company standard. Source: SEC (2008a) 
Table A.2: SBI Scaled Disclosure: Impact on 10-K and DEF14A File Size

\begin{tabular}{|c|c|c|c|c|c|c|}
\hline & $\begin{array}{c}\text { 10-K size } \\
(1)\end{array}$ & $\begin{array}{c}\text { Part I length } \\
(2) \\
\end{array}$ & $\begin{array}{c}\text { Part II length } \\
(3)\end{array}$ & $\begin{array}{c}\text { Part III length } \\
(4) \\
\end{array}$ & $\begin{array}{c}\text { Part IV length } \\
(5)\end{array}$ & $\begin{array}{c}\text { DEF14A size } \\
(6)\end{array}$ \\
\hline SBI & $\begin{array}{c}-0.141^{* * *} \\
{[0.014]}\end{array}$ & $\begin{array}{c}-11.187^{* * *} \\
{[1.337]}\end{array}$ & $\begin{array}{c}-9.637^{* * *} \\
{[1.611]}\end{array}$ & $\begin{array}{c}71.688^{* * *} \\
{[3.534]}\end{array}$ & $\begin{array}{c}-82.709^{* * *} \\
{[2.833]}\end{array}$ & $\begin{array}{c}-0.041^{* * *} \\
{[0.005]}\end{array}$ \\
\hline Public float $(\$ \mathrm{~m})$ & $\begin{array}{c}0.008^{* * *} \\
{[0.001]}\end{array}$ & $\begin{array}{c}0.574^{* * *} \\
{[0.079]}\end{array}$ & $\begin{array}{c}0.332^{* * *} \\
{[0.096]}\end{array}$ & $\begin{array}{c}2.110^{* * *} \\
{[0.267]}\end{array}$ & $\begin{array}{l}0.285^{*} \\
{[0.162]}\end{array}$ & $\begin{array}{c}0.001^{* * *} \\
{[0.000]}\end{array}$ \\
\hline $\operatorname{Ln}$ (sales) & $\begin{array}{c}0.031^{* * *} \\
{[0.007]}\end{array}$ & $\begin{array}{c}0.810 \\
{[0.644]}\end{array}$ & $\begin{array}{c}2.954^{* * *} \\
{[0.770]}\end{array}$ & $\begin{array}{c}0.729 \\
{[2.048]}\end{array}$ & $\begin{array}{c}4.765^{* * *} \\
{[1.187]}\end{array}$ & $\begin{array}{l}-0.002 \\
{[0.003]}\end{array}$ \\
\hline Leverage & $\begin{array}{c}0.036^{* * *} \\
{[0.013]}\end{array}$ & $\begin{array}{c}0.715 \\
{[1.037]}\end{array}$ & $\begin{array}{c}3.970^{* * *} \\
{[1.346]}\end{array}$ & $\begin{array}{c}15.419^{* * *} \\
{[3.512]}\end{array}$ & $\begin{array}{c}6.303^{* * *} \\
{[2.343]}\end{array}$ & $\begin{array}{l}-0.000 \\
{[0.008]}\end{array}$ \\
\hline Sales growth & $\begin{array}{l}-0.000 \\
{[0.009]}\end{array}$ & $\begin{array}{c}1.105 \\
{[0.738]}\end{array}$ & $\begin{array}{c}0.251 \\
{[0.849]}\end{array}$ & $\begin{array}{c}7.749^{* * *} \\
{[2.867]}\end{array}$ & $\begin{array}{l}-2.292 \\
{[1.453]}\end{array}$ & $\begin{array}{l}-0.007 \\
{[0.005]}\end{array}$ \\
\hline ROA & $\begin{array}{l}-0.003 \\
{[0.002]}\end{array}$ & $\begin{array}{c}0.096 \\
{[0.172]}\end{array}$ & $\begin{array}{c}0.087 \\
{[0.210]}\end{array}$ & $\begin{array}{c}-1.630^{* *} \\
{[0.717]}\end{array}$ & $\begin{array}{l}-0.513 \\
{[0.313]}\end{array}$ & $\begin{array}{l}-0.003^{*} \\
{[0.002]}\end{array}$ \\
\hline NPPE/Assets & $\begin{array}{l}-0.039 \\
{[0.028]}\end{array}$ & $\begin{array}{l}-0.373 \\
{[2.618]}\end{array}$ & $\begin{array}{l}-2.310 \\
{[3.179]}\end{array}$ & $\begin{array}{l}-9.154 \\
{[8.450]}\end{array}$ & $\begin{array}{c}0.367 \\
{[4.861]}\end{array}$ & $\begin{array}{c}-0.029^{* *} \\
{[0.013]}\end{array}$ \\
\hline Dep. var. mean & 0.508 & 50.4 & 49.4 & 46.5 & 103.3 & 0.162 \\
\hline SIC2 FE & Yes & Yes & Yes & Yes & Yes & Yes \\
\hline Year FE & Yes & Yes & Yes & Yes & Yes & Yes \\
\hline Observations & 10,883 & 10,883 & 10,883 & 10,883 & 10,883 & 6,424 \\
\hline
\end{tabular}

This table compares the size or length of 10-K and DEF14A (proxy statement) filed by SBI and non-SBI firms. Columns 1 and 6 examine file size (in MBs), and columns 2 to 5 examine the length of Parts I to IV of 10-K (string length removed of html and line breaks, scaled by 1000). SBI filers are identified by 10-KSB filings and non-SBI filers are identified by 10-K filings. The sample focuses on the common support where both SBI and non-SBI filers exist: firms with less than $\$ 25 \mathrm{~m}$ float and less than $\$ 25 \mathrm{~m}$ sales between fiscal years 1993 and 2007 . All columns control for industry (SIC 2-digit) fixed effects and year fixed effects. Standard errors are clustered by firm. 
Table A.3: Major, Non-Threshold Based Regulations

\begin{tabular}{lr}
\hline Regulation Name & Year \\
\hline Rule 415 (Shelf Registration) & Regulations on public firms \\
Introduction of Edgar & 1982 \\
Ownership Reports and Trading by Officers, Directors and Principal Security Holders & 1993 \\
Amendments to Rules on Shareholder Proposals & 1996 \\
Amendments to Beneficial Ownership Disclosure & 1998 \\
Regulation of Takeovers and Security Holder Communications & 1998 \\
Amendments to Rule 9b-1 Relating to the Options Disclosure Document & 1999 \\
Selective Disclosure and Insider Trading & 2000 \\
Reg FD & 2000 \\
Revised Accounting Independence Rule & 2000 \\
FASB ends pooling of interests accounting & 2000 \\
Option expensing & 2001 \\
Regulation National Market System & 2004 \\
Regulation D & 2005 \\
Increased asset threshold for exempt from registration from $\$ 5 \mathrm{~m}$ to \$10m & 1982 \\
National Securities Markets Improvement Act (NSMIA) & 1996 \\
\hline
\end{tabular}

This table presents the timeline of other major, non-threshold based regulations not considered in our paper. 
Table A.4: Other Margins of Regulatory Avoidance

\begin{tabular}{|c|c|c|c|c|c|c|c|}
\hline Dep. var. & $\begin{array}{c}\ln (\text { total } \\
\text { assets }) \\
(1)\end{array}$ & $\begin{array}{l}\text { PPE/ } \\
\text { assets } \\
(2)\end{array}$ & $\begin{array}{c}\text { Sales/ } \\
\text { assets } \\
(3)\end{array}$ & $\begin{array}{c}\text { Gross profit/ } \\
\text { assets } \\
(4) \\
\end{array}$ & $\begin{array}{c}\ln (\text { total } \\
\text { payout }) \\
(5)\end{array}$ & $\begin{array}{c}\text { Bad news } \\
\text { in Q2 } \\
\quad(6) \\
\end{array}$ & $\begin{array}{c}\text { Bad news } \\
\text { in Q3 } \\
(7)\end{array}$ \\
\hline & \multicolumn{7}{|c|}{ Panel A. $\$ 25 \mathrm{~m}$ threshold } \\
\hline \multirow[t]{2}{*}{ Below $\$ 25 \mathrm{~m} \times$ Bunching years } & -0.032 & -0.012 & 0.053 & 0.000 & $0.075^{*}$ & $0.019^{* * *}$ & 0.024 \\
\hline & {$[0.069]$} & {$[0.011]$} & {$[0.076]$} & {$[0.031]$} & {$[0.041]$} & {$[0.003]$} & {$[0.047]$} \\
\hline Year FE and SIC2 FE & Yes & Yes & Yes & Yes & Yes & Yes & Yes \\
\hline $\mathrm{N}$ & 1603 & 1566 & 1589 & 1582 & 1603 & 998 & 1004 \\
\hline \multirow[t]{2}{*}{ Adj. R-sq } & 0.884 & 0.755 & 0.469 & 0.402 & 0.401 & 0.012 & 0.008 \\
\hline & \multicolumn{7}{|c|}{ Panel B. $\$ 75 \mathrm{~m}$ threshold } \\
\hline \multirow[t]{2}{*}{ Below $\$ 75 \mathrm{~m} \times$ Bunching years } & -0.02 & 0.006 & 0.044 & 0.018 & $0.039^{*}$ & $0.037 * *$ & 0.02 \\
\hline & {$[0.051]$} & {$[0.005]$} & {$[0.034]$} & {$[0.021]$} & {$[0.022]$} & {$[0.016]$} & {$[0.024]$} \\
\hline Year FE and SIC2 FE & Yes & Yes & Yes & Yes & Yes & Yes & Yes \\
\hline $\mathrm{N}$ & 3499 & 3418 & 3489 & 3485 & 3499 & 2824 & 2869 \\
\hline \multirow[t]{2}{*}{ Adj. R-sq } & 0.912 & 0.872 & 0.782 & 0.613 & 0.487 & 0.024 & 0.053 \\
\hline & \multicolumn{7}{|c|}{ Panel C. $\$ 700 \mathrm{~m}$ threshold } \\
\hline \multirow[t]{2}{*}{ Below $\$ 700 \mathrm{~m} \times$ Bunching years } & -0.060 & 0.013 & 0.014 & 0.024 & $0.207^{*}$ & $0.122^{* *}$ & 0.051 \\
\hline & {$[0.077]$} & {$[0.027]$} & {$[0.079]$} & {$[0.059]$} & {$[0.109]$} & {$[0.058]$} & {$[0.065]$} \\
\hline Year FE and SIC2 FE & Yes & Yes & Yes & Yes & Yes & Yes & Yes \\
\hline $\mathrm{N}$ & 235 & 216 & 235 & 235 & 235 & 238 & 244 \\
\hline Adj. R-sq & 0.886 & 0.868 & 0.665 & 0.657 & 0.681 & 0.021 & 0.029 \\
\hline
\end{tabular}

This table examines other margins of float manipulation. Columns 1-4 examine whether firms manipulate by changing operations such as total assets, tangibility, asset turnover, or ROA. Column 5 shows that firms reduce public float by increasing total payout (dividends plus repurchases). Columns 6-7 examine whether firms manipulate public float by strategically releasing bad news in Q2 before calculating float, but not so in Q3. Bad news is the fraction of news released in the 2nd (or 3rd) fiscal quarter that has a RavenPack sentiment score below 50 . RavenPack event sentiment score has a value between 0 and 100, with 50 indicating neutral sentiment and higher values indicating more positive news. The score is determined by systematically matching stories categorized by financial experts as having a positive or negative impact, which is then fed into RavenPack's proprietary algorithm. The specifications and samples are the same as those in Table 2. Robust standard errors clustered by industry and year are in parentheses. ${ }^{*}$ indicates statistical significance at the $10 \%$ level, ${ }^{* *}$ at the $5 \%$ level, and ${ }^{* * *}$ at the $1 \%$ level. 
Table A.5: Total Regulatory Costs

\begin{tabular}{lllll}
\hline Time Period & $<25$ mil & $25-75$ mil & $75-700$ mil & $>700$ mil \\
\hline $1992-2002$ & ER & ER+SD & ER+SD & ER+SD \\
$2003-2007$ & ER & ER+SD & ER+SD+404+delay & ER+SD+404+delay \\
$2008-2011$ & ER & ER & ER+SD+404+delay & ER+SD+404+delay \\
$2012-2018 \&$ public age $>5$ & ER & ER & ER+SD+404+delay & ER+SD+404+delay \\
$2012-2018 \&$ public age $<=5$ & 0 & 0 & 0 & ER+SD+404+delay \\
\hline
\end{tabular}

This table aggregates the different types regulatory costs we identify in the paper by time period and public float interval. It is derived from Table 1. 404 denotes the costs of SOX 404(b) compliance; delay denotes the cost of filing 10-K and 10-Q 15 days earlier; $S D$ denotes the costs of full

disclosure relative to scaled disclosure; $E R$ denotes residual costs from losing EGC benefits not covered by 404, delay, or $S D: 1)$ shorter financial history in registration statement, 2) delay in compliance with new accounting standards, and 3) the ability to use test-the-waters communications with institutional investors when issuing securities. In other words, total costs of losing all EGC benefits EGC=ER+SD+404+delay. 
Table A.6: Total Regulatory Costs: Counterfactuals

Panel A: Without SOX

\begin{tabular}{lllll}
\hline Time Period & $<25$ mil & $25-75$ mil & $75-700$ mil & $>700$ mil \\
\hline $1992-2002$ & ER & ER+SD & ER+SD & ER+SD \\
$2003-2007$ & ER & ER+SD & ER+SD+delay & ER+SD+delay \\
$2008-2011$ & ER & ER & ER+SD+delay & ER+SD+delay \\
$2012-2018 \&$ public age $>5$ & ER & ER & ER+SD+delay & ER+SD+delay \\
$2012-2018 \&$ public age $<=5$ & 0 & 0 & 0 & ER+SD+delay \\
\hline
\end{tabular}

Panel B: Without JOBS Act

\begin{tabular}{lllll}
\hline Time Period & $<25$ mil & $25-75$ mil & $75-700$ mil & $>700$ mil \\
\hline $1992-2002$ & ER & ER+SD & ER+SD & ER+SD \\
$2003-2007$ & ER & ER+SD & ER+SD+404+delay & ER+SD+404+delay \\
$2008-2011$ & ER & ER & ER+SD+404+delay & ER+SD+404+delay \\
○̋ & ER & ER & ER+SD+404+delay & ER+SD+404+delay \\
\hline
\end{tabular}

This table presents counterfactual versions of Table A.5 without SOX 404(b) (Panel A) and without JOBS Act (Panel B). 
Table A.7: Alternative Bunching Period for the $\$ 75 \mathrm{M}$ Threshold

\begin{tabular}{lc}
\hline Threshold & $\$ 75$ mil \\
\hline & Panel A. Estimates \\
\hline Marginal firm $(\bar{e})(\$ \mathrm{~m})$ & 97.414 \\
& {$[1.248]$} \\
Regulatory costs $(\mathrm{k})(\$ \mathrm{~m})$ & 0.156 \\
& {$[0.015]$} \\
PV $($ regulatory costs $) /$ Firm value $(\%)$ & 0.902 \\
& {$[0.087]$} \\
Non-bunching fraction $(\alpha)$ & 0.750 \\
& {$[0.040]$} \\
Leverage & 0.121 \\
Public float/Assets $(\eta)(\%)$ & {$[0.007]$} \\
Pobin's Q $(q)$ & Panel $B$. Parameters \\
\hline
\end{tabular}

Bunching sample

2008-2018

Non-bunching sample

1994-2002

Identified regulation

Filing delay +

SOX $404+$

Scaled discl.

This table presents the bunching estimation results for the $\$ 75 \mathrm{~m}$ threshold using an alternative bunching period 2008 to 2018. Marginal firm is the public float of the firm that is indifferent between bunching and not bunching. Regulatory costs are the estimated annual costs of regulation $k$. Regulatory costs are in $\$$ million. PV/Firm value is the percentage of the present value of future regulatory costs over the total firm value. Bootstrapped standard errors are reported in brackets. 
Table A.8: Heterogeneity

\begin{tabular}{lcccccc}
\hline & $\$ 25$ mil & $\$ 75$ mil & $\$ 700$ mil & $\$ 25$ mil & $\$ 75$ mil & $\$ 700$ mil \\
\cline { 2 - 7 } & \multicolumn{2}{c}{ Regulatory costs $(k)$} & $(\$ \mathrm{~m})$ & \multicolumn{2}{c}{ PV $($ regulatory costs $) /$ Firm value $(\%)$} \\
\hline Baseline & 0.026 & 0.122 & 0.713 & 0.622 & 0.725 & 0.772 \\
High competition & 0.036 & 0.139 & 0.715 & 0.838 & 0.815 & 0.774 \\
Low competition & 0.012 & 0.087 & 0.653 & 0.293 & 0.539 & 0.713 \\
Manufact. & 0.019 & 0.098 & 0.458 & 0.450 & 0.598 & 0.514 \\
Non-manufac. & 0.029 & 0.131 & 0.727 & 0.693 & 0.775 & 0.786 \\
High tangibility & 0.024 & 0.083 & 0.711 & 0.579 & 0.515 & 0.770 \\
Low tangibility & 0.033 & 0.175 & 0.631 & 0.763 & 0.998 & 0.691 \\
Fin or utility & 0.022 & 0.130 & 0.726 & 0.535 & 0.768 & 0.785 \\
Non-fin or utility & 0.027 & 0.102 & 0.634 & 0.642 & 0.621 & 0.693 \\
\hline
\end{tabular}

This table shows the heterogeneity of our baseline estimates in Table 3 across different industry cuts: manufacturing (SIC 2000-3999) vs other industries, high vs low competition (based on Hoberg and Phillips (2016) firm-level Total Similarity score), high vs low tangibility, and financial and utility (SIC 6000-6999 and 4900-4949) vs other industries. Our baseline estimates for all industries are presented in the first row for comparison. Regulatory costs are the estimated annual costs of regulation $k$. Regulatory costs are in $\$$ million. PV/Firm value is the percentage of the present value of future regulatory costs over the total firm value. Bootstrapped standard errors are reported in brackets. 
Table A.9: Robustness: Excluding Two Years Before Regulation Change

\begin{tabular}{|c|c|c|c|}
\hline Threshold & $\begin{array}{c}\$ 25 \text { mil } \\
(1)\end{array}$ & $\begin{array}{c}\$ 75 \text { mil } \\
(2)\end{array}$ & $\begin{array}{c}\$ 700 \mathrm{mil} \\
(3)\end{array}$ \\
\hline & \multicolumn{3}{|c|}{ Panel A. Estimates } \\
\hline Marginal firm $(\bar{e})(\$ \mathrm{~m})$ & $\begin{array}{l}26.835 \\
{[0.457]}\end{array}$ & $\begin{array}{l}95.374 \\
{[1.945]}\end{array}$ & $\begin{array}{c}838.133 \\
{[6.331]}\end{array}$ \\
\hline Regulatory costs $(k)(\$ \mathrm{~m})$ & $\begin{array}{c}0.021 \\
{[0.009]}\end{array}$ & $\begin{array}{c}0.132 \\
{[0.022]}\end{array}$ & $\begin{array}{c}0.711 \\
{[0.057]}\end{array}$ \\
\hline PV(regulatory costs)/Firm value (\%) & $\begin{array}{c}0.509 \\
{[0.210]}\end{array}$ & $\begin{array}{c}0.778 \\
{[0.128]}\end{array}$ & $\begin{array}{c}0.770 \\
{[0.061]}\end{array}$ \\
\hline Non-bunching fraction $(\alpha)$ & $\begin{array}{c}0.370 \\
{[0.172]}\end{array}$ & $\begin{array}{c}0.760 \\
{[0.043]}\end{array}$ & $\begin{array}{c}0.540 \\
{[0.121]}\end{array}$ \\
\hline \multirow[t]{2}{*}{$\Delta$ Leverage } & $\begin{array}{c}0.050 \\
{[0.013]}\end{array}$ & $\begin{array}{c}0.112 \\
{[0.011]}\end{array}$ & $\begin{array}{c}0.073 \\
{[0.003]}\end{array}$ \\
\hline & \multicolumn{3}{|c|}{ Panel B. Parameters } \\
\hline Public float/Assets $(\eta)(\%)$ & 2.000 & 0.880 & 1.572 \\
\hline Tobin's Q $(q)$ & 2.720 & 1.680 & 3.570 \\
\hline \multirow[t]{2}{*}{ Interest rate $(r)$} & 0.115 & 0.093 & 0.049 \\
\hline & \multicolumn{3}{|c|}{ Panel C. Samples } \\
\hline Bunching sample & 1994-2005 & $2003-2007$ & $2012-2018$ \\
\hline Non-bunching sample & 2009-2018 & $1994-2000$ & $1997-2009$ \\
\hline Identified regulation & $\begin{array}{c}\text { Scaled } \\
\text { disclosure }\end{array}$ & $\begin{array}{l}\text { Sox } 404+ \\
\text { filing delay }\end{array}$ & $\begin{array}{c}\text { EGC } \\
\text { benefits }\end{array}$ \\
\hline
\end{tabular}

This table presents a robustness check of our main bunching estimation results by dropping firm-years in the two years before a regulation change. Marginal firm is the public float of the firm that is indifferent between bunching and not bunching. Regulatory costs are the estimated annual costs of regulation $k$. Regulatory costs are in $\$$ million. $P V$ (regulatory costs)/Firm value is the percentage of the present value of future regulatory costs over the total firm value. Bootstrapped standard errors are reported in brackets. 
Table A.10: Robustness: Alternative Counterfactual Distribution

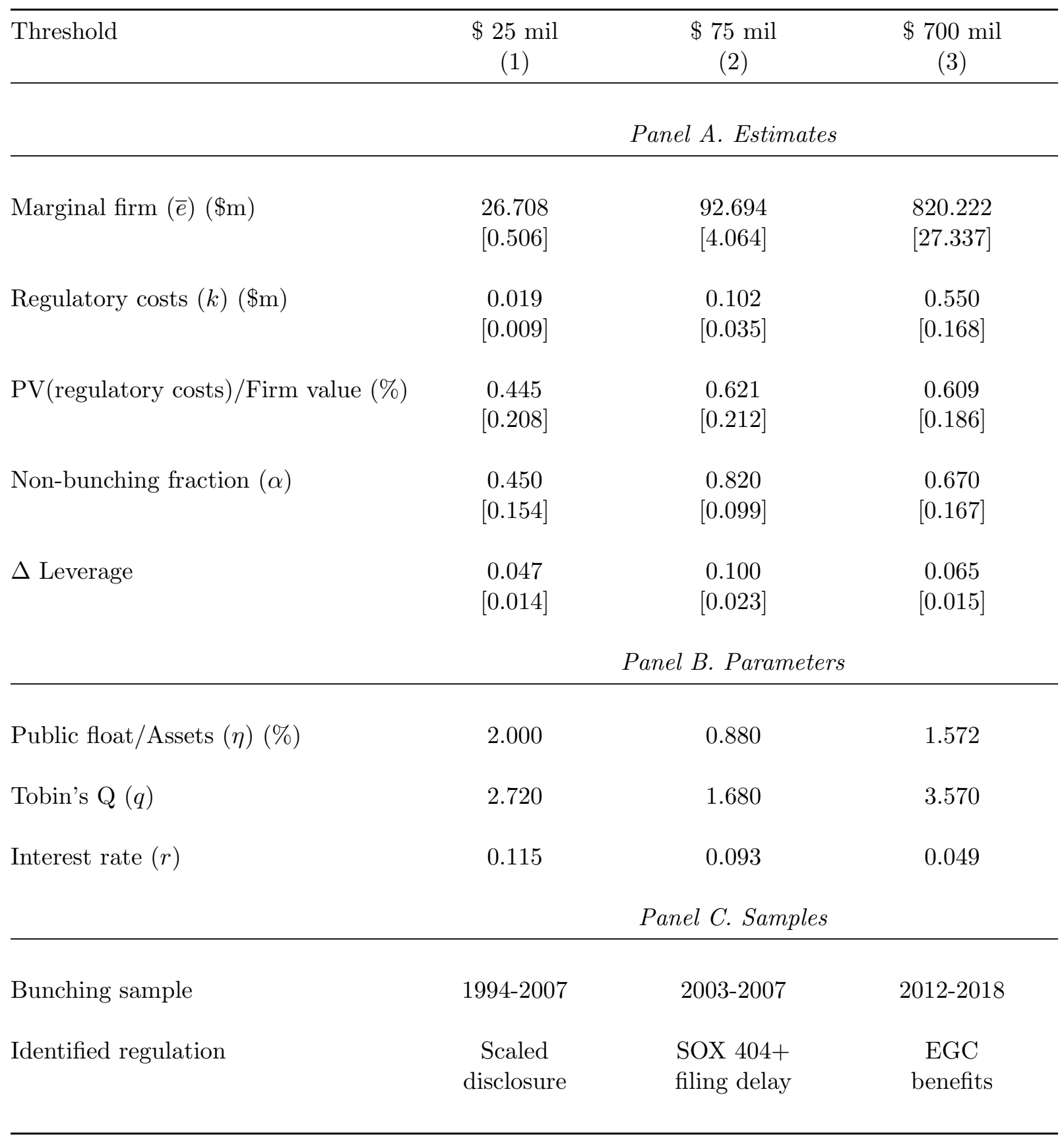

This table presents a robustness check of our main bunching estimation results using the counterfactual distribution constructed by fitting a smooth polynomial to the bunching sample excluding observations around the threshold. Marginal firm is the public float of the firm that is indifferent between bunching and not bunching. Regulatory costs are the estimated annual costs of regulation $k$. Regulatory costs are in $\$$ million. PV/Firm value is the percentage of the present value of future regulatory costs over the total firm value. Bootstrapped standard errors are reported in brackets. 
Table A.11: Robustness: Alternative Parameter Choices

\begin{tabular}{|c|c|c|c|}
\hline Threshold & $\begin{array}{c}\$ 25 \text { mil } \\
(1)\end{array}$ & $\begin{array}{c}\$ 75 \text { mil } \\
(2)\end{array}$ & $\begin{array}{c}\$ 700 \mathrm{mil} \\
(3)\end{array}$ \\
\hline & \multicolumn{3}{|c|}{ Panel A. Estimates } \\
\hline Marginal firm $(\bar{e})(\$ \mathrm{~m})$ & $\begin{array}{l}27.044 \\
{[0.283]}\end{array}$ & $\begin{array}{l}94.493 \\
{[2.380]}\end{array}$ & $\begin{array}{c}838.313 \\
{[5.349]}\end{array}$ \\
\hline Regulatory costs $(k)(\$ \mathrm{~m})$ & $\begin{array}{c}0.030 \\
{[0.007]}\end{array}$ & $\begin{array}{c}0.120 \\
{[0.024]}\end{array}$ & $\begin{array}{c}0.872 \\
{[0.060]}\end{array}$ \\
\hline PV(regulatory costs)/Firm value (\%) & $\begin{array}{c}0.510 \\
{[0.125]}\end{array}$ & $\begin{array}{c}0.750 \\
{[0.153]}\end{array}$ & $\begin{array}{c}0.767 \\
{[0.052]}\end{array}$ \\
\hline Non-bunching fraction $(\alpha)$ & $\begin{array}{c}0.480 \\
{[0.119]}\end{array}$ & $\begin{array}{c}0.780 \\
{[0.047]}\end{array}$ & $\begin{array}{c}0.530 \\
{[0.114]}\end{array}$ \\
\hline \multirow[t]{2}{*}{$\Delta$ Leverage } & $\begin{array}{c}0.046 \\
{[0.006]}\end{array}$ & $\begin{array}{c}0.107 \\
{[0.013]}\end{array}$ & $\begin{array}{c}0.069 \\
{[0.003]}\end{array}$ \\
\hline & \multicolumn{3}{|c|}{ Panel B. Parameters } \\
\hline Public float/Assets $(\eta)(\%)$ & 1.684 & 0.920 & 1.445 \\
\hline Tobin's Q $(q)$ & 2.741 & 1.769 & 3.438 \\
\hline \multirow[t]{2}{*}{ Interest rate $(r)$} & 0.133 & 0.088 & 0.057 \\
\hline & \multicolumn{3}{|c|}{ Panel C. Sample } \\
\hline Bunching sample & 1994-2007 & $2003-2007$ & $2012-2018$ \\
\hline Non-bunching sample & 2009-2018 & 1994-2002 & $1997-2011$ \\
\hline Identified regulation & $\begin{array}{c}\text { Scaled } \\
\text { disclosure }\end{array}$ & $\begin{array}{l}\text { SOX 404+ } \\
\text { filing delay }\end{array}$ & $\begin{array}{c}\text { EGC } \\
\text { benefits }\end{array}$ \\
\hline
\end{tabular}

This table presents a robustness check of our main bunching estimation results using firms around instead of above the float of the marginal bunching firm to obtain parameters $q, \eta$, and $r$. Marginal firm is the public float of the firm that is indifferent between bunching and not bunching. Regulatory costs are the estimated annual costs of regulation $k$. Regulatory costs are in $\$$ million. PV(regulatory costs)/Firm value is the percentage of the present value of future regulatory costs over the total firm value. Bootstrapped standard errors are reported in brackets. 
Table A.12: Robustness: Local Estimates of the Marginal Cost of Debt

\begin{tabular}{lccc}
\hline & $\$ 25$ mil & $\$ 75$ mil & \$ 700 mil \\
& $(1)$ & $(2)$ & $(3)$ \\
\hline IOB & $4.637^{* * *}$ & $5.130^{* * *}$ & $6.192^{* * *}$ \\
& {$[2.937]$} & {$[3.970]$} & {$[3.317]$} \\
COL & $-0.022^{* * *}$ & $-0.021^{* * *}$ & -0.002 \\
& {$[-3.239]$} & {$[-2.773]$} & {$[-0.282]$} \\
LTA & $-0.074^{* *}$ & $-0.058^{* *}$ & $-0.061^{* *}$ \\
& {$[-2.616]$} & {$[-2.571]$} & {$[-2.090]$} \\
BTM & $0.015^{* *}$ & 0.009 & 0.007 \\
& {$[2.219]$} & {$[1.244]$} & {$[0.447]$} \\
INTANG & $-0.026^{* * *}$ & $-0.023^{* * *}$ & $-0.025^{* * *}$ \\
& {$[-3.342]$} & {$[-3.381]$} & {$[-3.410]$} \\
CF & $0.059^{* * *}$ & $0.053^{* * *}$ & $0.036^{* * *}$ \\
& {$[12.739]$} & {$[8.595]$} & {$[5.777]$} \\
DDIV & & & $0.067^{* * *}$ \\
& $0.104^{* * *}$ & $0.075^{* * *}$ & {$[5.236]$} \\
\hline Observations & {$[5.176]$} & $35.973]$ & 2,594 \\
\hline
\end{tabular}

This table provides alternative estimates for the marginal cost of debt following Binsbergen et al. (2010) for subsample of firms around the three public float thresholds. The variable of interest is expenses over book value (IOB), whose coefficient $\beta$ is used in our quantification of regulatory costs in equation (3). Each column uses a subsample of firms with public float between 0.5 and 2 times of the corresponding threshold. The observed interest expenses over book value (IOB) is instrumented by the area under the marginal benefit curve (AREA). COL is a proxy for firms' collateralizable assets over total book assets, LTA is the log of total assets, BTM is the book-to-market ratio, INTANG is a proxy for firms' intangible assets over total book assets, CF is the cash flows over total book assets, and DDIV indicates whether the firm pays dividends. The table also controls for but omitted from reporting LTCR (indicator for whether the firm has a S\&P long-term debt rating), STCR (indicator for whether the firm has a S\&P short-term debt rating), and CS (spread between Moody's Baa rating and Moody's Aaa rating). All control variables, except DDIV, LTCR, and STCR are standardized to have mean zero and standard deviation one. DDIV, LTCR, and STCR are binary variables with values $\{0,1\}$. Robust, clustered standard errors are reported in parentheses. Standard errors are clustered by both firm and year as in Thompson (2009) and Petersen (2009). Significance at the $10 \%$ level is indicated by *, $5 \%$ level by **, and $1 \%$ level by $* * *$. 
Table A.13: Robustness: Cost of Leverage Distortion Based on Korteweg (2010)

\begin{tabular}{|c|c|c|c|}
\hline Threshold & $\begin{array}{c}\$ 25 \mathrm{mil} \\
(1)\end{array}$ & $\begin{array}{c}\$ 75 \text { mil } \\
(2)\end{array}$ & $\begin{array}{c}\$ 700 \mathrm{mil} \\
(3)\end{array}$ \\
\hline & \multicolumn{3}{|c|}{ Panel A: Estimates } \\
\hline Marginal firm $(\bar{e})(\$ \mathrm{~m})$ & $\begin{array}{l}27.044 \\
{[0.283]}\end{array}$ & $\begin{array}{l}94.493 \\
{[2.380]}\end{array}$ & $\begin{array}{c}838.313 \\
{[5.349]}\end{array}$ \\
\hline PV(regulatory costs)/Firm value (\%) & $\begin{array}{c}0.580 \\
{[0.145]}\end{array}$ & $\begin{array}{c}0.683 \\
{[0.137]}\end{array}$ & $\begin{array}{c}0.770 \\
{[0.053]}\end{array}$ \\
\hline \multirow[t]{2}{*}{$\Delta$ Leverage } & $\begin{array}{c}0.056 \\
{[0.008]}\end{array}$ & $\begin{array}{c}0.108 \\
{[0.013]}\end{array}$ & $\begin{array}{c}0.073 \\
{[0.003]}\end{array}$ \\
\hline & \multicolumn{3}{|c|}{ Panel B: Parameters } \\
\hline PROF & 0.106 & 0.103 & -0.266 \\
\hline DEPR & 0.041 & 0.023 & 0.028 \\
\hline VOL & 2.588 & 0.473 & 0.785 \\
\hline PPE & 0.173 & 0.089 & 0.227 \\
\hline MB & 5.679 & 2.249 & 5.224 \\
\hline D_RECESS & 0.064 & 0.238 & 0.000 \\
\hline \multirow[t]{2}{*}{$\mathrm{LN}(\mathrm{TA})$} & 2.990 & 4.768 & 6.639 \\
\hline & \multicolumn{3}{|c|}{ Panel C: Samples } \\
\hline Bunching sample & $1994-2007$ & 2003-2007 & $2012-2018$ \\
\hline Non-bunching sample & 2009-2018 & $1994-2002$ & $1997-2011$ \\
\hline Identified regulation & $\begin{array}{c}\text { Scaled } \\
\text { disclosure }\end{array}$ & $\begin{array}{l}\text { SOX 404+ } \\
\text { filing delay }\end{array}$ & $\begin{array}{c}\text { EGC } \\
\text { benefits }\end{array}$ \\
\hline
\end{tabular}

This table demonstrates the robustness of our main bunching estimates to using an alternative cost function of leverage distortion based on Korteweg (2010) (see Appendix A.2 for details on the methodology). Panel A presents the estimates. Panel B shows the parameters that feed into the net benefits to leverage function in Korteweg (2010). The parameters are obtained from firms just above our marginal bunching firms. PROF is EBITDA over sales, $D E P R$ is depreciation over total assets, $V O L$ is volatility in profitability growth, $P P E$ is PPE over total assets, $M B$ is equity market-to-book ratio, $D \_R E C E S S$ is a dummy indicating NBER recession, $L N(T A)$ is the logarithm of total assets. Bootstrapped standard errors are reported in brackets 
Table A.14: Robustness: Excluding Firms With Agency Issues

\begin{tabular}{|c|c|c|c|}
\hline Threshold & $\begin{array}{c}\$ 25 \text { mil } \\
(1)\end{array}$ & $\begin{array}{c}\$ 75 \text { mil } \\
(2)\end{array}$ & $\begin{array}{c}\$ 700 \mathrm{mil} \\
(3)\end{array}$ \\
\hline & \multicolumn{3}{|c|}{ Panel A. Estimates } \\
\hline Marginal firm $(\bar{e})(\$ \mathrm{~m})$ & $\begin{array}{l}27.408 \\
{[0.261]}\end{array}$ & $\begin{array}{l}94.354 \\
{[2.305]}\end{array}$ & $\begin{array}{c}837.345 \\
{[5.587]}\end{array}$ \\
\hline Regulatory costs $(k)(\$ \mathrm{~m})$ & $\begin{array}{c}0.036 \\
{[0.007]}\end{array}$ & $\begin{array}{c}0.120 \\
{[0.024]}\end{array}$ & $\begin{array}{c}0.704 \\
{[0.050]}\end{array}$ \\
\hline PV(regulatory costs)/Firm value (\%) & $\begin{array}{c}0.840 \\
{[0.161]}\end{array}$ & $\begin{array}{c}0.717 \\
{[0.143]}\end{array}$ & $\begin{array}{c}0.763 \\
{[0.055]}\end{array}$ \\
\hline Non-bunching fraction $(\alpha)$ & $\begin{array}{c}0.450 \\
{[0.120]}\end{array}$ & $\begin{array}{c}0.770 \\
{[0.047]}\end{array}$ & $\begin{array}{c}0.530 \\
{[0.140]}\end{array}$ \\
\hline \multirow[t]{2}{*}{$\Delta$ Leverage } & $\begin{array}{c}0.065 \\
{[0.007]}\end{array}$ & $\begin{array}{c}0.107 \\
{[0.013]}\end{array}$ & $\begin{array}{c}0.072 \\
{[0.003]}\end{array}$ \\
\hline & \multicolumn{3}{|c|}{ Panel B. Parameters } \\
\hline Public float/Assets $(\eta)(\%)$ & 2.000 & 0.880 & 1.572 \\
\hline Tobin's Q $(q)$ & 2.720 & 1.680 & 3.570 \\
\hline \multirow[t]{2}{*}{ Interest rate $(r)$} & 0.115 & 0.093 & 0.049 \\
\hline & \multicolumn{3}{|c|}{ Panel C. Sample } \\
\hline Bunching sample & 1994-2007 & $2003-2007$ & $2012-2018$ \\
\hline Non-bunching sample & 2009-2018 & 1994-2002 & $1997-2011$ \\
\hline Identified regulation & $\begin{array}{c}\text { Scaled } \\
\text { disclosure }\end{array}$ & $\begin{array}{l}\text { SOX 404+ } \\
\text { filing delay }\end{array}$ & $\begin{array}{c}\text { EGC } \\
\text { benefits }\end{array}$ \\
\hline
\end{tabular}

This table presents a robustness check of our main bunching estimation results by dropping firms that may have severe agency issues, that is, those with bottom decile institutional ownership and bottom decile of board independence. Marginal firm is the public float of the firm that is indifferent between bunching and not bunching. Regulatory costs are the estimated annual costs of regulation $k$. Regulatory costs are in $\$$ million. $P V$ (regulatory costs)/Firm value is the percentage of the present value of future regulatory costs over the total firm value. Bootstrapped standard errors are reported in brackets. 
Table A.15: Regulatory Costs and Going Public Decisions: Incorporating Dynamics

Panel A: Present Value of Regulatory costs and IPO Decision

\begin{tabular}{|c|c|c|}
\hline & \multicolumn{2}{|c|}{ IPO } \\
\hline & $(1)$ & $(2)$ \\
\hline & Coefficients & Marginal Effects \\
\hline \multirow[t]{2}{*}{ PV of regulatory costs $(\ln )$} & $-0.06498^{* * *}$ & $-0.00024^{* * *}$ \\
\hline & {$[0.01556]$} & {$[0.00006]$} \\
\hline \multirow[t]{2}{*}{ Imputed public float (ln) } & $0.25235^{* * *}$ & $0.00094^{* * *}$ \\
\hline & {$[0.02508]$} & {$[0.00011]$} \\
\hline \multirow{2}{*}{ Total funding raised (ln) } & $0.87869^{* * *}$ & $0.00328^{* * *}$ \\
\hline & {$[0.03165]$} & {$[0.00015]$} \\
\hline \multirow[t]{2}{*}{ Years since founding } & $-0.06678^{* * *}$ & $-0.00025^{* * *}$ \\
\hline & {$[0.00831]$} & {$[0.00003]$} \\
\hline Industry-Year FE & Yes & Yes \\
\hline State FE & Yes & Yes \\
\hline Observations & 110,666 & 110,666 \\
\hline
\end{tabular}

Panel B: IPO Counterfactuals

\begin{tabular}{|c|c|c|c|c|c|}
\hline & $\begin{array}{c}\text { Actual regulation } \\
\text { (1) }\end{array}$ & $\begin{array}{c}\text { Actual regulation } \\
\text { (2) }\end{array}$ & $\begin{array}{c}\text { No SOX } \\
(3)\end{array}$ & $\begin{array}{c}\text { No JOBS Act } \\
(4)\end{array}$ & $\begin{array}{c}\text { Zero regulation } \\
(5)\end{array}$ \\
\hline & Pre-2000 & \multicolumn{4}{|c|}{ Post-2000 } \\
\hline Regulatory costs $(\$ \mathrm{~m})$ & 0.079 & 0.085 & 0.061 & 0.132 & 0.000 \\
\hline Regulatory costs / Public float (\%) & 0.509 & 0.274 & 0.266 & 0.509 & 0.000 \\
\hline IPO probability (\%) & 6.933 & 0.954 & 0.963 & 0.726 & 1.514 \\
\hline Yearly no. of IPOs & 141.4 & 50.2 & 50.6 & 36.4 & 76.0 \\
\hline Total no. of IPOs & 1044.0 & 912.0 & 920.6 & 693.7 & 1447.0 \\
\hline Total IPO public float $(\$ b)$ & 107.9 & 337.0 & 346.8 & 314.3 & 628.5 \\
\hline
\end{tabular}

Panel A reproduces Table 6 using the present value of future regulatory costs instead of the annual cost upon IPO. Panel B shows IPO counterfactuals based on the estimates in Panel A (analogous to Table 7). We extrapolate the public float of potential IPO firms over a seven year horizon (the average number of years IPO firms stay public in our sample period) based on float growth rates estimated from actual IPO firms. We then calculate yearly regulatory costs based on the corresponding float and the regulations prevailing in the year the firm considers IPO. Last, we calculate the present value of these yearly regulatory costs using a $7 \%$ discount rate to arrive at the variable $P V$ of regulatory costs (ln). 